\title{
Proteum - Um Ambiente de Teste Baseado na Análise de Mutantes
}

\author{
Márcio Eduardo Delamaro
}

Orientador: Prof. José Carlos Maldonado.

Dissertação apresentada ao Instituto de Ciências Matemáticas de São Carlos, Universidade de São Paulo, como parte dos requisitos para obtenção do título de Mestre em Ciências, na área de Ciências de Computação e Matemática Computacional.

USP - São Carlos

Outubro - 1993 
À D. Olga, com muita saudade. 
"Ninguém tem autoridade moral para embargar o estrangeirismo, já que esse tem sido o recurso que tornou o miserável linguajar do século XII num dos mais viçosos idiomas do mundo moderno."

Cândido Jucá (filho). 


\section{Agradecimentos}

Agradeço ao meu orientador, Prof. Dr. José Carlos Maldonado, primeiramente pela confiança ao me aceitar como orientado. Depois, por todo ensinamento, orientação, apoio e principalmente amizade oferecidos durante todo o periodo deste trabalho.

À minha familia, que sem dúvida tem muito crédito (ou culpa) por esse trabalho. À Loise e à $\mathrm{D}$. Olga que sempre deram (às vezes com certa dificuldade) condições para que eu pudesse ingressar e continuar na vida universitária; ao Maurício e à Lucelena que, apesar de distantes, me serviram como exemplo; ao Gilberto - a pessoa mais bonita que eu conheço e que dá a honra de ser meu tio e amigo - por sua constante preocupação e ajuda.

"Ainda que eu falasse a lingua dos homens e falasse a lingua dos anjos, sem amor eu nada seria". Meu agradecimento à Márcia. Sem ela eu nada seria.

A todos os companheiros do Grupo de Engenharia de Software pela ajuda e amizadade. À Sandra e ao Craveiro pelas valiosas revisões desta dissertação. À Ana Cláudia e à Lurdes pelo auxílio na avaliação da ferramenta.

Ao Marcos L. Chaim pela ajuda no desenvolvimento do Proteum.

A todos os novos amigos conquistados em São Carlos, sem os quais estes quase dois anos e meio não teriam sido tão agradáveis. Em especial aos amigos Craveiro, Guilherme, João, Luís Paulo, Cláudia, Rosana, Graça, Jacques, Marquinho, Tchelo, Gawa, Gláucia, Lilian, Omar e Vera que fazem ou fizeram parte do meu cotidiano. Uma lembrança particular ao Stein, que agüentou estes dois anos com muita paciência.

A todos os professores do ICMSC-USP pelos conhecimentos transmitidos, dentro e fora das salas de aulas (incluíndo quadras de futebol). Aos funcionários que, direta ou indiretamente, colaboraram para que este trabalho se realizasse. Aos que não tiveram tão boa vontade assim em ajudar, também agradeço pois acredito que eles trabalharam no limite da sua competência.

Aos amigos e companheiros do tempo da Itatutec que me ensinaram ou me ajudaram a aprender muito sobre informática e sobre profissionalismo.

À Ms. Shirley Shrum do Software Engineering Research Center - Purdue University, pela gentileza e atenção em conseguir alguns artigos fundamentais para a realização deste trabalho.

Ao Prof. Dr. Mário Jino e ao Prof. Dr. Paulo César Masiero por suas participações na minha banca de dissertação.

À CAPES e à FAPESP pelo suporte financeiro. 


\section{Sumário}

Com o avanço da tecnologia de hardware, a Análise de Mutantes - um dos critérios de teste baseados em erros - tem sido mais recentemente investigada por diversos pesquisadores e se mostrado um critério atrativo e factível para o uso na produção de software. A relevância e necessidade de ferramentas de teste săo amplamente reconhecidas pela comunidade e esforços têm sido feitos para o desenvolvimento de ferramentas de apoio a este critério.

Nesta dissertação são apresentados os principais aspectos da especificação e implementação de um ambiente de teste multilinguagem, denominado Proteum (Program Testing Using Mutants), que apóia a aplicação do critério Análise de Mutantes para programas em C. Esta ferramenta, além de características comuns a outras ferramentas de teste, procura incorporar algumas características próprias como facilidades para a realização de experimentos empíricos.

A Análise de Mutantes, bem como os principais trabalhos relacionados com este critério, são revistos, procurando fornecer subsídios para a caracterização do Proteum. Aspectos funcionais da ferramenta são mostrados, principalmente através de um exemplo que ilustra a operação da ferramenta. A arquitetura e os principais aspectos de implementação desta ferramenta são apresentados. Uma avaliação da ferramenta é feita testando-se alguns programas extraidos da literatura. 


\section{Abstract}

With the advance in hardware technology, Mutation Analysis - an error based testing criteria - has been recently investigated by many researchers, and evidences have been found that it is an atractive and practical testing criterion for software production. The necessity and relevance of testing tools are widely recognized and efforts have been carried out for developing tools to support application of this criterion.

In this thesis, the main aspects of specification and implementation of a multilanguage testing tool, named Proteum (Program Testing Using Mutants), which supports aplication of Mutation Analysis criterion for testing $\mathrm{C}$ programs, are presented. In addition to common features available in similar tools, Proteum offers facilities for conducting experimental studies.

Mutation Analysis, as well as related works, are reviewed, aiming at specifying functional and operational requirements of the Proteum tool. A complete example is given to illustrate the implemented characteristics. An evaluation of the tool, based on testing a set of programs extracted from the literature, is presented. 


\section{Conteúdo}

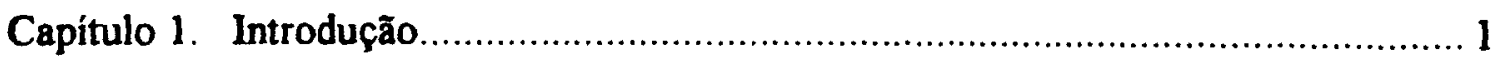

Capitulo 2. Teste de Software ........................................................................ 5

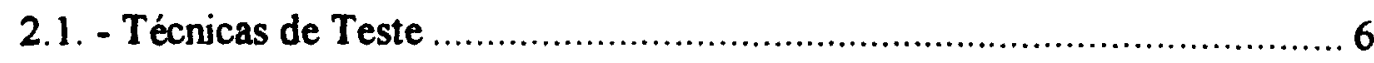

2.1.1. - Técnica Funcional de Teste …….............................................

2.1.2. - Técnica Estrutural de Teste ................................................. 7

2.1.3. - Técnica de Teste Baseada em Erros........................................ 9

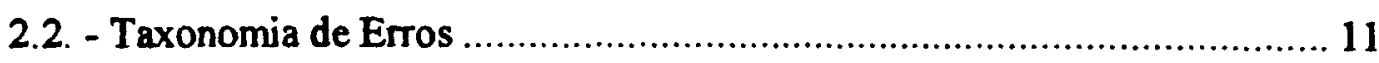

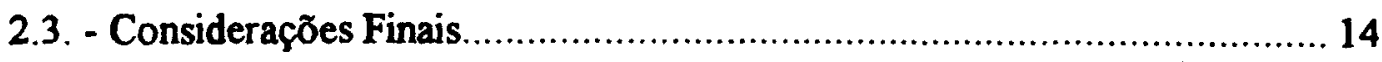

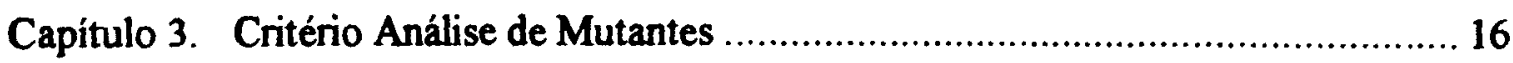

3.1. -Técnicas Relacionadas com a Análise de Mutantes ……........................... 16

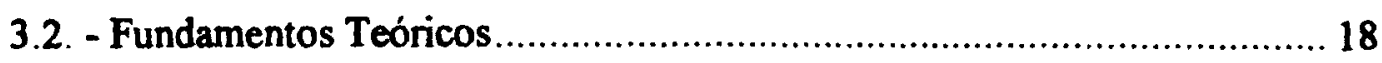

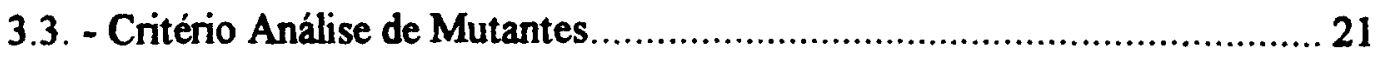

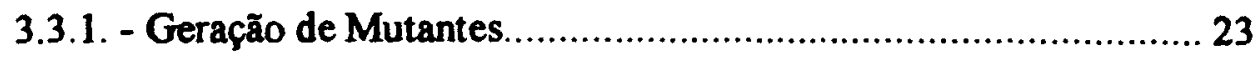

3.3.2. - Execução do Programa Testado ............................................... 24

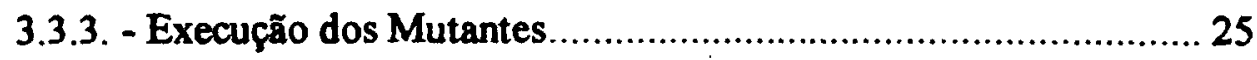

3.3.3.1. - Diminuição do Tempo de Execução dos Mutantes .... 28

3.3.3.2. - Diminuição do Número de Mutantes........................... 30

3.3.4. - Análise dos Mutantes Vivos ...................................................... 33

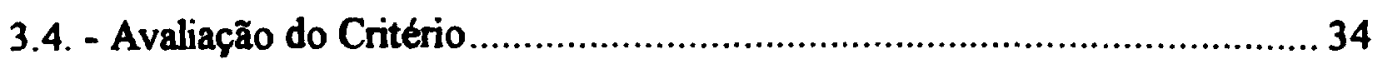

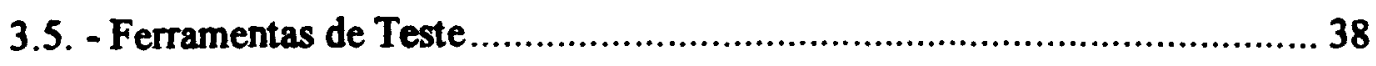

3.6. - Algumas Tendências Atuais ................................................................. 42

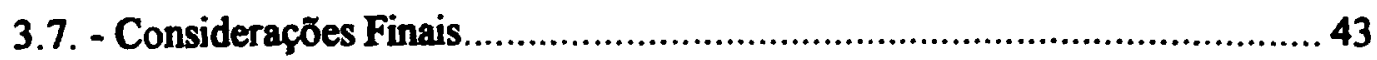


Capitulo 4. Especificą̧ão e Implementação do Proteum 45

4.1. - Aspectos Relevantes da Implementação do Proteum ................................ 51

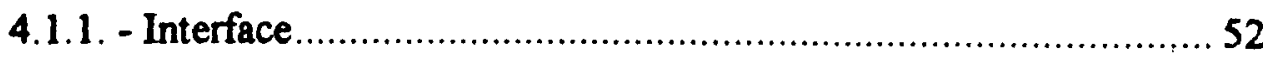

4.1.2. - Módulos Não Dependentes da Linguagem ................................ 53

4.1.2.1. - Arquivo de Teste ..................................................... 54

4.1.2.2. - Arquivo de Casos de Teste e Arquivo de Entradas/Saidas

4.1.2.3. - Arquivo de Índices e Arquivo de Descritores de Mutantes.

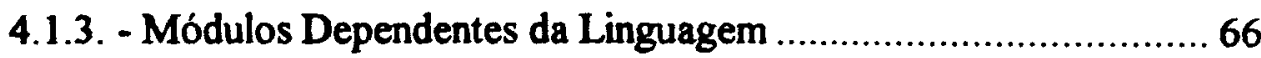

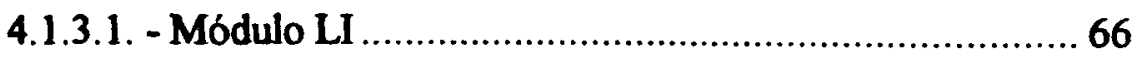

4.1.3.2. - Módulo Opmuta ........................................................... 69

4.2. - Aspectos de Configuração do Proteum ................................................... 71

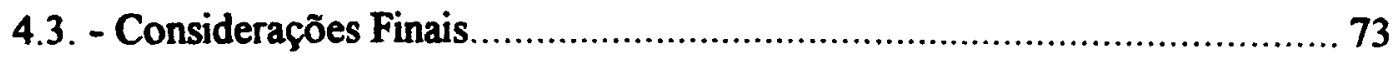

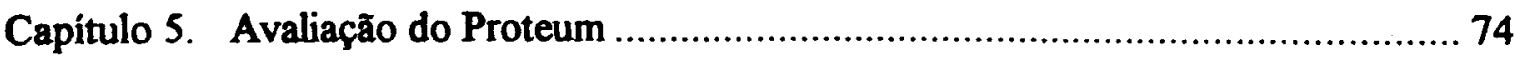

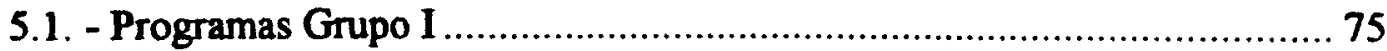

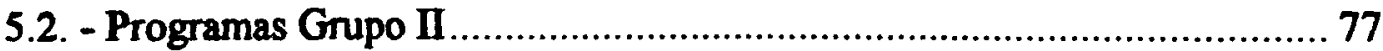

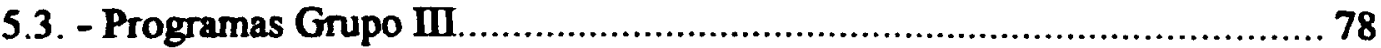

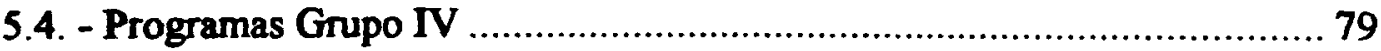

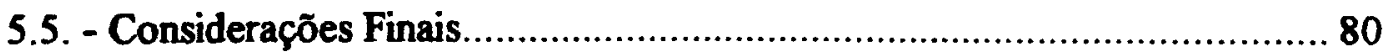

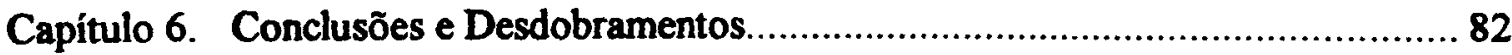

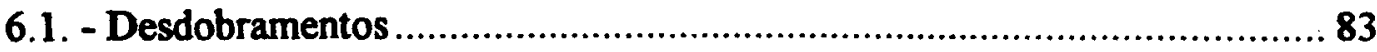

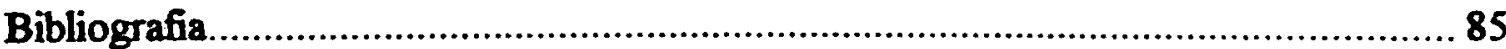

Apêndice A. Um Exemplo Completo ……...........................................................90

A.1. - A Sessão de Teste ................................................................................ 90 


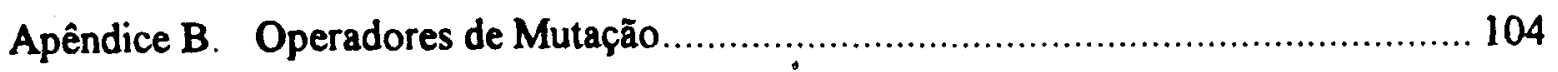

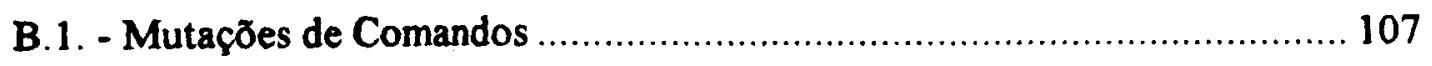

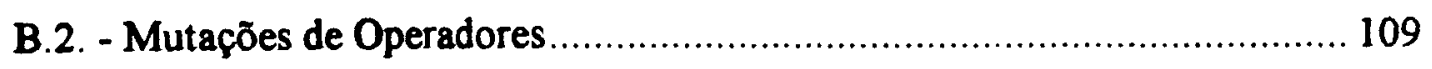

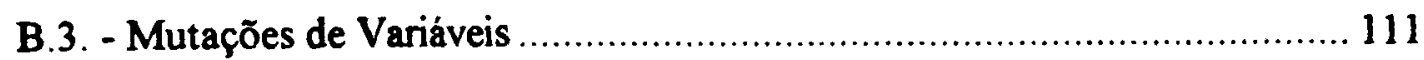

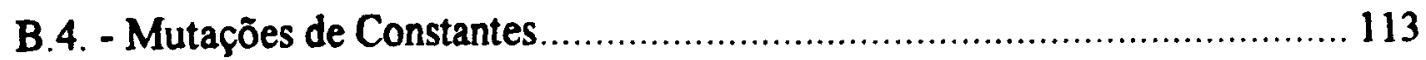




\section{Lista de Figuras}

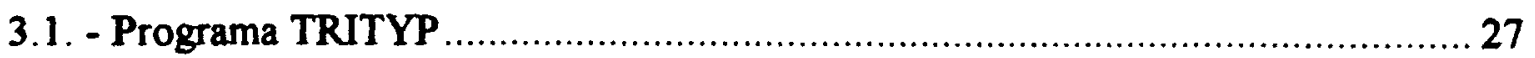

3.2. - Operações para a Execução Vetorizada de um Programa e Seus Mutantes ......... 28

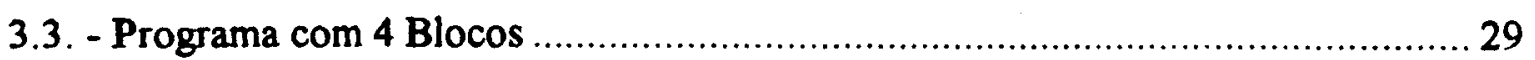

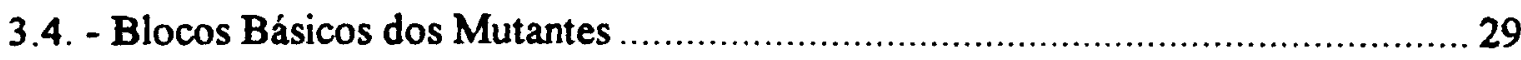

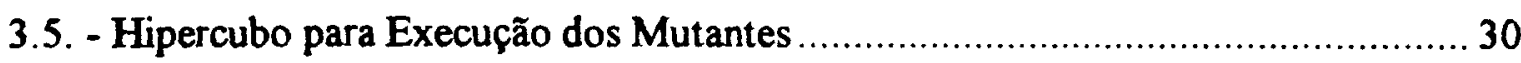

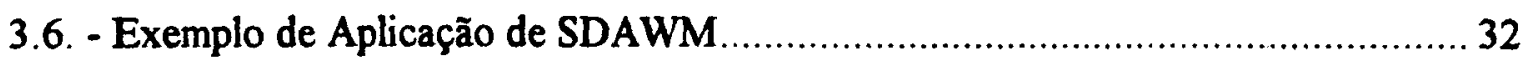

3.7. - Restrições Associadas aos Mutantes ................................................................. 35

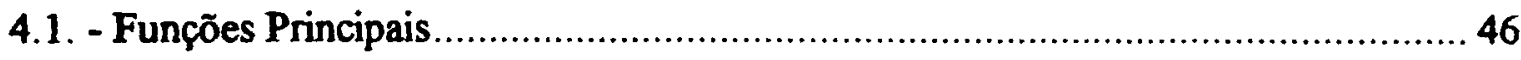

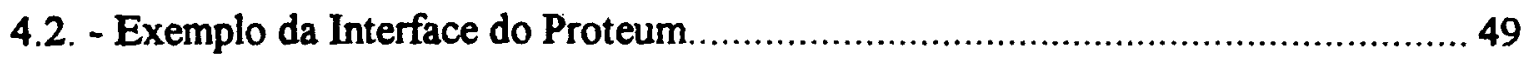

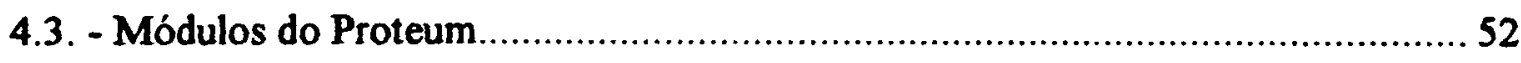

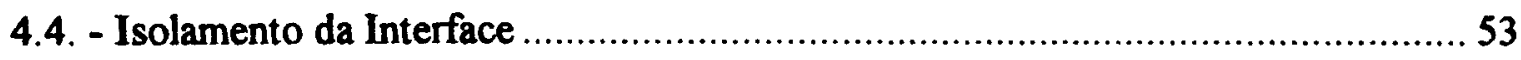

4.5. - Arquivo de Teste

4.6. - Estrutura do Arquivo de Casos de Teste ………………………………….........56

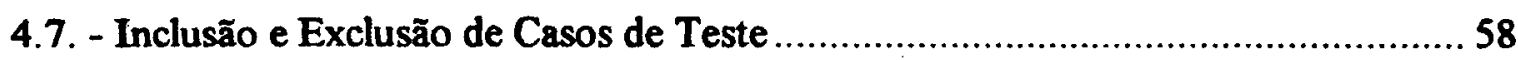

4.8. - Estrutura do Arquivo de Entradas/Saídas .........................................................5

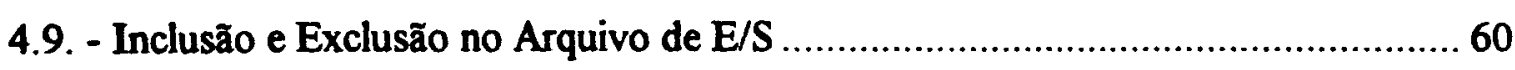

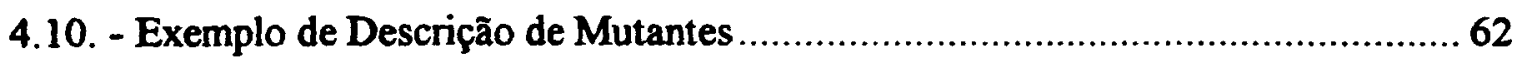

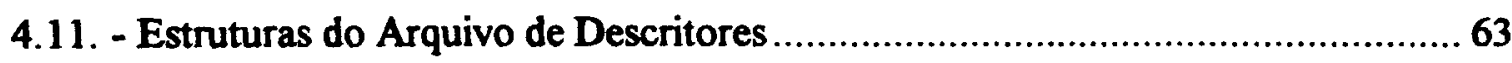

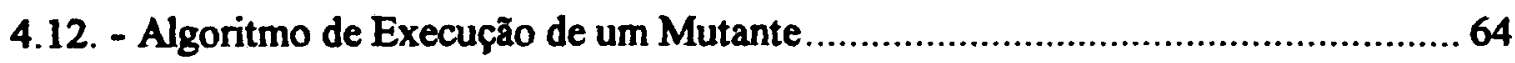

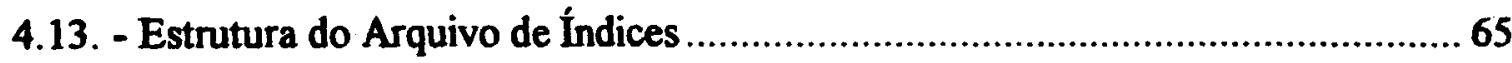

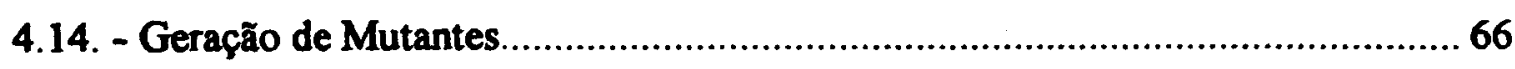

4.15. - Exemplo de Tradução de Programa C para LI ................................................... 68 
4.16. - Possivel Implementação de um Operador de Mutação (1) .............................. 69

4.17. - Possivel Implementação de um Operador de Mutação (2) ............................. 70

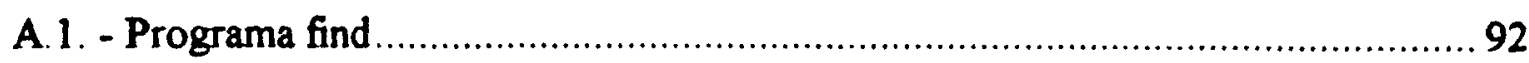

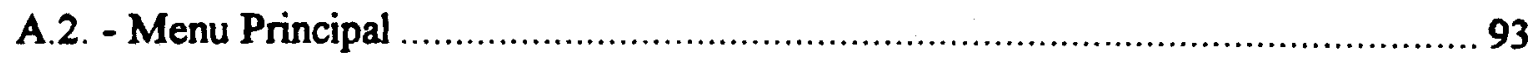

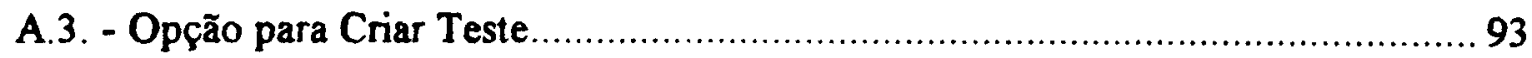

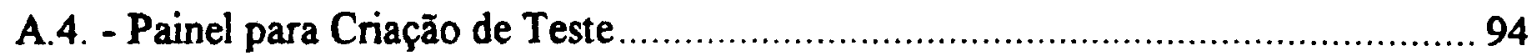

A.5. - Confirmando a Criação de um Teste ......................................................... 94

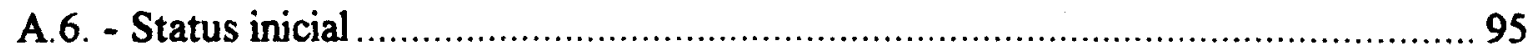

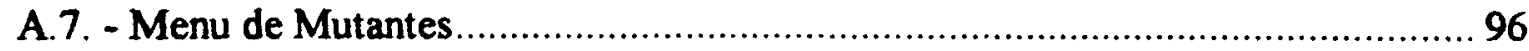

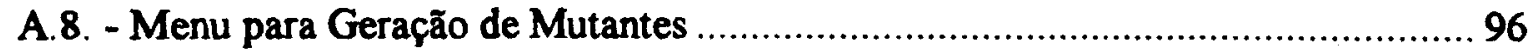

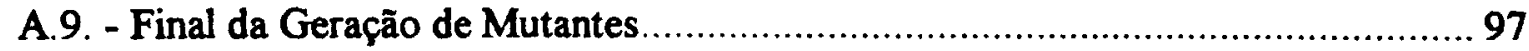

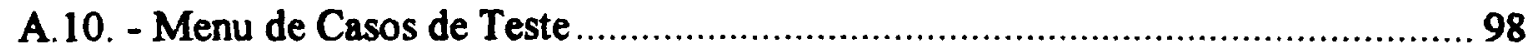

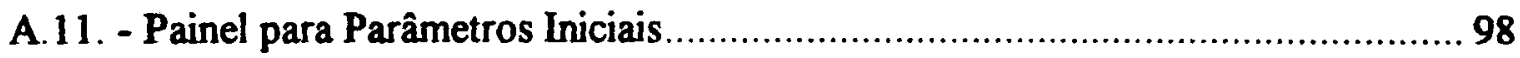

A. 12. - Tela de Inclusão de Caso de Teste ..................................................... 99

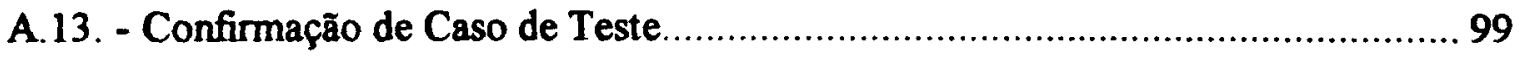

A. 14. - Execução dos Mutantes em Andamento ................................................ 100

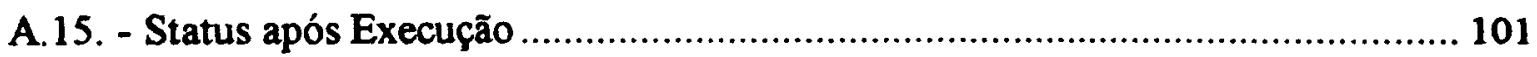

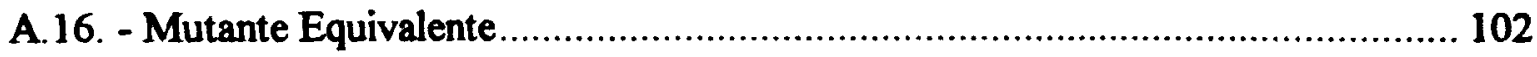

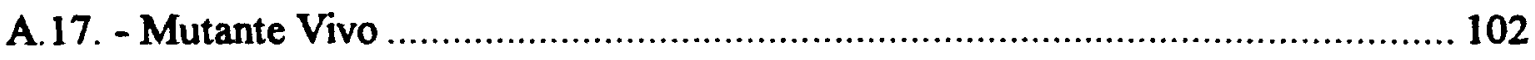

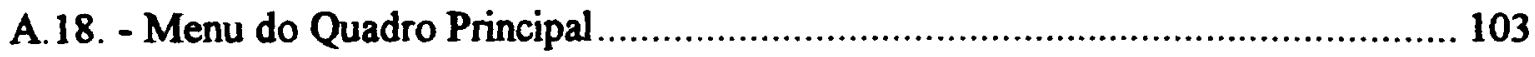

A.19. - Confirmação para sair do Proteum................................................... 103 


\section{Lista de Tabelas}

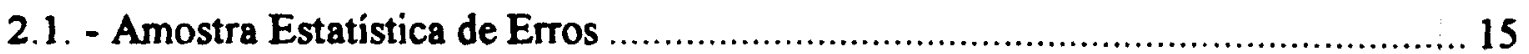

3.1. - Ferramentas de Teste

4.1. - Outras Características de Ferramentas de Teste ..................................................43

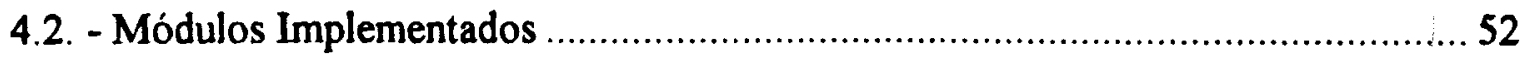

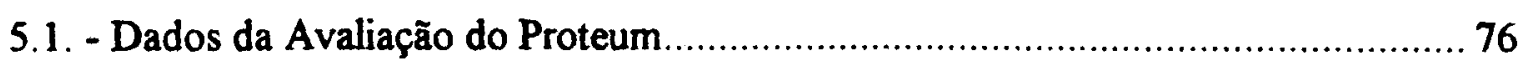

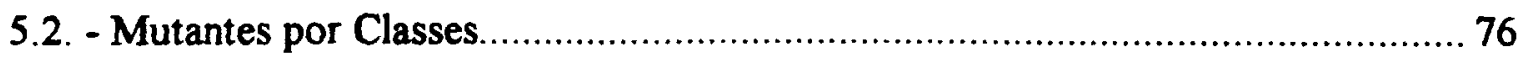

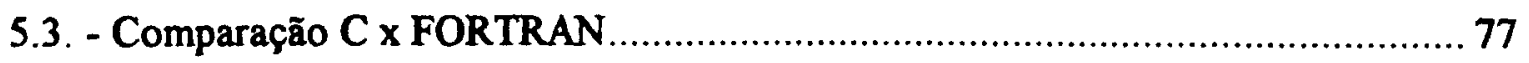

5.4. - Sintese Comparativa entre Critérios Potenciais Usos e Análise de Mutantes........ 78

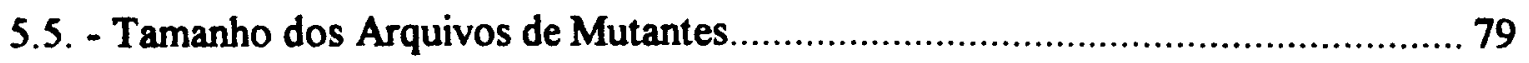

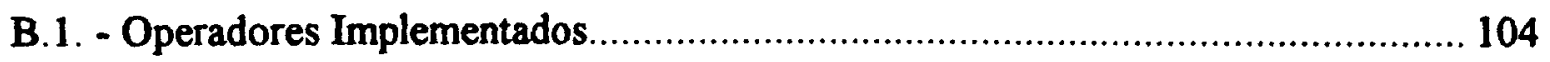

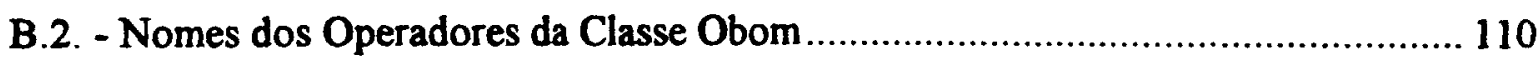




\section{Capítulo 1.}

\section{Introdução}

No início da era da computação eletrônica, o maior desafio que se apresentava era o de desenvolver máquinas com um poder cada vez maior de processar e armazenar informação. Hoje, quando tem-se a capacidade de processamento de um antigo mainframe encapsulada num único chip, torna-se necessário, dada a gama de aplicações que se viabilizam com essa evolução dos computadores, criar softwares cada vez mais complexos e sofisticados que acompanhem a evolução do hardware.

Em meados da década de 70 foram identificados vários problemas envolvendo a produção de software; era a chamada crise do software. Entre outros fatores, o custo do desenvolvimento crescia rapidamente, faltavam meios para preverem-se custos e prazos dos projetos e o produto final não tinha a qualidade desejada.

Para superar esses problemas têm surgido métodos e técnicas que coletivamente formam a Engenharia de Software; é dada ao software uma abordagem de um produto de engenharia que requer planejamento, análise, projeto, implementação, teste e manutenção.

Uma das definições de Engenharia de Software coloca-a como sendo: "aplicação de princípios de engenharia com o objetivo de produzir software de alta qualidade e com baixo custo". Nesse ponto é preciso que a seguinte pergunta seja respondida: como definir qualidade de software? Uma das definições aponta qualidade de software como sendo:

"Adequação a requisitos explícitos de performance e funcionais, a padrões de deservolvimento explicitamente documentados e a caracteristicas implicitas que são esperadas de todo software produzido profissionalmente" [PRE92].

Avaliar a qualidade de um software quase nunca é tarefa fácil. Ela é uma mistura complexa de fatores que variam de aplicą̧ão para aplicação e de usuário para usuário. 
Pressman cita uma lista de fatores que se concentra em três aspectos importantes do software: suas características operacionais, sua capacidade de sofrer mudanças e sua adaptação a diferentes ambientes. Nessa lista estão fatores como: correção ("correctnes"), confiabilidade ("reliability"), eficiência ("effectiveness"), integridade ("integrity"), usabilidade ("usability"), manutenibilidade ("maintainability"), flexibilidade ("flexibility") e outros [PRE92].

Durante todo o ciclo de vida do software, paralelamente à sua construção, um conjunto de atividades denominadas de Garantia de Qualidade de Software ("Software Quality Assurance") é conduzido com o objetivo de assegurar que tanto o processo de desenvolvimento quanto o produto final atinjam niveis de qualidade especificados

Dentre as atividades de Garantia de Qualidade de Software, a atividade de teste é sem dúvida uma das técnicas de validação mais utilizadas. A atividade de teste pode ser descrita como: observar o comportamento do programa através da sua execução sobre um conjunto de dados [ADR82].

A própria atividade de teste está sujeita a erros, e deve ser submetida ao controle de qualidade; várias técnicas foram propostas para se conduzir e para se avaliar a qualidade das atividades de teste. É o caso das técnicas de teste funcional, de teste cstrutural, e de teste baseado em erros.

É importante notar que nenhuma das técnicas de teste é completa, no sentido de que nenhuma delas é, em geral, suficiente para garantir a qualidade da atividade de teste. $\mathrm{Na}$ verdade, essas diferentes técnicas se complementam e devem ser aplicadas em conjunto para se tentar assegurar um teste de boa qualidade.

Nesse sentido, são importantes os estudos teóricos e empíricos conduzidos com o intuito de avaliar a eficiência e revelar características importantes de cada uma das técnicas de teste. Só assim torna-se possivel saber com mais clareza o que se pode obter com cada técnica e onde e quando aplicar-se cada uma delas [BEI90].

Para que esses estudos possam ser feitos, têm-se utilizado ferramentas de teste ("testing tools") que são armas poderosas para auxiliar na aplicação de alguma técnica de teste com o auxílio do computador [HOR92]. Nos últimos tempos, algumas dessas ferramentas foram construidas. É o caso, por exemplo da POKE-TOOL [CHA91], um ambiente para auxiliar a execução de teste estrutural de programas. Com a disponibilidade de uma ferramenta como esta é possivel, através de experimentos empiricos e medições estatísticas, avaliar as características das técnicas e critérios de teste nos quais a ferramenta se baseia.

Isso, porém, não é suficiente. É preciso pesquisar e descobrir como as diferentes técnicas de teste se inter-relacionam, onde elas se sobrepõem e como elas podem se complementar.

Esta dissertação tem como objetivo principal a especificação e implementação de um ambiente de teste denominado Proteum (Program Testing Using Mutants), que apoia 
a aplicação da Análise de Mutantes, um critério de teste que se enquadra dentro da técnica de teste baseada em erros. Esse ambiente deve apoiar a aplicação do critério para o teste de programas escritos em diversas linguagens de programação; numa primeira versão, a linguagem a ser tratada é a linguagem $C$. Deve-se ressaltar que, apesar de ter-se conhecimento da existência de outra ferramenta que apóia a aplicação da Análise de Mutantes para essa linguagem [KRA91b], não se tem conhecimento da sua utilização comercialmente ou no meio acadêmico.

Com a construção dessa ferramenta, cria-se a possibilidade de desenvolverem-se vários outros trabalhos, tanto na comparação com outras técnicas de teste [BUD80, DEM81, HOR92] quanto em outras áreas, relacionadas ou não diretamente com a atividade de teste. Como exemplo, temos a área de processamento paralelo ou distribuído: um dos problemas da Análise de Mutantes é o custo, em termos de tempo de execução, de sua aplicação. Uma das soluções para tentar resolver esse problema é a utilização de arquiteturas de alto desempenho com processamento paralelo ou distribuído. Vários trabalhos já foram desenvolvidos por outros pesquisadores nessa linha, onde algumas arquiteturas $e$ alguns algoritmos utilizando essa abordagem, foram apresentados [CHO89a, KRA88, MAT88].

O Capitulo 2 apresenta uma revisão sobre técnicas e critérios de teste. Como a Análise de Mutantes faz parte da técnica baseada em erros, são apresentadas algumas tentativas de se construir uma taxonomia para classificar os erros mais comuns cometidos no desenvolvimento de software.

O Capítulo 3 aborda especificamente o critério Análise de Mutantes. Inicialmente alguns trabalhos que estão relacionados ou que derivaram da Análise de Mutantes são apresentados. A atividade de teste, apesar de essencialmente prática, possui um embasamento teórico. Os aspectos mais relevantes dessa teoria que procura sustentar a Análise de Mutantes são apresentados também no terceiro capítulo. Em seguida, são sintetizados os principais resultados de estudos empiricos envolvendo a Análise de Mutantes, conduzidos, obviamente, com o apoio de ferramentas de teste. Ainda, são descritas as principais ferramentas para apoiar este critério, culminando em um conjunto mínimo de características que essas ferramentas devem possuir. Essas características forneceram diretrizes para a especificação do Proteum, alvo principal desta dissertação. Finalmente, sāo mostradas quais as tendências das pesquisas na área de teste, envolvendo a Análise de Mutantes.

O Capítulo 4 apresenta a especificação e a descrição de um ambiente, denominado Proteum, para auxiliar na condução de teste baseado na Análise de Mutantes e os pontos mais relevantes de sua implementação.

O Capitulo 5 mostra alguns resultados obtidos com a utilização do Proteum no teste de programas extraidos essencialmente de livros e artigos de congressos e revistas científicas. 
O Capítulo 6 sumariza os principais resultados, as conclusð̄es e desdobramentos desta dissertação.

O Apêndice A mostra um exemplo completo da utilização do Proteum, onde alguns pontos como a definição de casos de teste, aplicação de operadores de mutação, geração, execução e análise de mutantes são apresentados com mais detalhes.

O Apêndice $\mathbf{B}$ apresenta a lista e a descrição dos operadores de mutação que foram implementados no Proteum. 


\section{Capítulo 2.}

\section{Teste de Software}

O teste de software é um elemento crítico para a garantia de qualidade de software e representa a última revisão da especificação, projeto e código [PRE92].

Apesar das várias técnicas, métodos e ferramentas utilizadas durante todo o processo de desenvolvimento de software, que procuram evitar que erros sejam introduzidos no produto, ainda assim, a etapa de teste continua sendo de grande importância para a eliminação dos erros que persistem [MAL91].

Beizer [BEI90] cita o mito existente entre os que desenvolvem software, de que um programa para poder ser utilizado deve ser perfeito e não conter erro algum. Isso nem sempre é verdade, continua, pois existem erros cujo custo para deteç̧ão e correção supera o prejuízo causado pela sua existência, ou seja, é preferivel conviver com eles a corrigilos.

Além disso, existe o fato de que, em geral, não se consegue, através de testes, provar que um programa está correto. Então, testar apenas contribui para aumentar a confiança de que o software desempenha as funçōes que se esperam dele. $O$ objetivo é realizar testes suficientes e que garantam que a probabilidade da existência de erros seja suficientemente baixa. É claro que o que é "suficientemente baixa" para um programa de vídeo game não o é para um reator nuclear. Em outras palavras, cada aplicação tem seus próprios requisitos e padrões de qualidade a serem alcançados.

Apesar das limitações características da atividade de teste, sua aplicação de maneira sistematizada e bem planejada pode garantir ao software algumas características mínimas que são importantes no estabelecimento da qualidade do produto e relevantes também para o seu processo de evolução. Além disso, é importante lembrar que o teste é apenas uma das atividades de validação e que, em geral, sua utilização isolada não é suficiente para alcançar um produto de boa qualidade; outras técnicas devem ser utilizadas em conjunto com o teste como inspeção, "walkthrough", verificação formal, etc. [ADR82].

Com os argumentos dados acima, pode-se afirmar que a atividade de teste não pode ser conduzida na força bruta. Torna-se necessária a aplicação de alguma técnica que 
dê indicaçðes de como testar o software, quando parar o teste e que, se possível, forneça uma medida do nivel de confiança e de qualidade alcançado com os testes realizados [DEM80].

\section{1. - Técnicas de Teste}

Duas questões são importantes na atividade de teste:

"Como os dados de teste devem ser selecionados?" e

"Como se pode dizer que um programa foi testado suficientemente?"

Define-se método de seleção de dados de teste como um procedimento para escolher casos de teste e critério de adequaçáo dos dados de teste como um predicado usado para avaliar os casos de teste. Existe uma forte correspondência entre métodos de seleção e critérios de adequação de dados de teste pois, dado um critério de adequação $C$, existe um método de seleção $\mathrm{M}_{\mathrm{C}}$ que estabelece: "selecione um conjunto de teste que satisfaça o critério C". De forma análoga, dado um método de seleção $M$, existe um critério de adequação $C_{M}$ que diz: "um conjunto de casos de teste é adequado se ele foi gerado pelo método $\mathbf{M}^{\prime \prime}$. Em geral, um critério de adequação é um dos ítens usados para decidir o encerramento das atividades de teste [MAL91]

Basicamente, pode-se classificar um critério de teste em três técnicas: funcional, estrutural ou baseada em erros. 0 que diferencia essas três técnicas é a origem da informação usada para avaliar ou para construir conjuntos de casos de teste [MAL91].

Como aponta Beizer [BE190], não existe uma fronteira precisa entre função e estrutura, o que faz com que um critério possa ora ser visto em um contexto e ora noutro. Além disso, na literatura existe alguma divergência entre autores em como classificar determinados critérios. Por exemplo, basta ver a classificação dada para a Análise de Mutantes; esse critério já foi colocado como um critério baseado em erros [WU88], como um critério funcional [WHI81] e como um critério estrutural [COW88].

1 Neste trabalho o termo critério será usado tanto como critério de avaliaça quanto como método de seleçio de casos de teste. 


\subsection{1. - Técnica Funcional de Teste}

O teste funcional é também chamado de teste caixa preta [MYE79] pois é como tal que o software é tratado, ou seja, uma caixa cujo conteúdo é desconhecido e da qual só se consegue ver o lado externo: os dados de entrada fornecidos ao programa e as respostas produzidas por ele.

Nesse tipo de teste, o testador usa essencialmente a especificação funcional do programa para escolher os casos de teste a serem empregados, não se importando com detalhes da implementaf̧ão [BEI90].

Um exemplo de critério desse tipo é a construção do grafo causa-efeito. Primeiramente, são levantadas as possiveis condiç̋̃es de entradas (causas) e as possiveis ações (efeitos) do programa. Em seguida é construido um grafo, com simbologia própria, relacionando as causas e efeitos levantados. Esse grafo é convertido em uma tabela de decisão que é utilizada na construção dos casos de teste [PRE92].

Outro exemplo é o particionamento em classes de equivalência, que procura dividir o domínio de entrada em classes que têm como característica o fato de que a execução do programa com qualquer um dos elementos de uma classe produz o mesmo resultado, ou seja, se um dado de teste encontra um erro, todos os outros dados pertencentes à mesma classe devem encontrar o mesmo erro. Na verdade, são escolhidas classes que se aproximem dessa característica pois, em geral, é impossível caracterizar-se exatamente as classes de equivalência [MYE79].

A ańlise de valor limite ("Boundary Value Analysis") acrescenta algumas características ao critério de partição em classes de equivalência. Ao invés de selecionar qualquer elemento de uma classe, os casos de teste são escolhidos nas fronteiras das classes pois é á que se concentra um grande número de erros. Além disto, o espaço de saida do programa também é particionado e são exigidos casos de teste que produzam resultados nos limites dessas classes de saida [PRE92].

\subsection{2. - Técnica Estrutural de Teste}

Nesse tipo de teste, às vezes chamado de caixa branca [MYE79], em oposição ao nome "caixa preta", os aspectos de implementação são importantes na escolha dos casos de teste.

Em geral, a técnica de teste estrutural utiliza uma representação para programas conhecida como grafo de nuxo de controle ("control flowgraph") ou grafo de programa. Um grafo de fluxo de controle é um grafo orientado onde cada vértice representa um bloco indivisivel de comandos e cada aresta representa um desvio de um 
bloco para outro. Um bloco desse tipo tem as seguintes caracteristicas: não existem desvios para o meio do bloco e uma vez que o primeiro comando do bloco seja executado, todos os demais comandos do bloco são executados seqüencialmente.

Olhando-se o grafo de programa podem ser escolhidos os componentes que devem ser executados, caracterizando assim os critérios de teste estrutural. Tais critérios podem basear-se em diferentes tipos de estruturas para determinar quais partes do programa têm sua execução requerida. $O$ primeiro tipo de critério, baseado no fluxo de controle ("control-flow based"), usa apenas características de controle da execução do programa como comandos ou desvios, para determinar quais estruturas são requeridas. Como exemplos podem ser citados os critérios todos os nós e todos os arcos. $O$ primeiro exige que a execução do programa passe pelo menos uma vez por cada vértice do grafo de fluxo ou equivalentemente, que cada comando do programa seja executado pelo menos uma vez. O critério todos os arcos requer que cada aresta do grafo (cada desvio do programa) seja exercitada pelo menos uma vez [PRE92].

Outra classe de critérios associa ao grafo de fluxo, informaçōes sobre o fluxo de dados do programa ("data flow based"), ou seja, explora associações entre pontos do programa onde é atribuído um valor a uma variável (chamado de definição da variável) e pontos onde esse valor é utilizado (chamado de referência ou uso da variável). Com base nessas associações são determinados os caminhos a serem exercitados. Por exemplo, o critério todos os usos [RAP85] exige que pelo menos um caminho entre todas as associaçð̃es definição-uso de cada variável seja exercitado pelos casos de teste.

Outro critério classificado como estrutural é o teste de domínio ("domain test") [WHI80]. Os comandos de desvio no programa particionam o espaço de valores das variáveis de entrada em subconjuntos chamados de dominios, cada um correspondendo a um caminho do programa e consistindo de pontos que fazem com que esse caminho seja percorrido. O critério consiste em calcular esses dominios e escolher pontos que examinem se os seus limites, determinados pelo programa, estão corretos em relação à especificação.

Segundo Beizer [BE190], esse critério pode ser aplicado usando-se apenas informação da especificação do programa, não sendo necessários detalhes da implementação do programa para determinar os dominios e os casos de teste. Se usado dessa maneira, o critério caracteriza-se como funcional e não como estrutural.

Existe outra classe de critérios que utiliza informação sobre a complexidade do programa para determinar os requisitos de teste; são denominados critérios baseados na complexidade ("complexity based"). Um critério bastante conhecido dessa classe é o critério de McCabe que utiliza a complexidade ciclomática para derivar os requisitos de teste. Essencialmente, esse critério requer que um conjunto linearmente independente de caminhos do grafo de programa seja executado [PRE92]. 


\subsection{3. - Técnica de Teste Baseada em Erros}

Nos critérios de teste que se enquadram nessa categoria é usada informação sobre erros mais frequentes no processo de desenvolvimento de software e sobre tipos especificos de erros que se desejam localizar [DEM91].

Um exemplo de critério desse tipo é o de semeadura de erros ("error seeding"). Para melhor entender esse critério, Budd [BUD81] cita o seguinte texto estatístico:

"Suponha que 1.000 peixes são pegos mum lago, marcados com a cor vermelha $e$ soltos. Depois de algum tempo, mais 1.000 peixes são pegos e entre eles são contados 100 que possuem a marca vermelha. Assumimos naturalmente que as duas coletas podem ser consideradas como amostras randómicas da populasão de todos os peixes do lago. Esses fatos justificam a afirmação de que o mimero de peixes no lago está entre 8.500 e 12.000."

Neste exemplo, tem-se:

- número de peixes na primeira captura: $\mathbf{n}_{1}=1.000$.

- número de peixes na segunda captura: $r=1.000$.

- número de peixes vermelhos na segunda captura: $\mathbf{k}=100$.

- probabilidade de que o segundo lote contenha exatamente $k$ peixes vermelhos: $q_{k}(n)$.

- número total de peixes no lago: $\mathbf{n}$.

Deseja-se calcular, usando-se a hipótese de que os peixes estão distribuídos uniformemente no lago, os valores de $n$ que fazem com que a probabilidade $q_{k}(n)$ seja alta. Maiores detalhes de como os cálculos podem ser efetuados são encontrados no livro de Feller [FEL75].

No critério de semear erros, os peixes vermelhos correspondem a erros artificialmente introduzidos no programa a ser testado. Dado que um conjunto de casos de teste descobre um certo número de erros no programa, a relação entre o número de erros naturais e erros artificiais descobertos deve, pelo menos em teoria, dar alguma indicação do número de erros que restam no programa.

Sobre esse critério, vários pontos podem ser questionados. Um deles diz respeito ao tamanho da amostra. Dificilmente encontram-se programas suficientemente grandes 
para conter 10.000 erros ou quantidade parecida e que dê aos valores calculados estatisticamente, um significado não questionável.

Um segundo ponto é que para aplicar esse critério assume-se que os erros são assim como os peixes no lago - uniformemente distribuídos no programa, coisa que em geral não é verdade. Na prática encontram-se longos trechos de programas com código simples, pouco propensos a erros, e trechos pequenos, porém complexos, onde os erros tendem a acumular-se. Como cita Pressman [PRE92], uma região onde um erro é identificado tem grande probabilidade de conter outros erros.

No critério em que estamos interessados, a Análise de Mutantes, não são necessárias hipóteses quanto à distribuição estatística de erros nos programas [BUD81].

A Análise de Mutantes surgiu no final da década de 70 com um grupo de pesquisadores das universidades YALE e Georgia Institute of Technology [DEM78] e pode ser descrita da seguinte maneira: o testador deve fornecer um programa $P$ a ser testado e um conjunto de casos de teste $T$ cuja qualidade deseja-se avaliar. $O$ programa é executado sobre $T$ e se apresenta resultados incorretos, então um erro foi detectado e o teste termina. Caso contrário, o programa pode ainda conter erros que o conjunto $T$, por não ser sensível o suficiente, não conseguiu revelar. São criados então programas $\mathbf{P}_{1}, \mathbf{P}_{2}$, ..., $\mathbf{P}_{\mathbf{k}}$ que são mutantes de $\mathbf{P}$ e que diferem de $\mathbf{P}$ somente na ocorrência de erros simples. Por exemplo, se $\mathbf{P}$ contém a expressão " $\mathrm{A}<\mathrm{B}$ ", um dos mutantes de $\mathbf{P}$ irá ter no lugar dessa, a expressão " $A<=B$ ".

Em seguida, todos os mutantes são executados usando-se os casos de teste de $T$ como entradas. Se um mutante $\mathbf{P}_{\mathbf{i}}$ apresenta resultados diferentes de $\mathbf{P}$ diz-se que esse mutante está morto; nesse caso $\mathrm{T}$ conseguiu identificar o "erro" no mutante, ou mais precisamente, conseguiu revelar a diferença entre $P$ e $P_{i}$. Por outro lado, se $\mathbf{P}_{\mathbf{i}}$ apresenta respostas idênticas a $P$ diz-se que ele continua vivo. Isto pode ocorrer por dois motivos: ou porque $T$ não contém casos de teste capazes de distinguir $\mathbf{P}_{\mathbf{i}}$ de $\mathbf{P}$ ou porque ambos os programas executam as mesmas funções, ou seja, são equivalentes. No primeiro caso, novos casos de teste podem ser adicionados a $T$ para matar o mutante. No caso de mutantes equivalentes, nenhum caso de teste será capaz de distingui-los, pois seus resultados são sempre iguais aos de $P$.

O objetivo é achar um conjunto de casos de teste que consiga matar todos os mutantes não equivalentes. Tais conjuntos são considerados adequados para 0 teste de $P$, no sentido de que, ou $P$ está correto ou contém um erro sutil e inesperado, o que deve ser raro se as modificações usadas para criar os mutantes forem cuidadosamente escolhidas.

Um ponto importante destacado por DeMillo [DEM80] é que a Análise de Mutantes fornece uma medida objetiva do nivel de confiança na adequação dos casos de testes analisados. Através do escore de mutação ("mutation score"), que relaciona o número de mutantes gerados com o número de mutantes mortos, pode-se avaliar a 
adequação dos casos de testes usados e, como consequeência, a confiabilidade do programa testado.

Nesse ponto é importante ressaltar que a questão que se coloca no planejamento e desenvolvimento de software não é escolher qual das técnicas ou critérios aplicar, e sim como e quando utilizá-los adequadamente, uma vez que todos apresentam vantagens e possuem, por outro lado, limitações.

Na seção seguinte apresentam-se os tipos de erros mais comuns identificados no processo de desenvolvimento de software; a caracterização e classificação desses tipos de erros são fundamentais tanto para a avaliação dos métodos, técnicas e critérios existentes como para a evolução e proposição de novos métodos, técnicas e critérios de desenvolvimento de software.

\section{2. - Taxonomia de Erros}

Beizer [BEI90] apresenta uma classificação para os erros mais freqüentemente encontrados no desenvolvimento de software mas adverte que essa classificação não pode ser rigida, pois erros são dificeis de categorizar-se. Dependendo das circunstâncias, um erro pode ser colocado ora numa classe, ora em outra. Tem-se como exemplo um programa que apresenta um erro em que um único caracter é digitado errado mas que não ocasiona erro sintático. Como consequência pode ocorrer que dados sejam modificados em uma área diferente da desejada e que a função computada seja diferente da especificada. Que tipo de erro seria esse? De digitação, de codificação, de dados, ou um erro funcional?

A seguir estão as principais classes de erros citadas na taxonomia de Beizer.

\section{Erros de requisitos, de caracteristicas e de funcionalidade.}

Requisitos e especificações de software podem ser incompletos, ambíguos, contraditórios ou podem ser interpretados de maneira incorreta. Mesmo especificaçð̃es que não possuem esses defeitos podem mudar durante o projeto fazendo com que o projetista esteja sempre "mirando um alvo móvel".

Como conseqüência, o software pode adquirir características indesejáveis, supérfluas ou não apresentar características que seriam necessárias. 


\section{Erros estruturais.}

Nesta classe são colocados: erros de controle, lógicos, de processamento, de inicialização e de fluxo de dados.

Erros de controle são relacionados com problemas no fluxo de execução do programa, como código não alcançável, aninhamento impróprio de comandos, condição de parada de laço incorreta.

Como erros lógicos são colocados aqueles relacionados com a interpretação errada de como funcionam comandos de seleção tipo case e de como funcionam, combinados ou não, os operadores lógicos. Outro problema é quanto à ordem em que uma expressão booleana é calculada, como nas condições de comandos IF-THEN-ELSE. $O$ resultado dessas expressões muitas vezes pode ser obtido sem que todos os termos sejam calculados mas o programador pode estar esperando que todos os termos sejam sempre avaliados.

Erros de processamento estão relacionados com a avaliação de expressões aritméticas, algébricas, booleanas, cálculo de funções matemáticas e processamento em geral. Muitos problemas surgem da conversão de um tipo de representação dos dados para outra: "overflow"; zero negativo; comparação com zero real; etc.

Erros de inicialização são comuns; tanto a falta de inicialização quanto a inicialização redundante. Erros típicos são: falta de inicialização de registradores ou variáveis; erro no primeiro valor de uma variável de controle de um loop; inicialização com formato ou tipo de dado incorreto; etc.

Erros de fluxo de dados estão principalmente ligados a algumas anomalias relacionadas com a declaração de variáveis, atribuição de valores e usos desses valores. Por exemplo, usar uma variável sem que ela tenha sido inicializada, modificar o valor de uma variável e não usar esse valor ou inicializar duas vezes uma variável constituem anomalias de fluxo de dados e podem indicar erros deste tipo.

\section{Lrros de dados.}

São erros que decorrem da definição dos dados do programa, quer em seu formato, número de objetos ou valores iniciais. Beizer ressalta que apesar de subestimados, esses tipos de erros são tão frequentes quanto erros no código do programa. 


\section{Erros de codificação.}

Nessa classe são colocados os erros de sintaxe, porém sem grande importância do ponto de vista de teste, pois qualquer compilador é capaz de eliminá-los totalmente e o processo de teste só comę̧a quando erros desse tipo não existem mais.

Entretanto, erros de digitação ou tipográficos que não causam erros de sintaxe são também incluídos nesta classe. Aqui são colocados, ainda, erros causados pelo não entendimento da semântica de algum comando ou instrução ou por efeitos colaterais surgidos com a execução de alguma instrução ou comando.

\section{Erros de interface.}

Esta classe de erros está relacionada com a interligação do software com o mundo externo e de "pedaços" do software entre si. Além da interação entre subrotinas e funções do programa, a comunicação com elementos externos como usuário, sistema operacional e hardware pode ser causa de erros.

Tipicamente são erros como: tipo incorreto ou valor fora do intervalo esperado para parâmetros de subrotinas ou funçōes, falta de conhecimento de como trabalha 0 sistema operacional e o hardware, assumir erroneamente que não ocorrem internupções durante a execução do programa ou que o código é reentrante ou que é residente e problemas no compartilhamento de recursos como memória ou disco.

\section{Erros de projeto de teste.}

Esta classe na verdade não trata de erros no software em si. Ela abrange problemas no planejamento das atividades de teste e que podem levar a que erros não sejam revelados.

Existem outras classificações menos abrangentes, como a proposta por Howden [HOW76] que identifica dois tipos de erros: erros de domínio ("domain errors") que ocorrem quando uma entrada faz com que o caminho seguido no programa seja incorreto e erros computacionais ("computation errors") quando o caminho é correto mas um erro em alguma atribuição faz com que um valor incorreto seja calculado para alguma variável de saida.

Ao realizarem um experimento para avaliar a eficiência de um determinado critério de teste, Budd e seus companheiros [BUD80] concluiram que é dificil construir um esquema de classificação que não seja nem especifico demais, de modo que cada erro constitua sua própria classe, nem demasiado geral, fazendo com que padrões importantes 
sejam esquecidos. Concluiram também que nenhum dos sistemas existentes para classificar erros conseguia dar um significado suficientemente intuitivo para as classes de erros propostas. Para conduzir o experimento, os autores optaram por dividir os erros em cinco grupos: caminho ausente ("missing path"), predicado incorreto ("incorrect predicate"), comando computacional incorreto ("incorrect computation statement"), comando computacional ausente ("missing computation statement") e cláusula de predicado ausente ("missing clause in predicate").

A Tabela 2.1., extraida de [BEI90] mostra um experimento estatístico onde são avaliadas as porcentagens relativas com que cada classe de erro contribui no total de erros das amostras. Pode-se observar que três dessas classes que são: erros estruturais, de dados e de codificação, são responsáveis por grande parte do total de erros, ou seja, $57 \%$. É principalmente nessas classes de erros, ou seja, erros que se refletem na implementação do programa, que espera-se que a Análise de Mutantes seja, pelo menos parcialmente, efetiva.

\section{3. - Considerações Finais}

Este capitulo caracterizou as atividades de teste, mostrando algumas técnicas e alguns critérios de teste, entre eles a Análise de Mutantes; procurou-se também classificar erros comuns no processo de desenvolvimento de software, pois tal classificação pode auxiliar na definição e aplicação de critérios de teste.

Em seguida, no Capítulo 3, serão vistos mais detalhes sobre o critério Análise de Mutantes, sua aplicação e trabalhos relacionados. 
Tabela 2.1. - Amostra Estatistica de Erros [BEI90]

\begin{tabular}{|c|c|c|}
\hline \multicolumn{3}{|c|}{ size of sample $-6,877,000$ statements (comments included) } \\
\hline \multicolumn{3}{|c|}{ total reported bugs - 16,209 - bugs per 1000 stalements -2.36} \\
\hline 1XXX REQUIREMENTS & 1317 & $8.1 \%$ \\
\hline 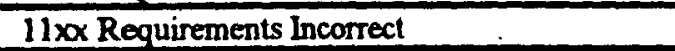 & 649 & $4.0 \%$ \\
\hline $12 \times x$ Requirements Logic & 153 & $0.9 \%$ \\
\hline $13 \times x$ Requirements, Completness & 224 & $1.4 \%$ \\
\hline $15 \times x$ Presentation, Documentation & 13 & $0.1 \%$ \\
\hline 16xx Reguirements Changes & 278 & $1.7 \%$ \\
\hline 2xxx FEATURES AND FUNCTIONALITY & 2624 & $16.2 \%$ \\
\hline 21xx Feature/Function Correctness & 456 & $2.8 \%$ \\
\hline 22xx Feature Completness & 231 & $1.4 \%$ \\
\hline 23xx Functional Case Completness & 193 & $1.2 \%$ \\
\hline $24 \times x$ Domain Bugs & 778 & $4.8 \%$ \\
\hline 25xx User Messages and Diagnostics & 857 & $5.3 \%$ \\
\hline 26xx Exception Condition Mishandled & 79 & $0.5 \%$ \\
\hline 29xx Other Function Bugs & 30 & $0.2 \%$ \\
\hline 3x00 STRUCTURAL BUGS & 4082 & $25.2 \%$ \\
\hline 31xx Control Flow and Sequencing & 2078 & $12.8 \%$ \\
\hline $32 \times x$ Processing & 2004 & $12.4 \%$ \\
\hline $4 \times 0 \times$ DATA & 3638 & $22.4 \%$ \\
\hline $41 \times \times$ Data Definition and Structure & 1805 & $11.1 \%$ \\
\hline 42xx Data Access and Handling & 1831 & $11.3 \%$ \\
\hline 49xx Other Data Problems & 2 & $0.0 \%$ \\
\hline 5X0X MMPLEMENTATION AND CODING & 1601 & $9.9 \%$ \\
\hline 51xx Coding Typographical & 322 & $2.0 \%$ \\
\hline $52 \times x$ Style and Standards Violations & 318 & $2.0 \%$ \\
\hline 53xx Documentation & 960 & $5.9 \%$ \\
\hline $54 \times x$ Other Implementation & 1 & $0.0 \%$ \\
\hline 6x00 DNTEGRATION & 1455 & $9.0 \%$ \\
\hline $61 \times x$ Internal Interfaces & 859 & $5.3 \%$ \\
\hline 62xa External Interfaces Timing, Throughput & 518 & $3.2 \%$ \\
\hline 69xx Other Integration & 1 & $0.0 \%$ \\
\hline $7 \times 0 \times$ SYSTEM, SOFTWARE, ARCHITECTURE & 282 & $1.7 \%$ \\
\hline $71 \times \times \mathrm{O} / \mathrm{S}$ Call and Use & 47 & $0.3 \%$ \\
\hline 72xo Software Architecture & 139 & $0.9 \%$ \\
\hline $73 \times \times$ Recovery and Accountability & 4 & $0.0 \%$ \\
\hline 74xx Performance & 64 & $0.4 \%$ \\
\hline $75 \times x$ Incorrect Diagnostics, Exceptions & 16 & $0.1 \%$ \\
\hline 76xx Partitions, Overlays & 3 & $0.0 \%$ \\
\hline 77xx Sysgen, Environment & 9 & $0.1 \%$ \\
\hline 8xx TEST DEFINITION AND EXECUTION & 447 & $2.8 \%$ \\
\hline $81 \times x$ Testing Design Bugs & 11 & $0.1 \%$ \\
\hline $82 \times x$ Test Execution Bugs & 355 & $2.2 \%$ \\
\hline $83 \times x$ Test Documentation & 11 & $0.1 \%$ \\
\hline $84 \times x$ Test Case Completness & 64 & $0.4 \%$ \\
\hline 89xx Other Testing Bugs & 6 & $0.0 \%$ \\
\hline 9x0x OTHER, UNSPECIFIED & 763 & $4.7 \%$ \\
\hline
\end{tabular}




\section{Capítulo 3. ${ }^{*}$}

\section{Critério Análise de Mutantes}

Neste capitulo procura-se situar a Análise de Mutantes, mostrando-se trabalhos relacionados com este critério. São trabalhos que vão desde modelos para teste de circuitos lógicos até novos critérios que têm como "inspiração" a Análise de Mutantes. Além disso, a teoria de teste que fundamenta a aplicação do critério e as tendências atuais de pesquisa na área são apresentadas.

Os principais aspectos para utilização da Analise de Mutantes, suas vantagens e problemas são mostrados também neste capitulo, bem como aspectos de automatização e trabalhos empíricos de avaliação deste critério.

\section{1. - Técnicas Relacionadas com a Análise de Mutantes}

A Análise de Mutantes, descrita no capitulo anterior e detalhada mais à frente, é fortemente relacionada com um método clássico para deteçăo de erros lógicos em circuitos digitais. Várias falhas como curto-circuitos ou circuitos abertos manifestam-se ao nivel lógico na forma de linhas presas em 0 ou em 1 . O modelo de teste de falha única ("single fault testing model") [FRI75] assume que apenas uma linha de cada vez pode estar defeituosa, ou seja, presa em 1 ou em 0 ; então são geradas combinaçōes dos sinais de entrada capazes de revelar essas condiçōes de erro. Esse método advoga ainda a hipótese de que testes construídos dessa maneira são, na prática, bons também para detectar erros múltiplos. Para alguns casos, tal propriedade pode até mesmo ser demonstrada [AGA79]. Dessa forma, o número de testes necessários para validar um circuito é normalmente bem inferior ao número (exponencial em relação ao número de linhas de entrada) requerido para testar-se o circuito exaustivamente.

Fazendo a analogia com a Análise de Mutantes, cada circuito contendo uma linha presa pode ser visto como um mutante que deve ser morto com a escolha de uma entrada que produza para este circuito uma saída diferente daquela produzida pelo circuito original. Também a hipótese que relaciona a eficiência dos testes para erros únicos e para 
erros múltiplos tem na Análise de Mutantes seu correspondente conhecido como efeito de acoplamento ("coupling efect") [BUD81] e que será tratado mais à frente.

Um dos maiores problemas para sua utilização sempre foi sua complexidade computacional pois é necessário um número grande de execuçð̃es de mutantes para conduzir-se o teste de um programa. Com o desenvolvimento de novas e mais poderosas arquiteturas de hardware, surgiram alguns trabalhos [CH089a, KRA88, MAT88, KRA91a, CHO93] procurando explorar esses avanços para que a Análise de Mutantes possa ser utilizada dentro de limites economicamente viáveis. Além disso, surgiram soluções como a proposta em [MAR90] que sugere o uso da análise estática de anomalias de fluxo de dados para reduzir o número de mutantes gerados. Alguns novos critérios [HOW82, WO088] derivados da Análise de Mutantes também foram criados com 0 intuito de solucionar os problemas por ela apresentados.

Um desses critérios é o de mutação fraca ("weak mutation testing") [HOW82]. Este critério considera que um programa $P$ a ser testado é formado de vários componentes, que normalmente correspondem a estruturas computacionais elementares como: referência a uma variável, expressão aritmética, expressão booleana ou relação entre expressões aritméticas. Dado um componente $\mathbf{C}$ do programa $\mathbf{P}$, uma transformação é aplicada a $\mathbf{C}$ produzindo $\mathbf{C}^{\prime}$ que é a versão mutada de $\mathbf{C}$. $\mathbf{O}$ critério de mutação fraca requer que um caso de teste $t$ seja construido com a propriedade de que $\mathbf{C}$ seja executado quando $\mathrm{P}$ é executado usando $t$ e que pelo menos uma das vezes em que $\mathbf{C}$ é executado, $\mathrm{C}$ produza um resultado diferente do seu semelhante $C^{\prime}$. Como o próprio autor observa, mesmo que $\mathbf{C}$ e $\mathbf{C}^{\prime}$ computem valores diferentes, é possivel que $\mathbf{P}$ e $\mathbf{P}^{\prime}$ (que contém o componente $C^{\prime}$ ) produzam as mesmas saidas, ou em outras palavras, conjuntos de casos de teste adequados em relação à mutação fraca podem não ser adequados para a Análise de Mutantes. É essa a desvantagem da mutação fraca pois ela não garante, ao contrário da Análise de Mutantes (ou mutaçao forte como usa Howden para diferenciar os dois critérios), que serão revelados todos os erros da classe associada a um tipo de transformação (mutação).

Woodward e Halewood observam que a idéia básica da mutaçāo fraca ou forte é a mesma: fazer uma pequena mudança no programa e comparar os resultados da versão original com os da versão modificada. Na mutação fraca pode-se considerar que um mutante é criado imediatamente antes da execução de um componente e que a comparação dos resultados é feita logo após sua execução. Já na mutação forte, a criação do mutante se dá antes do inicio da execução do programa e a comparação acontece depois que a execução se completa; neste caso podemos pensar no programa como sendo um "componente de tamanho maior". Entre esses dois extremos existe a possibilidade de uma solução intermediária: introduzir no programa pontos onde as alterações são efetuadas e pontos onde os estados do programa original e do programa mutante são comparados, antes do final da execução. A principal vantagem desse critério, batizado de mutação firme ("firm mutation") em relação à Análise de Mutantes seria, segundo seus autores, a capacidade de diminuir o custo da execução dos mutantes pois apenas 
execuçōes parciais são necessárias para se decidir se um mutante morre ou continua vivo [W0088].

A Análise de Mutantes tem mostrado, através de experimentos empíricos [DEM80, BUD80, HOR92] (além de estudos teóricos), ser, na prática, um critério atrativo para teste de programas. Isso em parte torna-se possível graças às bem sucedidas tentativas de construírem-se ferramentas que apoiam a aplicação deste critério no teste de programas [BUD81, DEM88].

A existência desse tipo de ferramenta torna possivel, ainda, que outras áreas de pesquisa sejam exploradas e experimentadas na prática; é o caso da geração automática de casos de teste [DEM91]; da comparação entre critérios de teste [HOR92]; da automação da função de oráculo de teste [DEM88]; e da aplicação de heurísticas para reconhecimento automático de programas equivalentes [BUD81].

\section{2. - Fundamentos Téricos}

Alguns resultados importantes têm sido obtidos na construção de uma teoria que fundamente as atividades de teste. Importantes, principalmente porque demonstram o que pode e o que não pode ser obtido com o teste. Particularmente, sabe-se que não é possivel, em geral, provar-se através de teste, a correção de um programa. É preciso então mostrar até que ponto pode-se chegar com a aplicação de testes, ou mais especificamente, com a aplicação de determinada técnica ou determinado critério de teste. [DEM91]

Esta seção procura extrair de alguns trabalhos dados que forneçam uma visão da teoria que sustenta a Análise de Mutantes.

Primeiramente, é preciso uma definição de correção ("correctness") de um programa, que pode ser:

Um programa $P$ é correto com relação a uma função $F$ se $P$ computa $F$.

Para provar a correção de um programa, um conjunto de teste deve ser confíável ("reliable") [HOW76], ou seja: 
Um conjunto de teste $T$ é confiável para um programa $P$ e uma função $F$, dado que $F$ e $P$ coincidem em $T$, se e somente se $P$ computa $F$. Se $P$ não computa $F$, então $T$ deve conter um ponto $x$ tal que $F(x) \neq P(x)$.

Se por um lado é simples mostrar que para qualquer programa existe sempre um conjunto de teste finito e confível, por outro lado, não existe um procedimento efetivo para gerar conjuntos de casos de teste confiáveis ou avaliar se um conjunto de teste é ou não confiável [DEM91].

Com o intuito de obter-se uma definição mais realista, no sentido de que possa ser empregada na prática, uma outra abordagem para correção é apresentada. Nessa abordagem, considera-se um conjunto $\Phi$ de programas alternativos, que depende de $P$, e do qual $P$ é membro. Tal conjunto $\Phi(P)$ é chamado de vizinhança ("neighborhood") de $P$.

A intenção é mostrar que um programa é correto através de um processo de eliminação, mostrando que nenhum programa na vizinhança de $P$, não equivalente a $P$, é correto. Isso pode ser feito usando-se um conjunto de teste $T$ para 0 qual todos os membros de $\Phi(P)$, não equivalentes a $P$, falhem em pelo menos um caso de teste. Tal conjunto é definido em seguida.

Um conjunto de teste $T$ é adequado para $P$ em relação a $\Phi(P)^{2}$ se para cada programa $Q \in \Phi$, ou $Q$ é equivalente a $P$ ou $Q$ falha em pelo menos um ponto do conjunto de teste.

Observe-se que a definição não aborda o problema da indecidibilidade sobre a equivalência entre programas.

A relação entre correção de um programa $P$ e adequação de um conjunto de teste é mostrada pelo seguinte teorema:

Dado um programa $P$ e uma vizinhanca $\Phi(P)$, se algum programa em $\Phi(P)$ computa a função correta $F$ e $T$ é adequado para $P$ em relação a $\Phi$ e $P$ coincide com $F$ em $T$, então $P$ é correto [BUD82].

20 termo adequado para $P$ será usado futuramente significando adequado para $P$ em relação a $\Phi(\mathbf{P})$. 
Tomando $\Phi$ como o conjunto de todos os programas, garante-se que existe um programa em $\Phi$ que computa $F$ e assim poder-se-ia provar a correção de $P$. Porém, a escolha de uma vizinhança como esta acarreta um problema prático, como aponta DeMillo [DEM91]. O problema é que $\Phi$ é infinito, sendo impraticável demonstrar que $T$ é adequado em relação a ele.

$\mathrm{Na}$ verdade, a escolha de qualquer vizinhança de tamanho infinito não interessa pois, para tais conjuntos, nem sempre existe um conjunto de teste $T$ que seja adequado [BUD82]. Pior que isso, existem vizinhanças para as quais o problema se existe ou não um conjunto de teste adequado é indecidivel. Ou seja, tomando uma vizinhança $\Phi$ de tamanho infinito, não é possivel decidir-se sobre a existência, para um programa $P$, de um conjunto de teste $\mathrm{T}$ que seja adequado em relação a $\Phi$.

Por outro lado, esse problema não existe para $\Phi(P)$ finito. Nesse caso, é demonstrado que sempre existe um conjunto T que seja adequado para $P$ em relação a $\Phi$. É importante notar que ao restringir-se a vizinhança, escolhendo-se $\Phi$ como um subconjunto entre todos os possíveis programas, abandona-se o desejo ideal de provar que o programa está correto e procura-se demonstrar uma "correção relativa" de P sobre um pequeno conjunto de programas.

Na Análise de Mutantes, a chamada hipótese do programador competente afirma que um programa, produzido por um programador competente, ou está correto ou está "próximo" do correto. Dessa forma, as atenções podem concentrar-se em uma vizinhança bem menor que o universo de todos os programas, ou seja, naqueles programas que são parecidos com $\mathrm{P}$. De modo similar, a noção de restringir o conjunto de programas alternativos pode ser vista como a delimitação dos tipos de erros que se deseja considerar.

Para todo programa $P$ e vizinhança $\Phi(P)$ finita, viu-se que sempre existe pelo menos um conjunto de teste $T$ que é adequado para $P$ em relação a $\Phi$. Porém duas perguntas precisam ser respondidas:

- existe um procedimento para construir T?

- existe um procedimento que, dado um conjunto de teste $T_{1}$, avalie se $T_{1}$ é ou não adequado?

Budd [BUD82]define dois procedimentos:

Um procedimento $A(P, T)$ é um aceitador ("acceptor") se ele retorna VERDADEIRO quando $T$ é adequado para $P$ em relasão a $\Phi(P)$ e retorna FALSO, caso contrário. 
Um procedimento $G(P)$ é um gerador ("generator") se ele produz um conjunto de teste $T$ que é adequado para $P$ em relação a $\Phi(P)$.

Budd mostra que sempre que existir um aceitador existirá também um gerador e vice versa, mas isso nem sempre acontece. A existência desses dois procedimentos está relacionada com a existência de um verificador de equivalência $S\left(P_{1}, P_{2}\right)$ que responde VERDADEIRO quando os programas $P_{1}$ e $P_{2}$ são equivalentes e FALSO, caso contrário. Mais precisamente, mostra que existe um aceitador se e somente se existe um gerador e se e somente se existe um verificador de equivalência.

Para classes restritas de programas é possivel demonstrar-se a equivalência entre dois programas. É o caso por exemplo, de programas que computam o valor de polinômios. Dois programas $\mathrm{P}$ e $\mathrm{Q}$ que computam polinômios de grau n são equivalentes se seus resultados coincidem em $n+1$ pontos distintos [HOW78]. Porém, para classes mais abrangentes de programas como o conjunto de todos os programas escritos em $\mathrm{C}$ ou FORTRAN, ou na maioria das linguagens de programação, o problema da equivalência entre programas é indecidivel [BUD81]. Por outro lado, na Análise de Mutantes, tal problema está restrito a decidir se o programa $P$ é ou não equivalente aos demais elementos de $\Phi(P)$, os quais são "parecidos" com P. Nesse caso, existem heurísticas, ou em última instância, a intervenção do usuário testador, que permitem que a equivalência seja decidida. Assim, torna-se possivel criar aceitadores e geradores de conjuntos casos de teste baseados na Análise de Mutantes.

Na próxima seção descreve-se com mais detalhes como o critério de Análise de Mutantes é empregado. Vale notar que o modo de uso do critério na prática, define, na verdade, $o$ algoritmo de um aceitador $e$ de um gerador.

\section{3. - Critério Análise de Mutantes}

Pode-se encontrar a descrição de como aplicar a Análise de Mutantes em vários trabalhos [ACR79, DEM78]. Basicamente, dado um programa P e um conjunto de casos de teste T, cuja qualidade deseja-se avaliar, seguem-se os seguintes passos para aplicar o critério:

\section{1) - Geração de mutantes.}

Constrói-se a vizinhança $\Phi(P)$ efetuando-se pequenas mudanças em $P$. Cada programa gerado dessa forma é um mutante de $P$. 


\section{2) - Erecuçăo de P.}

O programa $\mathbf{P}$ é executado sobre o conjunto de casos de teste $T$. Se $P$ apresenta algum resultado incorreto, então um erro foi encontrado e o processo termina. Caso contrário, se nenhum dos casos de teste revelou erro, o teste continua no passo seguinte.

\section{3) - Erecução dos mutantes.}

Cada um dos mutantes é executado usando os casos de teste de T. Se um mutante $M$ apresenta resultado diferente de $P$, isto significa que os casos de teste utilizados são sensiveis e conseguiram expor a diferença entre $\mathbf{P}$ e $\mathbf{M}$; neste caso, $M$ está morto e é descartado. Por outro lado, se $M$ apresenta comportamento igual a $P$, isto indica ou uma fraqueza em $T$, pois não conseguiu distinguir $P$ de $M$, ou que $P$ e $M$ são equivalentes; neste caso, diz-se que $M$ continua vivo. Terminada a execuçăo dos mutantes, pode-se usar a relação entre o número de mutantes gerados e o número de mutantes mortos como um indicativo da qualidade de $\mathbf{T}$.

\section{4) - Análise dos mutantes vivos.}

Examinando-se cada um dos mutantes que permaneceram vivos, duas conclusões são possíveis. A primeira é que o mutante é equivalente a $P$ e assim tal mutante pode ser abandonado, ou seja, não devem ser feitas novas tentativas de matá-lo. A segunda conclusão possivel é que o mutante não morreu porque $T$ não posui um caso de teste que consiga distingui-lo de $\mathbf{P}$; neste caso, novos casos de teste podem ser criados e retorna-se ao passo 2 usando-se esses novos casos de teste. $O$ processo termina quando todos os mutantes não equivalentes, ou pelo menos a maioria deles, estiverem mortos.

É importante notar que o procedimento descrito acima exige, além da execução do programa sendo testado, que algumas tarefas sejam executadas de forma automática. Pelo grande esforço de processamento que demanda tarefas como gerar e executar os mutantes e comparar os resultados produzidos, é praticamente impossivel executá-las com precisão e eficiência sem o uso do computador. Assim, na prática, deve-se associar à aplicação do critério, um "sistema de mutação" que interage com o testador na execução do teste. Tal sistema, além de interativo, é também iterativo pois envolve a repetição de três passos básicos: criar casos de teste, executar os mutantes, e analisar os mutantes que permanecem vivos.

Em seguida são analisados com mais detalhes os passos da aplicação do critério Análise de Mutantes. 


\subsection{1. - Geração de Mutantes}

Essa é a fase chave na Análise de Mutantes. O sucesso da aplicação do critério depende totalmente da escolha da vizinhança $\Phi(P)$, que deve ter as seguintes características:

- ser abrangente, de modo que um conjunto de casos de teste que passe pela Análise de Mutantes, ou em outras palavras, que seja adequado para $P$ em relação a $\Phi(P)$, consiga revelar a maior parte dos erros de $\mathbf{P}$.

- ter cardinalidade pequena para que o problema, de gerar ou de verificar se um conjunto de casos de teste é ou não adequado, seja tratável.

Assumindo a validade da hipótese do programador competente, pode-se afirmar que erros são introduzidos nos programas através de desvios sintáticos que, apesar de não causarem erros sintáticos, alteram a semântica do programa $e$, como conseqüência, conduzem o programa a um comportamento incorreto. Para revelar tais erros, a Análise de Mutantes identifica os desvios sintáticos mais comuns e, aplicando pequenas transformações sobre o programa em teste, encoraja o testador a construir casos de teste que mostrem que tais transformaçð̃es conduzem a um programa incorreto [AGR89].

Além disso, alguns estudos [BUD80, ACR79] mostram, como conclusão de procedimentos empíricos, que conjuntos de casos de teste que revelam erros simples como os descritos acima conseguem, em geral, revelar outros tipos de erros. Esse é o chamado efeito de acoplamento ("coupling effect") que, usando as palavras de DeMillo, pode ser descrito da seguinte maneira:

"Dados de teste que distinguem todos os programas que diferem' de um programa correto somente em erros simples são tão sensíveis que também distinguem, implicitamente, erros mais complexos" [DEM78].

Budd mostra que para alguns casos, como programas baseados em tabelas de decisão, o efeito de acoplamento pode ser demonstrado [BUD80].

Para modelar os desvios sintáticos mais comuns, gerando o conjunto de mutantes $\Phi(P)$, a Análise de Mutantes utiliza operadores de mutação ("mutant operators").

Um operador de mutação aplicado a um programa $P$ transforma $P$ em um programa similar: um mutante. Em geral, a aplicação de um operador de mutação gera mais que um mutante pois se $\mathbf{P}$ contém várias entidades que estão no domínio de um 
operador, então esse operador é aplicado a cada uma dessas entidades, uma de cada vez. Como exemplo, considere-se o operador de mutação que retira um comando de $\mathbf{P}$. Todos os comandos do programa eståo no dominio desse operador que, quando aplicado sobre $P$, gera tantos mutantes quantos forem os comandos em P. Cada mutante contém todos os comandos de $P$ exceto um, retirado pelo operador de mutação [AGR89].

Um mutante criado como descrito acima é um mutante de erro induzido ("fault induced mutant"). Outro tipo de operador de mutação é o que gera mutantes instrumentados ("instrumented mutants"). Nesse caso, uma função armadilha ("trap function") é incluida no programa P para gerar o mutante. A execução dessa função aborta a execução do mutante, fazendo com que ele seja considerado morto. Esse tipo de operador não tem como objetivo modelar algum tipo especial de erro e sim garantir que os casos de teste alcancem algum tipo de cobertura. Considere-se por exemplo, o operador que cria um mutante $M$ substintuindo um comando de $\mathbf{P}$ por uma chamada de função armadilha. Para matar $M$, exige-se um caso de teste que faça com que o comando trocado e, em conseqüência, a armadilha, seja executado. Fazendo isso com todos os comandos de P, garante-se a cobertura de todos os comandos do programa, ou seja, garante-se que o conjunto de casos de teste satisfaz o critério todos-nós.

Além dos tipos de erros que se desejam revelar e da cobertura que se quer garantir, a escolha de um conjunto de operadores de mutação depende também da linguagem em que os programas a serem testados estão escritos. Em [BUD81] encontrase a relação de 22 operadores de mutação utilizados por um sistema de mutação, chamado EXPER, para programas em FORTRAN. Para Cobol, são 27 operadores, utilizados pelo sistema CMS [ACR80]. Já para a linguagem C, Agrawal e seus companheiros definem um conjunto de 77 operadores de mutação [AGR89].

No Apêndice B são dados alguns exemplos de operadores de mutação propostos para a linguagem C [AGR89].

É importante notar que em princípio é possivel gerar-se mutantes com a aplicação de mais de um operador de mutação de uma só vez. Mutantes gerados a partir de k alterações simultâneas no programa $\mathbf{P}$ sendo testado são chamados de mutantes de ordem $\mathbf{k}$. Experiências passadas [BUD80] mostram que mutantes de ordem superiores, além de não contribuirem de forma significativa para a construção de casos de teste melhores, têm um custo de geração e execução demasiado alto. Portanto, tem-se utilizado na Análise de Mutantes uma vizinhança composta apenas dos mutantes de primeira ordem.

\subsection{2. - Execução do Programa Testado}

Esse passo na Análise de Mutantes não é diferente de outros critérios de teste. Consiste em executar o programa P usando os casos de teste selecionados e verificar se seu 
comportamento é o esperado. Se não for, ou seja, se o programa apresenta resultados incorretos para algum caso de teste, então um erro foi revelado.

Em geral, a tarefa de oráculo, ou seja, de decidir se o resultado produzido é correto ou não, é desempenhada pelo testador. Isso não acontece apenas na Análise de Mutantes, mas na maioria das técnicas e critérios de teste [MAL91].

\subsection{3. - Execução dos Mutantes}

Essa fase pode ser totalmente automatizada, não requerendo a intervenção do testador. Cada um dos mutantes gerados é executado usando-se os casos de teste fornecidos pelo testador. Os resultados obtidos são comparados com aqueles produzidos pelo programa original no passo anterior e o próprio sistema de mutação pode marcar como mortos os mutantes que apresentam resultados diferentes.

Após a execução dos mutantes pode-se ter uma idéia da adequação dos casos de teste utilizados, através do escore de mutação ("mutation score"). 0 escore de mutação varia entre 0 e 1 e fornece uma medida objetiva do grau de adequação do conjunto de casos de teste analisado.

Dado o programa $P$ e o conjunto de casos de teste $T$, calcula-se 0 escore de mutação $\mathrm{ms}(\mathrm{P}, \mathrm{T})$ da seguinte maneira:

$$
m s=\frac{D M(P, T)}{M(P)-E M(P)}
$$

onde:

$\mathrm{DM}(\mathrm{P}, \mathrm{T})$ : número de mutantes mortos pelos casos de teste em $\mathrm{T}$.

M(P): número total de mutantes gerados.

EM(P): número de mutantes gerados equivalentes a $P$.

Ou seja, o escore de mutação pode ser obtido calculando-se a razão entre o número de mutantes efetivamente mortos por $\mathrm{T}$ e $\mathrm{O}$ número de mutantes que é possivel matar-se, dado pelo número total de mutantes gerados subtraido do número de mutantes equivalentes.

Note-se que apenas DM(P,T) depende do conjunto de casos de teste utilizado. Apesar disto, não se conhece a princípio o número de mutantes equivalentes gerados. EM(P) é obtido iterativamente à medida que $o$ testador decide, ou decide-se 
automaticamente através da aplicação de heurísticas, na fase seguinte do teste, marcar como equivalente um mutante $\mathrm{M}$ que continua vivo.

Um dos problemas relacionados com essa fase da Análise de Mutantes é decidir se um mutante está morto ou vivo. Mais precisamente, determinar quais entidades devem ser comparadas para decidir-se se o resultado do mutante e do programa original são os mesmos. A opção mais simples é capturar as seqüências de caracteres enviadas pelos programas para os dispositivos de saida e comparar as seqüências produzidas pelo programa original e pelos mutantes. Alternativamente, pode-se comparar somente os caracteres não brancos [WOO88]. Além disso, outros pontos podem ser usados para tentar distinguir o comportamento dos programas. 0 código de retorno, valor que indica se a execução terminou normalmente ou qual foi a causa da terminação, é também usado com esse propósito. Além disso, se a Análise de Mutantes estiver sendo aplicada num ambiente interpretado, onde o sistema de mutação tem controle sobre a execução dos mutantes e do programa em teste, então pode-se usar também o valor final das variáveis ou até mesmo estados intermediários do programa para decidir-se se um mutante deve morrer ou não [OFF87]. Assim, decidir quais entidades devem ser monitoradas é mais uma questão de implementação do sistema de mutação do que uma característica intrínseca da Análise de Mutantes. Não são bem claras quais são as conseqũências de escolher-se como parâmetro de decisão, essa ou aquela entidade.

Com certeza, o principal problema na Análise de Mutantes diz respeito à complexidade da execução dos mutantes. Muitas vezes o número de mutantes criados é muito grande, fazendo com que a complexidade computacional da execução de todos eles seja proibitiva. Krauser [KRA88] cita o exemplo do programa TRITYP, mostrado na Figura 3.1., que apesar de ter apenas 29 linhas de código apresenta, quando mutado, 970 mutantes. Usando-se um gerador automático obtiveram-se 420 casos de teste para 0 programa TRITYP. Com isso tem-se no pior caso, quando todos os mutantes e o programa original são executados usando-se todos os casos de teste, um total de $\mathbf{4 0 7 . 8 2 0}$ execuçōes. Em geral, o pior caso não ocorre, pois se um mutante é morto por um caso de teste não é necessário executá-lo usando-se os demais.

A esse respeito, Budd observa dois pontos importantes. 0 primeiro é que, em geral, o número de linhas ou de comandos do programa não é um bom parâmetro para estimar-se a complexidade do teste baseado na Análise de Mutantes. Como exemplo, dois programas examinados, ambos com 33 comandos, produziram números de mutantes bem diferentes um do outro. O primeiro, um processador de texto simples, produziu 859 mutantes enquanto que o segundo, um programa para multiplicar matrizes, criou 28.382. Essa discrepância ocorre porque o primeiro programa possui 13 objetos entre constantes, variáveis e arrays e 55 referências a esses objetos enquarito que o segundo possui 53 objetos e 407 referências a eles. Em geral, pode-se calcular o número esperado de mutantes multiplicando-se o número de objetos do programa pelo número de referências a esses objetos.

A segunda observação feita por Budd é que, em geral, independentemente da qualidade dos casos de teste utilizados, $80 \%$ dos mutantes gerados morrem na primeira 
execução, proporcionando um cenário bem distante do pior caso. Tal fato não significa porém que a geração e execução desses $80 \%$ seja um trabalho inútil, tendo em vista que sua eliminação não contribui para melhorar a qualidade do conjunto de casos de teste. Ocorre que determinar a priori quais são os mutantes que morrem rápido é pelo menos tão trabalhoso quanto matá-los usando os casos de teste [BUD80].

SUBROUTINE TRITYP(I,J,K, CODE)

C... 1,J AND K ARE SIDES OF THE PROPOSED TRIANGLE

C... CODE RETURNS THE TYPE OF THE PROPOSED TRIANGLE

C... CODE $=1$ FOR EQULLATERAL

C... CODE $=2$ FOR ISOSCELES

C... CODE $=3$ FOR SCALENE

C... CODE $=4$ FOR AN IMPOSSIBLE TRIANGLE

INTEGER I,J,K,CODE

INPUT I,J,K

RDONLY I,J,K

OUTPUT CODE

INTEGER MATCH

C... COUNT MATCHING SDES

MATCH $=0$

IF ( .EQ. ) MATCH $=$ MATCH +100

IF (I.EQ. K) $\mathrm{MATCH}=$ MATCH +200

IF (J.EQ. K) MATCH = MATCH + 300

C... SELECT POSSIBLE SCALENE TRIANGLES

IF (MATCH .EQ. 0) GOTO 10

C... SELECT POSSIBLE ISOCELES TRIANGLES

IF (MATCH .EQ. 100) GOTO 20

IF (MATCH .EQ. 200) GOTO 30

IF (MATCH .EQ. 300) GOTO 40

C... TRIANGLE MUST BE EQULAATERAL CODE $=1$

RETURN

C... POSSIBLE SCALENE

10 IF $((++)$.LE. $K$.OR (J+k).LE. I .OR. (I+K).LE. J) GOTO 50 CODE $=3$

RETURN

20 IF $(\boldsymbol{I}+\boldsymbol{I})$.LE. K) GOTO 50

GOTO 60

$30 \quad$ IF $((1+K)$.LE. K) GOTO 50 GOTO 60

40 IF ((J+K) .LE. I) GOTO 50 GOTO 60

C... NO TRIANGLE POSSIBLE

50 $\mathrm{CODE}=4$

RETURN

C... ISOSCELES

60 CODE $=2$

RETURN

END

Figura 3.1. - Programa TRITYP 
Várias estratégias têm sido utilizadas para fazer com que a Análise de Mutantes possa ser utilizada de maneira mais eficiente. Essas estratégias podem ser divididas basicamente em dois grupos: as que atacam o problema tentando diminuir o tempo de execução dos mutantes e as que procuram diminuir o número de mutantes gerados. A seguir são apresentados esses dois grupos.

\subsubsection{1. - Diminuição do Tempo de Execução dos Mutantes}

Uma das abordagens para diminuir o tempo de execução dos mutantes é a utilização de máquinas de alta performance.

Mathur [MAT88] apresenta um algoritmo para otimizar a execução de mutantes gerados a partir da substituição de cada referência a uma variável escalar do programa original por referências a todas as outras variáveis escalares do programa. Cada mutante desse tipo contém como diferença do programa original $\mathbf{P}$, uma única referência a alguma posição de memória, não existindo nenhuma diferença na estrutura dos comandos do mutante em relação a P. Para cada comando em cada mutante as sequiências de instruções a serem executadas são as mesmas; somente as posições de memória de onde os operandos são retirados e onde os resultados são armazenados é que mudam. Assim, essas operações, ao invés de serem executadas seqüencialmente, podem ser vetorizadas. A Figura 3.2. mostra um exemplo de como tais operações podem ser vetorizadas. A notação $[A, B]=[B, C]+[X, Y]$ indica que a operação de soma deve ser vetorizada usando-se como operandos primeiro $A=B+X$ e depois $B=C+Y$; quando usado $X^{\mathbf{n}}$ significa que a variável $\mathrm{X}$ é repetida $\mathrm{n}$ vezes.

\section{PROGRAM VP \\ INTEGER A,B,C,X,Y,Z \\ $\mathbf{A}=\mathbf{B}+\mathbf{C}$ \\ $\mathbf{X}=\mathbf{Y}+\mathbf{Z}$}

END

$\left[A, B, C, X, Y, Z, A^{5}, A^{5}, A^{15}\right]=\left[B, B^{5}, A, C, X, Y, Z, B^{5}, B^{15}\right]+\left[C, C^{5}, C^{5}, A, B, X, Y, Z, C^{15}\right]$

$\left[X^{15}, X, Y, Z, X, Y, Z, X^{5}, X^{5}\right]=\left[Y^{15}, Y, Y^{15}, X, Z, X, Y, Z, Y^{5}\right]+\left[X^{15}, Z, Z^{5}, Z^{5}, X, Y, X, Y, Z\right]$

Figura 3.2. - Operações para a Execução Vetorizada de um Programa e Seus Mutantes 
Outro trabalho nessa área utiliza o modelo de máquinas SIMD ("Single Instruction, Multiple Data Stream") para executar os mutantes de maneira concorrente. Basicamente, uma máquina SIMD possui vários processadores simples com memória local chamados de elementos processadores ou PE ("processing elements") que são controlados por uma unidade de controle ("control unit") CU que cuida de obter as instruções a serem executadas e distribuí-las para os PE's. Estes executam a mesma instrução simultaneamente sobre os operandos que estão nas memórias locais. A idéia é agrupar os mutantes gerados por um mesmo operador de mutação sobre o mesmo ponto do programa e executar as partes comuns desses mutantes de forma concorrente, um mutante em cada PE. Para isto o programa é representado na forma de um grafo de fluxo de controle, como já descrito anteriormente neste trabalho na Seção 2.2.2. Como exemplo, considere-se o programa da Figura 3.3. que tem 4 blocos de comandos e que, ao aplicar-se o operador de mutação $X$, gera 3 mutantes, $\mathbf{M X}_{1}, \mathbf{M}_{2}, \mathbf{M}_{3}$ que diferem do programa $P$ apenas no vértice número $B_{3}$. A Figura 3.4. mostra como são os blocos desses mutantes. Pode-se executar os comandos do bloco $B_{1}$ simultaneamente sobre os dados dos mutantes $\mathbf{M}_{\mathbf{i}}$, localizados cada um em um PE. $\mathbf{O}$ mesmo acontece para os blocos $\mathbf{B}_{2}$ e $\mathbf{B}_{4}$. Já os blocos $\mathbf{B}_{3,1}, \mathbf{B}_{3,2}$ e $\mathbf{B}_{3,3}$ devem ser executados sequencialmente, cada um sobre os dados do mutante e do PE correspondente [KRA88, KRA91a].

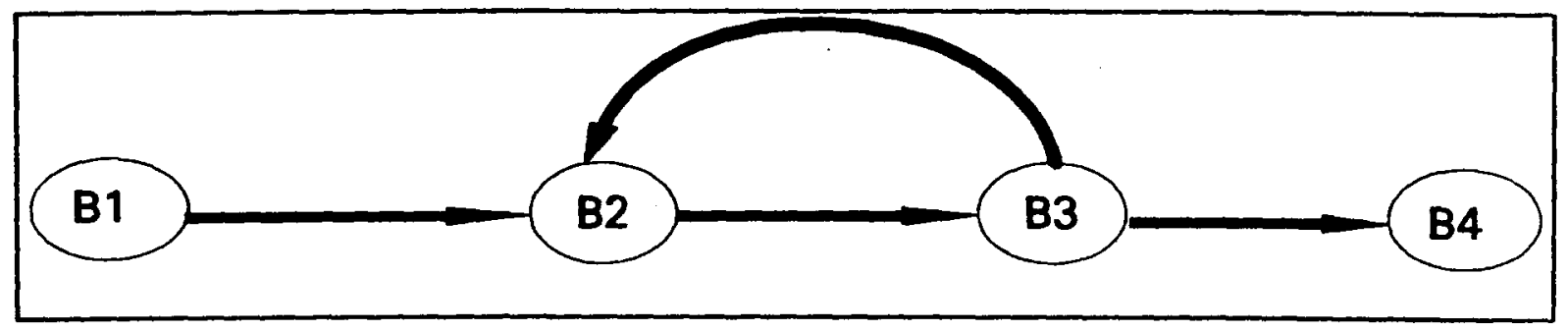

Figura 3.3. - Programa com 4 Blocos

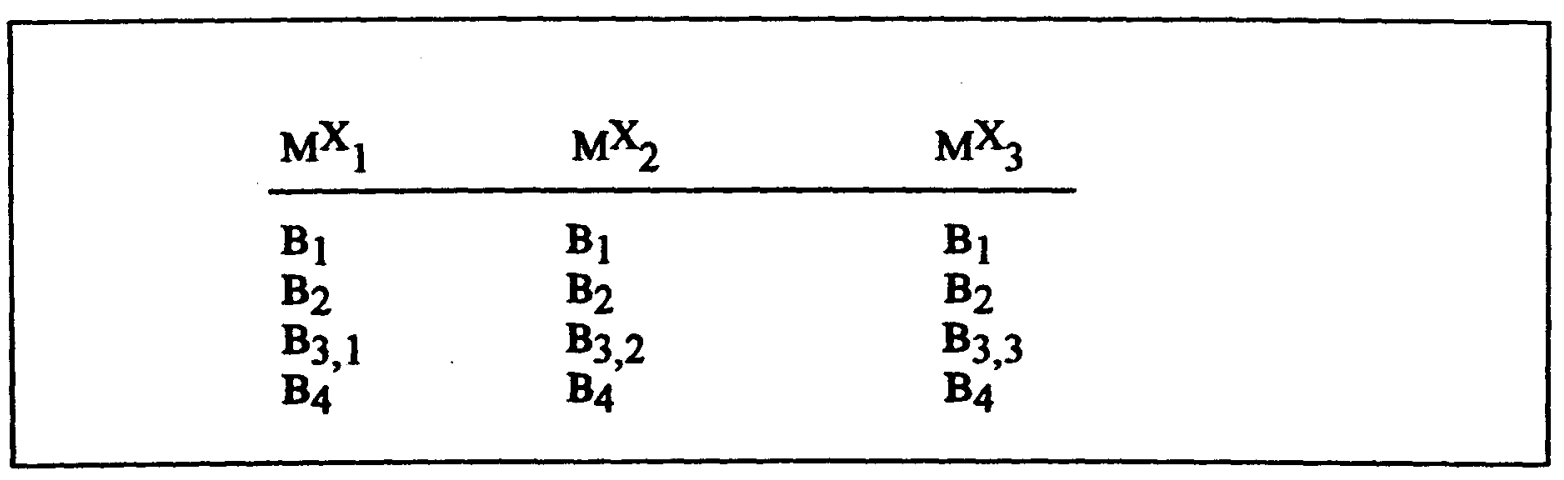

Figura 3.4. - Blocos Básicos dos Mutantes 
Choi [CHO89a] descreve uma implementação, resumida na Figura 3.5., de um sistema de mutação que utiliza uma arquitetura hipercubo para distribuir a execução dos mutantes. Basicamente, tem-se o sistema de mutação rodando numa máquina hospedeira ("host") e comunicando-se com um "pool" de processadores com memória local arranjados na forma de um hipercubo. Cada processador do hipercubo é alocado para executar e avaliar os resultados de um mutante de cada vez. No host existe um escalonador que cuida da comunicação com os processadores do hipercubo fornecendo dados, ou seja, o mutante a ser executado, os casos de teste a serem empregados e os resultados esperados, e recebendo de cada nó uma resposta se o mutante foi morto ou não. Os resultados obtidos mostram que ferramentas deste tipo permitem a utilização de critérios como a Análise de Mutantes para software de grande porte e com requisitos rigorosos de validação [CHO93].

Para diminuir o tempo de execução dos mutantes existe também a solução através de software. Como cada mutante difere do programa original em apenas um ponto e como a execução de ambos até esse ponto é igual, não é necessário executar-se esse trecho que ambos têm em comum, duas vezes. A idéia é, através da execução interpretada dos programas, fazer com que cada mutante inicie sua execução somente a partir do ponto onde ele difere do programa original [OFF87].

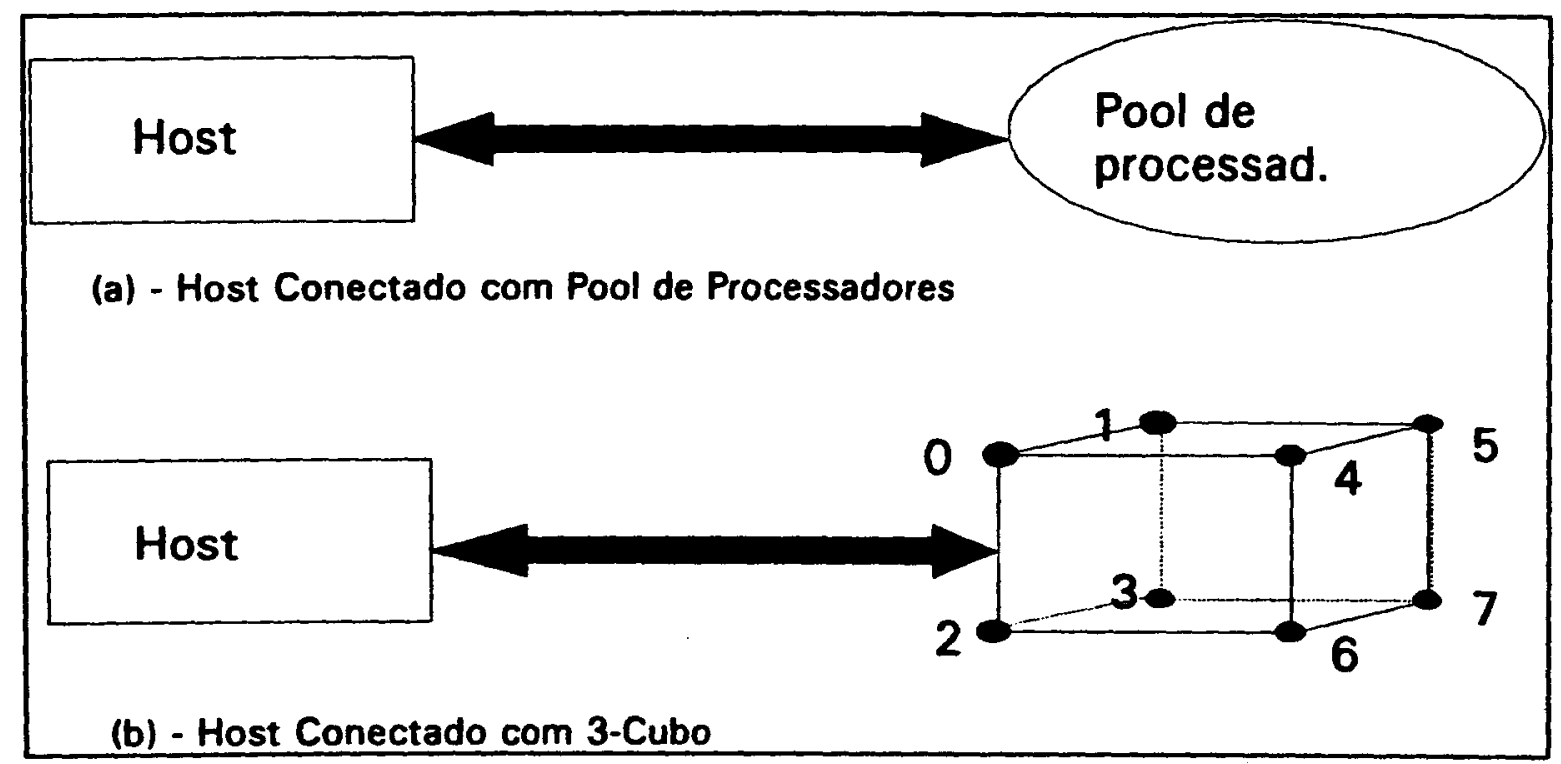

Figura 3.5. - Hipercubo para Execução dos Mutantes 


\subsubsection{2. - Diminuição do Número de Mutantes}

Uma abordagem completamente diferente das anteriores, é tentar selecionar entre os mutantes gerados, apenas um subconjunto deles, com o intuito de diminuir o número de execuções necessárias para conduzir o teste, porém, sem perder a qualidade.

A primeira dessas estratégias é apresentada em [MAR90]. Sobre cada variável do programa sendo testado pode-se efetuar três aç̃̄es: definição, quando um valor é atribuido à variável; referência, quando o valor da variável é utilizado mas não destruído; $e$ indefinição, quando uma operação torna o valor da variável indeterminado. Usa-se notar essas três açōes pelas letras D de "define", $R$ de "reference" e $U$ de "undefine".

Certas seqüências de ações sobre uma variável são consideradas suspeitas, no sentido de que podem indicar um erro no uso da variável. A ocorrência de tais sequeências é chamada de anomalia de fluxo de dados ("dataflow anomaly"). Claramente as seqüências abaixo são anômalas:

- UR: uma variável que tem um valor não determinado é referenciada.

- DD: uma variável é definida e redefinida sem ser referenciada.

- DU: uma variável é definida e nunca referenciada.

Ao criar-se um mutante substituindo o uso de uma variável do programa original por uma outra variável, pode-se introduzir no mutante uma anomalia de fluxo de dados pois a seqüência de ações efetuadas sobre as váriáveis é alterada. A mutação fraca auxiliada pela análise estática de fluxo de dados (SDAWM: "static dataflow-aided weak mutation analysis") propõe que os mutantes que apresentam anomalias de fluxo de dados devem ser descartados. Assim, antes da execução dos mutantes um préprocessamento pode ser feito com o intuito de localizar estaticamente essas anomalias e eliminar os mutantes que as possuam. Não se trata de matar os mutantes anômalos e sim de considerar uma vizinhança $\Phi(P)$ que não possua programas com anomalias de fluxo de dados. É como se a hipótese do programador competente fosse ampliada, afirmando-se que os programas criados por um programador experiente estão corretos ou próximos do correto e, além disto, não possuem anomalias de fluxo de dados.

Numericamente, chamando de $\mathrm{AM}(\mathrm{P})$ o número de mutantes com anomalias, pode-se interpretar o escore de mutação como:

$$
m s(P)=\frac{D M(P, T)}{M(P)-E M(P)-A M(P)}
$$


A Figura 3.6. mostra como exemplo: (a) um programa sobre o qual é aplicado apenas o operador de mutação de substituição de variáveis; (b) as seqüências de açōes, em forma de expressões regulares, sobre cada variável; (c) quais os mutantes eliminados usando-se SDAWM [MAR90]. Note-se que aproximadamente $66 \%$ dos mutantes do exemplo seriam descartados, o que representa uma grande economia na aplicação do critério.

A principal crítica ao método é que muitos programas corretos contêm anomalias de fluxo de dados intencionais, o que pode "confundir" a aplicação da SDAWM. A solução apontada pelo autor é fazer com que o testador verifique, antes da aplicação do método, cada uma das anomalias do programa e caso a anomalia seja confirmada como intencional, permitir que os mutantes tenham as mesmas anomalias que estão presentes no programa original. Deve-se ressaltar que não foram encontrados na literatura resultados que mostrem quais são as conseqüências sobre a qualidade dos casos de teste de aplicar-se esse relaxamento da Análise de Mutantes.

Outra tática utilizada para diminuir o número de mutantes a serem executados é a amostragem. Ao invés de considerar-se todos os mutantes gerados, seleciona-se aleatoriamente uma porcentagem deles $e$ a análise fica restrita apenas a esses mutantes selecionados. Em geral, mesmo uma amostragem com pequena porcentagem do total de mutantes é suficiente para construir bons casos de teste [DEM88, MAT93c].

Por fim, tem sido usada a prática de não se gerar todos os mutantes de uma só vez. Ao contrário, os operadores de mutação são divididos em classes que podem ser habilitadas e desabilitadas para a criação de mutantes. Assim, na fase de geração dos mutantes, somente os operadores de mutação habilitados produzem seus mutantes. Embora isso não diminua efetivamente o número de mutantes gerados, pode-se atacar o problema de matar os mutantes por etapas, facilitando a criação de casos de teste que eliminem mais rapidamente os mutantes. Como coloca Budd [BUD81] alguns tipos de mutantes são responsáveis pela deteç̧ão de um maior número de erros que outros. Assim, é interessante que tais mutantes sejam executados e mortos o mais cedo possivel, pois além de auxiliarem na construção de casos de teste mais poderosos, fazem com que o trabalho de re-teste, quando um erro é encontrado e corrigido, seja menor. Além disso, estudos mostram que pode-se escolher apenas alguns operadores para a geração dos mutantes e ainda assim obter-se bons conjuntos de casos de teste [MAT93c].

\subsection{4. - Análise dos Mutantes Vivos}

Essa é a fase da Análise de Mutantes que requer mais intervenção humana. Primeiro é preciso analisar os mutantes que sobreviveram à execução com os casos de teste disponiveis e decidir se esses mutantes são ou não equivalentes ao programa original. 


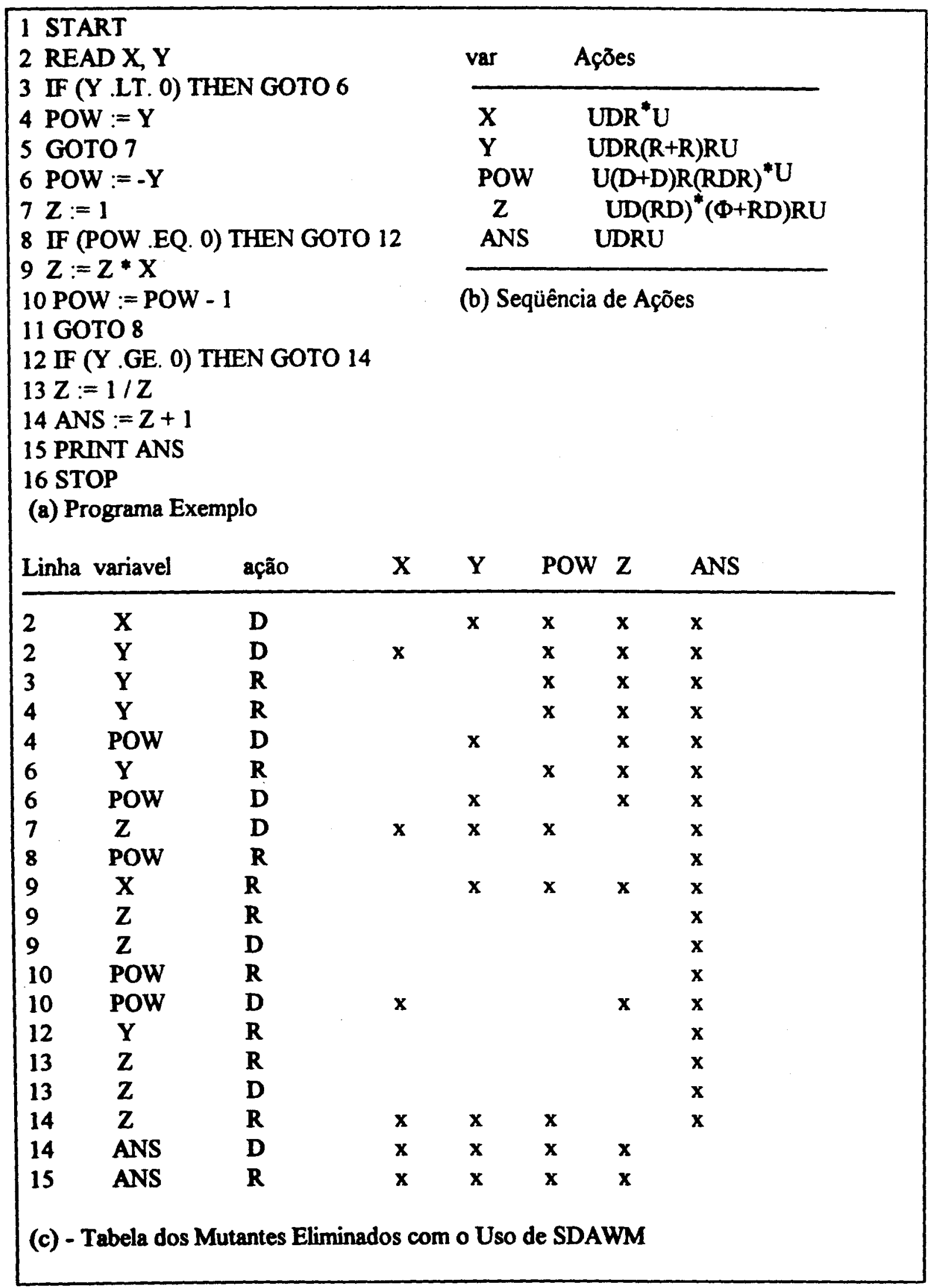

Figura 3.6. - Exemplo de Aplicação de SDAWM 
Como já foi dito, o problema de resolver se dois programas são equivalentes é, em geral, indecidível; essa limitação teórica não significa que o problema deve ser abandonado por não ter solução. Na verdade, alguns métodos e algumas heurísticas têm sido propostos para determinar a equivalência de programas em uma grande porcentagem dos casos de interesse [BUD81].

Tipicamente, para programas em FORTRAN, 4\% a 10\% dos mutantes gerados são equivalentes, sendo que alguns dos operadores de mutação são responsáveis pela criação de um número maior de equivalentes que outros operadores. Dentre os mutantes equivalentes cerca de $70 \%$ podem ter a equivalência determinada através de procedimentos automáticos simples. Aproximadamente apenas 3\% dos mutantes equivalentes (o que corresponde a $0,014 \%$ do total de mutantes) requerem um entendimento mais profundo do programa; os outros podem facilmente ser reconhecidos com intervenção humana [BUD81].

Uma vez decidido que um mutante não é equivalente ao programa $P$ em teste, é preciso, se o desejo é construir um conjunto de casos de teste adequado para $P$, elaborar um caso de teste que mate tal mutante. DeMillo [DEM91] apresenta uma solução para tentar criar-se automaticamente casos de teste que matem os mutantes sobreviventes. 0 método, chamado de geração automática baseada em restriç̋̃es ("constraint-based automatic test data generation") basicamente associa a cada operador de mutação um modelo que fornece, para cada mutante gerado por esse operador, uma restrição que deve ser satisfeita na construção dos casos de teste. Por exemplo, se um mutante é gerado trocando-se uma referência à variável $X$ pela variável $Y$, então a restrição a ser satisfeita para matar esse mutante é que $X \neq Y$. Assim, a tarefa do gerador de casos de teste é encontrar dados de entrada que satisfaçam essas restriçóes. A Figura 3.7. mostra o programa MAX com alguns de seus mutantes e suas respectivas restriçōes.

É bom notar que um caso de teste que satisfaça determinada restrição nem sempre consegue matar o mutante pois tal caso de teste apenas faz com que o estado do mutante M e o estado do programa P sejam diferentes imediatamente após a execução do comando alterado para criar $M$, o que nem sempre significa que $M$ e $P$, ao final da execução, vão apresentar resultados diferentes. Por isto, o método proposto cria conjuntos de casos de teste que estão próximos de serem adequados a $\mathrm{P}$; como diz DeMillo, são aproximadamente adequados \& $P$.

\section{4. - Avaliação do Critério}

Vários trabalhos foram realizados procurando mostrar experimentalmente a eficácia da Análise de Mutantes ou comparando-a com outros critérios. 
Acree [ACR80] relata alguns experimentos que visam analisar, principalmente, a validade do efeito de acoplamento, a capacidade de um testador em identificar mutantes equivalentes e a eficácia de cada operador de mutação. Para realizar tal experimento foi utilizado um sistema de mutação para programas em Cobol, chamado de CMS ("Cobol Mutation System") [ACR80].

\begin{tabular}{|c|c|}
\hline Programa/mutante & Restrições \\
\hline $\begin{array}{l}\text { FUNCTION MAX(M,N) } \\
\text { MAX = M } \\
\text { IF (N.GT. M) MAX =N } \\
\text { RETURN }\end{array}$ & \\
\hline $\begin{array}{l}\text { FUNCTION MAX(M,N) } \\
\text { MAX =N } \\
\text { IF (N .GT. M) MAX = N } \\
\text { RETURN }\end{array}$ & $\mathbf{M} \neq \mathbf{N}$ \\
\hline $\begin{array}{l}\text { FUNCTION MAX(M,N) } \\
\text { MAX = ABS(M) } \\
\text { IF (N.GT. M) MAX = N } \\
\text { RETURN }\end{array}$ & $M<0$ \\
\hline $\begin{array}{l}\text { FUNCTION MAX(M,N) } \\
\text { MAX = M } \\
\text { IF (N.LT. M) MAX = N } \\
\text { RETURN }\end{array}$ & $(\mathrm{N}>\mathrm{M}) \neq(\mathrm{N}<\mathrm{M})$ \\
\hline $\begin{array}{l}\text { FUNCTION MAX(M,N) } \\
\text { MAX = M } \\
\text { IF (N .GE. M) MAX = N } \\
\text { RETURN }\end{array}$ & $(\mathrm{N}>\mathrm{M}) \neq(\mathrm{N} \geq \mathbf{M})$ \\
\hline
\end{tabular}

Figura 3.7. - Restrições Associadas aos Mutantes

Para tentar mostrar a validade do efeito de acoplamento foram selecionados seis programas em Cobol e construidos para cada um deles um conjunto de casos de teste que satisfaz a Análise de Mutantes, ou seja, que mata todos os mutantes não equivalentes. Em seguida, mutantes de ordem 2 e posteriormente de ordens superiores (até ordem 5) foram criados e os casos de teste construidos foram aplicados a esses mutantes. Como resultado obteve-se a indicação de que em mais de $99 \%$ dos casos, dados de teste que revelam erros 
simples, representados pelos mutantes de primeira ordem, revelam também erros mais complexos, representados pelos mutantes de ordem superior.

Como em geral é necessária a interferência humana para identificar-se quais mutantes são equivalentes ao programa sendo testado, o experimento procurou medir também a capacidade dos testadores em localizar mutantes equivalentes. Foram usados quatro programas e dois testadores. Para cada um dos programas foram selecionados cinqüenta mutantes, os quais os testadores deveriam, separadamente, classificar como equivalentes ou não. $O$ resultado, embora não muito conclusivo, como comenta o próprio autor, é que cerca de $80 \%$ dos mutantes foram classificados corretamente por cada um dos testadores.

O mesmo trabalho procura demonstrar que a amostragem de mutantes, mesmo com percentagens pequenas como $10 \%$ do total de mutantes, apresenta bons resultados na construção de casos de teste.

Finalmente, o autor avalia a eficiência de cada operador de mutação utilizado pelo sistema, através do cálculo, para cada operador, do seguinte valor:

$$
\frac{m u+n e}{n t}
$$

onde execução,

nu: número de mutantes gerados pelo operador e que são eliminados na primeira

ne: número de mutantes equivalentes gerados pelo operador,

nt: número total de mutantes gerados pelo operador.

Na verdade, a métrica avalia a ineficiência do operador, contando o número de mutantes gerados que não contribuem para a criação de casos de teste, ou seja, mutantes equivalentes ou que morrem rapidamente. Como conclusăo final, o autor afirma que os experimentos realizados com esses programas Cobol aumentam a confiança de que um programa testado usando-se a Análise de Mutantes irá funcionar de forma confiável, ou em outras palavras, que a Análise de Mutantes é um bom critério para teste de programas Cobol.

Outros experimentos procuram mostrar como a Análise de Mutantes se relaciona com outros critérios de teste. Em geral, tais trabalhos procuram comparar os critérios usando conjuntos de casos de teste construidos com o auxílio da Analise de Mutantes e submetendo-os à análise dos outros critérios ou vice-versa [DEM81, HOR92]. Outra abordagem apresentada é utilizar programas com erros incluídos artificialmente e verificar se conjuntos de casos de teste que passam pela Análise de Mutantes são eficientes para detectar tais erros [BUD80, DEM80]. 
Acree [ACR79] realizou uma comparação entre a Análise de Mutantes e outros critérios mas de forma diferente. Na realidade, o trabalho mostra como a construção de alguns operadores de mutação garante, ou procura pelo menos em alguns casos, incluir outros critérios. É o caso, por exemplo, da cobertura de comandos e de desvios; deteç̧ão de anomalias de fluxo de dados; teste de dominios; teste de valores especiais, etc.

O escore de mutação, assim como outras medidas de adequação de casos de teste, pode ser visto como uma função $M: S \times P \times D \Rightarrow[0,1]$, onde $S$ é o conjunto de especificações possiveis, $\mathbf{P}$ é o conjunto de programas possíveis numa determinada linguagem e $D$ o conjunto de todas as entradas possiveis para programas em $P$. Desta forma, Zhu [ZHU93] propõe uma série de axiomas para este tipo de função e compara analiticamente critérios de adequação, verificando quais axiomas são satifeitos pelos critérios.

Recentemente Mathur e Wong [MAT93a, MAT93b, MAT93c] realizaram alguns experimentos procurando comparar a Análise de Mutantes (com um conjunto de operadores que pode-se chamar de "padrão") com critérios baseados em fluxo de dados, em particular os critérios propostos por Rapps e Weyuker [RAP85]. A primeira comparação [MAT93a], realizada analiticamente, mostra que, em geral, critérios de fluxo de dados e a Análise de Mutantes são incomparáveis; porém, não se pode concluir se é possivel criar-se outros operadores de mutação que façam com que a Análise de Mutantes inclua aqueles critérios.

O segundo experimento [MAT93b] avalia, utilizando a Análise de Mutantes, conjuntos de casos de teste que são todos-usos-adequados; avalia também conjuntos adequados segundo a Análise de mutantes, utilizando o critério todos-usos. Isso é feito utilizando-se duas ferramentas de teste, Atac [HOR92] e Mothra [CHO89b]. Uma das principais conclusões apresentadas é que os 120 conjuntos de casos de teste adequados à Análise de Mutantes, utilizados para testar 4 diferentes programas, eram também todosusos-adequados. Já dos 120 conjuntos todos-usos-adequados, nenhum obteve um escore de mutação de $100 \%$ sugerindo que, na prática, em geral, a Análise de Mutantes inclui o critério todos-usos.

Por outro lado, pode-se notar que o custo para a aplicação da Análise de Mutantes supera o custo de critérios de fluxo de dados, tanto no número de casos de teste requeridos quanto no número de execuf̧̋es de programas necessários para aplicação do critério. Procurou-se estudar o comportamento de critérios de mutaç̃o alternativos ("alternate mutation adequacy criteria"). Estes critérios: mutantes $\mathbf{x \%}$ randomicamente selecionados ("randomly selected $x \%$ mutation") e mutaşa restrita ("constrained mutation") diminuem o número de mutantes a serem utilizados e, por consequeência, o número de execuçōes necessárias, respectivamente, selecionando aleatoriamente uma pequena porcentagem de mutantes (entre 10 e 40\%) e utilizando mutantes gerados por poucos operadores de mutacãa (operador "inclusão de operador abs" e operador "troca de operador relacional"). Concluiu-se que estes critérios altemativos diminuem significativamente o custo de aplicaçăo do teste e que conjuntos adequados a estes critérios são "quase" adequados à Análise de Mutantes e ao critério todos-usos. Isso 
altos custos e produtos com baixa confiabilidade. Tem-se verificado que embora gastemse, em geral, $50 \%$ do orçamento de desenvolvimento do software em atividades de testes, um número significativo de defeitos permanece sem ser detectado nos softwares liberados; esses defeitos normalmente têm um impacto grande na operação normal do sistema.

Poucas pessoas gostam de teste e menos ainda de projeto de teste, principalmente se essas atividades duram tanto quanto o projeto e codificação do programa. $O$ mito de que bons programadores devem produzir programas sem erros faz com que a tarefa de testar torne-se uma atividade "destrutiva", pois sua função é basicamente revelar erros, causando assim uma boa dose de culpa [BE190].

Além disso, e especialmente porque a atividade de teste está também sujeita a erros, introduzidos principalmente por falha humana, justificam-se os esforços de pesquisadores que, através de ferramentas de teste, têm como ideal automatizar completamente as atividades de teste de forma que para um programa submetido a teste, sejam produzidos como evidência de correção, um conjunto de casos de teste, sem nenhuma intervenção humana. Nesse sistema ideal, quando um programa incorreto é testado, deve ser fornecido (outra vez, sem intervençăo humana) casos de teste que mostrem o comportamento errado do programa e uma lista dos possiveis erros e suas localizações numa forma que possa ser usada como entrada para uma ferramenta de depuração. Embora esse sistema ideal não possa ser alcançado, uma ferramenta de teste que esteja tão perto quanto possivel deste objetivo pode incrementar significativamente as atividades de teste [DEM91].

Uma ferramenta de teste pode auxiliar o processo de várias maneiras diferentes. Por exemplo, uma ferramenta para teste de software de tempo real deve ser capaz de fornecer um ambiente controlado no qual o teste possa ser realizado; se o sistema para o qual o software foi produzido é muito simples ou inconveniente para uso, pode-se simulálo numa máquina mais poderosa, obtendo acesso a um conjunto mais rico de ferramentas e a possibilidade de repetir-se uma execução particular do programa. É o caso do programa RUTE [LUT90].

Outras ferramentas, como o Xray/DX, têm como objetivo verificar a conformidade do programa às restrições de performance, fornecendo informações detalhadas sobre a operação do programa, identificando "gargalos" de desempenho [LUT90].

Ferramentas que são baseadas em algum critério de seleção de casos de teste têm como principal meta a escolha de casos de teste, ou seja, decidir quais combinações dos valores de entrada irão exercitar o programa de forma mais completa e provavelmente revelar mais erros [LUT90].

Como exemplo desse último tipo de ferramentas, pode-se citar a ASSET ("A System to Select and Evaluate Tests"). Essa ferramenta foi desenvolvida na New York University em 1985 e suporta testes de programas em Pascal, analisando a qualidade de dados de teste usando uma familia de critérios de adequação baseados na Análise de Fluxo 
de Dados, definida por Rapps e Weyuker [RAP85]. Outro exemplo nesta mesma linha é a ferramenta PROTESTE desenvolvida na Universidade Federal do Rio Grande do Sul [PRI90].

A POKE-TOOL (POtential Uses CRiteria TOOL for program testing) [MAL89, CHA91], desenvolvida na Faculdade de Engenharia Elétrica da Universidade Estadual de Campinas, auxilia a atividade de teste analisando a cobertura de um conjunto de casos de teste e fornecendo ao testador quais caminhos são necessários para satisfazer os Critérios Potenciais Usos [MAL91], que são baseados na análise de fluxo de dados.

Algumas ferramentas que apóiam a aplicação do critério Análise de Mutantes têm sido construídas. A primeira delas foi o FMS.1 (FORTRAN Mutation SYTEM - Versão 1), desenvolvida na Yale University, num computador PDP 10 e mais tarde transportado para um PRIME 400 na Georgia Institute of Technology e para um VAX 11 na University of California, Berkeley. FMS 1 tratava somente um subconjunto do FORTRAN, ou seja, programas compostos de apenas uma única subrotina com aritmética de inteiros e sem comandos de entrada e saída. 0 sucesso desse projeto foi suficiente para motivar a construção de outros sistemas mais elaborados.

FMS.2 foi também desenvolvido na Yale University e transportado para o Georgia Institute of Technology. Essa ferramenta já aceitava programas com várias subrotinas em ANSI FORTRAN, menos comandos de entrada e saída.

O Cobol Mutation System (CMS.1) foi desenvolvido na Georgia Institute of Technology por Allen Acree, Rich DeMillo, Jeanne Hanks e Fred Sayward, baseado no PMot Mutation System (PIMS, nome anterior do FMS.1) [ACR80].

Outra ferramenta, criada também em torno da mesma concepção dos sistemas citados acima, é o EXPER ("Experimental Mutation System"), sistema de mutação para programas FORTRAN desenvolvido também na Yale University [BUD81]

A ferramenta mais recente de Análise de Mutantes, que na verdade representa a evolução dos sistemas anteriores, é batizada com o nome de Mothra [DEM88, CHO89b]. Mothra é um ambiente de teste para programas FORTRAN-77, desenvolvido conjuntamente na Purdue University e Georgia Institute of Technology. Segundo os criadores do sistema, suas principais características, que os sistemas de mutação anteriores não possuiam, são:

- interface com o usuário baseada em janelas, que permite a apresentação de mais informações, facilitando o trabalho do testador;

- nenhuma restrição, a priori, do tamanho do programa a ser testado. O tamanho máximo dos programas é limitado apenas pela velocidade e capacidade de armazenamento da máquina onde o teste está sendo realizado;

- projeto capaz de permitir ao sistema suportar outras linguagens além do FORTRAN; 
- fácil incorporação de ferramentas como gerador de casos de teste, verificador de equivalência e oráculo;

O processo de gerar um conjunto de casos de teste para um dado programa é chamado no Mothra de experimento. É possivel, antes de gerar os mutantes, selecionar os operadores de mutação que serão aplicados ao programa, permitindo a partição do teste em diferentes fases. Além disto, o usuário pode escolher um valor para a intensidade de teste ("test strength") que nada mais é que a porcentagem dos mutantes que será aleatoriamente selecionada e utilizada no experimento. Quando o testador acaba de selecionar os operadores de mutação a serem utilizados, o sistema cria um arquivo com registros que descrevem como o programa original deve ser modificado para criar os mutantes.

Outra tarefa a ser realizada durante um experimento no Mothra é fornecer os casos de teste. Um caso de teste é composto de dois tipos de valores: valores iniciais ("initial values"), que são os valores dos argumentos do programa ou subprograma e valores em tempo de execução ("run-time values") que são lidos pelo programa durante a execução. Após o usuário ter fornecido os valores iniciais, Mothra começa a executar o programa sendo testado utilizando esses valores; quando o programa executa um comando de leitura, Mothra espera o testador fornecer os dados requisitados (opcionalmente, esses dados podem ser lidos de um arquivo). Uma vez terminada a execução do programa, caso não seja revelada a presença de um erro, os dados 'de entrada e os resultados são armazenados para serem utilizados na execução dos mutantes.

Uma vez fornecidos os casos de teste e gerados os mutantes, o usuário pode iniciar a execução dos mutantes, tarefa que é realizada de forma totalmente automatizada, sem necessidade de interaçào com o testador. Durante a fase de execução dos mutantes, Mothra cria cada programa correspondente aos mutantes, a partir do arquivo de descritores de mutantes, executa-o com o primeiro caso de teste fornecido e compara a saída produzida com a saida esperada para o caso de teste. Se o resultado difere, o mutante é marcado como morto e não é executado com os demais casos de teste. Se o mutante permanece vivo, ele é executado com os outros casos casos de teste até que ele morra ou até que todos os casos de teste fornecidos tenham sido tentados. Enquanto a execução dos mutantes está em andamento, Mothra mostra ao usuário uma série de dados estatisticos sobre o número de mutantes que vão morrendo.

Após a execução dos mutantes, o usuário pode, consultando os dados estatísticos fornecidos pelo Mothra, decidir terminar o experimento caso o número de mutantes mortos seja suficiente para satisfazer o critério de parada. Caso contrário, o testador pode analisar os mutantes vivos na tentativa de determinar se eles são ou não equivalentes ao programa original, ou ainda continuar com o experimento, habilitando novos operadores de mutação (e assim criar mais mutantes) e fornecendo novos casos de teste.

Uma das tarefas mais dificeis e que envolve problemas complexos durante esse processo é a de criar casos de teste [DEM88]. O Mothra tem acoplado a si uma ferramenta chamada Godzilla [DEM91] que gera automaticamente casos de teste que se 
aproximam da adequação, utilizando um esquema de restriçðes como o já descrito anteriormente.

A Tabela 3.1. abaixo sumariza as características mais importantes de algumas ferramentas que apóiam a seleção de casos de teste.

Tabela 3.1. - Ferramentas de Teste

\begin{tabular}{|l|c|c|c|}
\hline & Asset & POKE-TOOL & Mothra \\
\hline Linguagem & Pascal & $\begin{array}{c}\text { C, Cobol, } \\
\text { FORTRAN }\end{array}$ & FORTRAN \\
\hline Geração automática & Não & Não & Sim \\
\hline Edição de Casos de Teste & Não & Sim & Sim \\
\hline $\begin{array}{l}\text { Registro sobre caminhos não } \\
\text { executáveis ou mutantes } \\
\text { equivalentes }\end{array}$ & Não & Sim & Sim \\
\hline $\begin{array}{l}\text { Restrição de tamanho do } \\
\text { programa a ser testado }\end{array}$ & Sim & Não & Não \\
\hline $\begin{array}{l}\text { Eliminação de casos de teste } \\
\text { redundantes }\end{array}$ & Não & Não & Não \\
\hline Interface & Menu & Menu/janela & Menu/janela \\
\hline
\end{tabular}

Os capitulos seguintes mostram a especificação, as caracteristicas e os aspectos da implementação do Proteum, ferramenta que apoia a aplicação do critério Análise de Mutantes, desenvolvida no ICMSC - USP - São Carlos, objetivo desta dissertação de mestrado.

\section{6. - Algumas Tendências Atuais}

A escolha do conjunto de operadores de mutação é essencial para garantir a qualidade do teste baseado na Análise de Mutantes. Os operadores usados nos mais recentes sistemas de mutação são frutos de uma evolução de mais de dez anos na construção de ferramentas desse tipo. Apesar disso, novos operadores podem ser criados, tentando modelar diferentes classes de erros, com $o$ intuito de aumentar ainda mais a abrangência da Análise de Mutantes. É o caso de alguns erros que são ligados ao ambiente onde o software é executado ("Environmental Bugs"). Esses erros podem ser dificeis de se localizar pois, muitas vezes, o algoritmo pode estar completamente correto mas o comportamento da máquina não é aquele esperado pelo programador. Por exemplo, considere-se uma máquina que efetua operaçóes aritméticas de números inteiros na representação complemento de dois. Em toda expressão aritmética onde aparece uma variável inteira, é interessante que o testador construa casos de teste que provoquem as condiçoes de "overflow" e "underflow" para verificar como o programa se comporta nessas situaģ̋es. 
Para forçar essas condiçōes, podem ser definidos dois operadores de mutação que instrumentam o programa original, incluíndo uma função armadilha que recebe uma expressão inteira como argumento e devolve seu valor como resultado, a não ser que ocorra "overflow" ou "underflow"; nesse caso, o mutante morre. Outros erros ligados ao ambiente (e possivelmente outros tipos de erros) podem ser modelados através da criação de novos operadores de mutação. Portanto, essa continua sendo uma direção a ser seguida pela pesquisa no campo da Análise de Mutantes [SPA90].

Tradicionalmente, os compiladores disponiveis para programadores e testadores não oferecem nenhum suporte específico para as atividades de teste ou, quando muito, propiciam através de instrumentação, auxílio para a análise de cobertura de comandos e de desvios. Porém, durante a compilação está disponivel informação sintática e semântica suficiente para apoiar outros critérios de teste. E possível integrar a Análise de Mutantes diretamente dentro do compilador, permitindo que o programa possa ser modificado, ao nivel de código executável, após ser compilado, não necessitando de uma re-compilação. Para isso, é preciso que ao compilar-se um programa sejam criados, além do código objeto do programa, vários remendos ("patches"). Cada um desses remendos corresponde ao conjunto de instruções que devem ser colocadas no programa objeto para refletir uma mutação no programa fonte. Assim, para gerar os mutantes, após a compilação feita por um compilador com essa capacidade, basta incluir-se os remendos nos pontos corretos do programa objeto. Com isto, evita-se que cada mutante, tradicionalmente gerado ao nível de programa fonte, tenha de ser compilado separadamente, obtendo-se assim uma diminuição significativa no tempo necessário para conduzir-se o teste baseado na Análise de Mutantes [KRA91b].

\section{7. - Consideraçōes Finais}

Este capitulo abordou mais profundamente o critério Análise de Mutantes, buscando apresentar o contexto em que se insere e trabalhos relacionados. A teoria que fundamenta o critério foi apresentada.

Aspectos pertinentes ì sua utilização foram mostrados, apresentando-se detalhadamente os passos que compõem sua aplicação, ressaltando-se a necessidade de meios para a automatização do processo. Foram levantados também os principais problemas na aplicação do critério e mostrados os principais trabalhos que tentam minimizar esses problemas.

Este capitulo relacionou também algumas ferramentas para apoio à atividade de teste, procurando destacar características minimas que tais ferramentas devem possuir. Deu-se especial atenção para ferramentas que apóiam a aplicação de critérios de adequação de casos de teste.

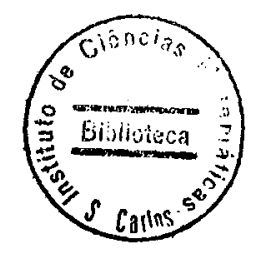


Finalmente, foram destacadas as principais tendências de pesquisa envolvendo a Análise de Mutantes.

Todos estes pontos deram subsídios para a definição de uma ferramenta de teste para apoiar a aplicação da Análise de Mutantes. A especificação e implementação dessa ferramenta, o Proteum, são abordadas no próximo capitulo. 


\section{Capítulo 4.}

\section{Especificação e Implementação do Proteum}

No capitulo anterior foram caracterizadas a relevância da disponibilização de ferramentas de teste e a conseqüente automatização das atividades de teste na produção de software. Neste capitulo são apresentados a especificação e os pontos mais relevantes da implementação de uma ferramenta de teste, denominada Proteum (Program Testing Using Mutants) que apoia a aplicação do critério Análise de Mutantes, como sugere o próprio nome. As características sintetizadas na Tabela 3.1. do Capítulo 3, as necessidades e tendências de pesquisa na área de teste, identificadas na revisão bibliográfica desta dissertação, nortearam a especificação do Proteum.

As atividades típicas de uma ferramenta de teste são: fazer análise estática do código fonte, auxiliar na instrumentação do código, medir a cobertura fornecida por um conjunto de casos de teste e fornecer relatórios [DEU82]. Especificamente, para a aplicação do critério Análise de Mutantes, estas atividades se traduzem num conjunto essencial de tarefas que devem ser executadas:

- definição de casos de teste;

- execução do programa em teste;

- geração de mutantes;

- execução dos mutantes;

- análise dos mutantes vivos; $\mathrm{e}$

- cálculo do escore de mutação.

A Figura 4.1. ilustra as principais funções implementadas no Proteum V1.0 - C e que viabilizam a realização das tarefas citadas acima, algumas de forma automatizada e outras fornecendo facilidades que permitam ao testador realizá-las. A Tabela 4.1. estende a tabela do Capítulo 3, procurando dar uma idéia das principais características do Proteum. 


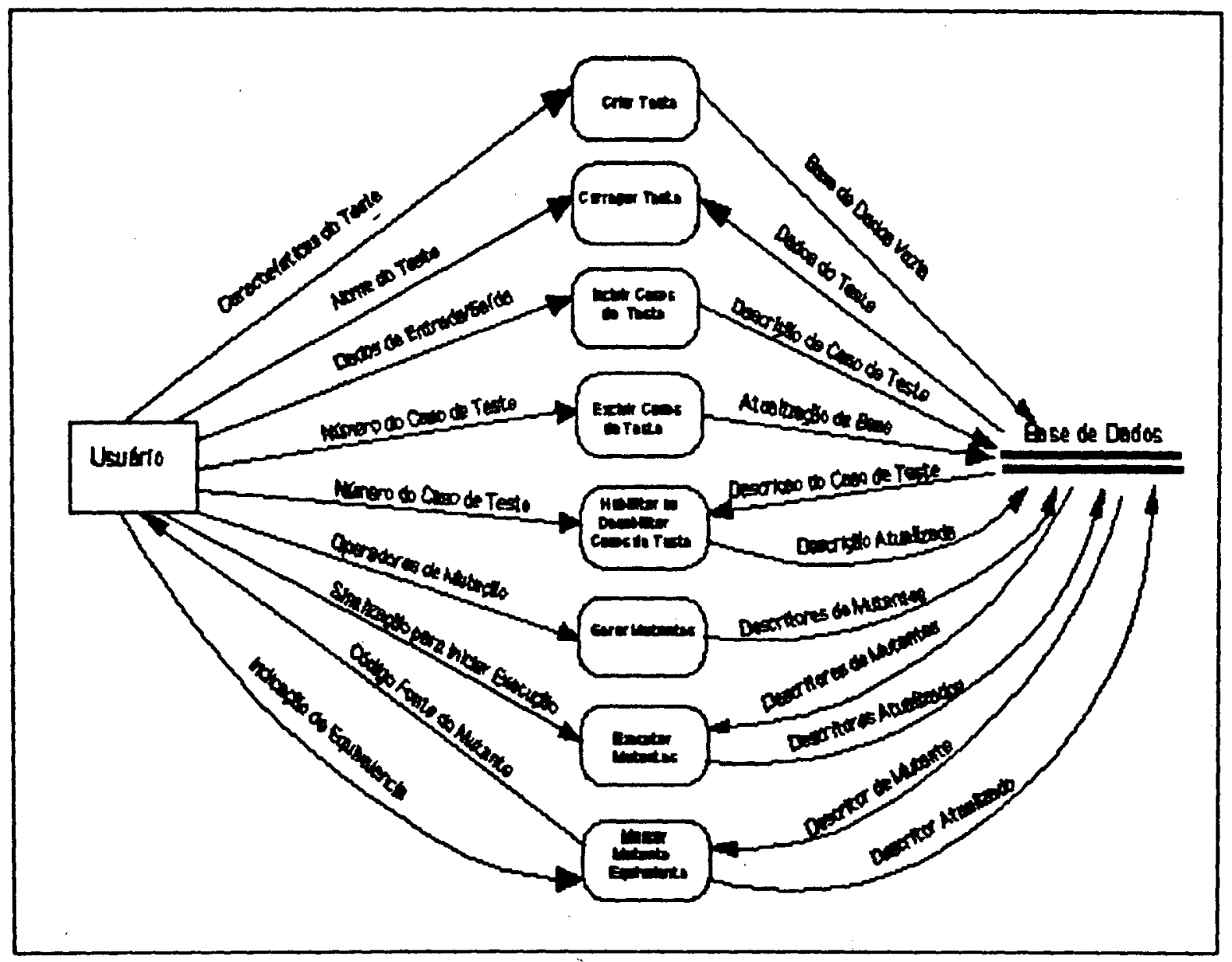

Figura 4.1. - Funções Principais

Basicamente, a ferramenta mantém uma base de dados com informação sobre casos de teste e sobre mutantes e seus estados. 0 usuário fornece o programa a ser testado e pode atuar sobre esta base de dados editando o conjunto de casos de teste a ser utilizado ou gerando mutantes, executando-os e eliminando os mutantes equivalentes. Ainda, relatórios sobre o andamento da atividade de teste podem ser gerados.

As funções Criar Teste e Carregar Teste permitem que o usuário trabalhe com sessôes de teste. A exemplo do que já acontece em outras ferramentas [CHA91], o Proteum permite que o teste de um programa seja realizado em etapas. Para isso, é necessário que os estados intermediários da aplicação do teste possam ser guardados e depois recuperados, permitindo ao usuário iniciar o teste de um programa (criar um teste) encerrar a atividade de teste, e posteriormente retomá-la do ponto em que foi deixada (carregar um teste), sem necessidade de reiniciá-la, caracterizando o que costuma-se chamar de uma sessão de teste.

A definição de um conjunto de casos de teste é feita através das funçð̃es Incluir Casos de Teste e Excluir Casos de Teste. Embora seja possivel apoiar de forma automatizada a geração de casos de teste, baseando-se na Análise de Mutantes[DEM91], o Proteum não o faz, ficando essa tarefa por conta do testador. Ao contrário de outras 
ferramentas, o Proteum permite que modifique-se dinamicamente o conjunto de casos de teste, isto é, que adicionem-se e removam-se casos de teste. Isto permite que casos de teste que se mostrem pouco efetivos, ou em outras palavras, que não matem mutantes, sejam eliminados e substituidos por outros casos de teste. A função Habilitar ou Desabilitar Casos de Teste facilita ainda mais a seleção de bons casos de teste. Ela permite que um caso de teste seja excluído logicamente (desabilitando-o) e reincluído (habilitando-o), facilitando a avaliação de diferentes combinaçōes de casos de teste sem o trabalho de inclusão e exclusão dos mesmos.

Tabela 4.1. - Outras Características de Ferramentas de Teste

\begin{tabular}{|l|c|c|c|}
\hline & POKE-TOOL & Mothra & Proteum \\
\hline Linguagem & $\begin{array}{c}\text { C, Cobol, } \\
\text { FORTRAN }\end{array}$ & FORTRAN & C \\
\hline Geração automática & Não & Sim & Não \\
\hline Edição de Casos de Teste & Sim & Sim & Sim \\
\hline $\begin{array}{l}\text { Registro sobre caminhos não } \\
\text { executáveis ou mutantes } \\
\text { equivalentes }\end{array}$ & Sim & Sim & Sim \\
\hline $\begin{array}{l}\text { Restrição de tamanho do } \\
\text { programa a ser testado }\end{array}$ & Não & Não & Não \\
\hline $\begin{array}{l}\text { Eliminação de casos de teste } \\
\text { redundantes }\end{array}$ & Não & Não & Não \\
\hline Interface & Menu/janelas & Menu/janelas & Janelas \\
\hline Sessões de Teste & Sim & Sim & Sim \\
\hline Apoio a experimentos & Não & Não & Sim \\
\hline Importação de casos de teste & Não & Não & Sim \\
\hline Geração seletiva de mutantes & - & Sim & Sim \\
\hline $\begin{array}{l}\text { Ambiente } \\
\text { compilado/interpretado }\end{array}$ & Compilado & Interpretado & Compilado \\
\hline Execução distribuída & Não & Sim & Não \\
\hline $\begin{array}{l}\text { Determinação automática de } \\
\text { mutantes equivalentes ou } \\
\text { caminhos não executáveis }\end{array}$ & & & \\
\hline & Sim & Não & Não \\
\hline
\end{tabular}

A inclusão de um caso de teste é feita de maneira simples, interativamente, como se fosse uma chamada ao programa através de um comando do Sistema Operacional. No Apêndice A, um exemplo mostra como tal operação é realizada.

A geração de mutantes é realizada através da função Gerar Mutantes. Cada operador de mutação, em geral, procura modelar um classe específica de erro. Assim, é interessante que o testador possa selecionar quais operadores serão utilizados na gerą̧ão dos mutantes de um programa e, como consequeencia, escolher quais classes de erros pretende-se priorizar. Além disto, possibilitando-se a geração de mutantes em etapas, permite-se ao usuário atacar o problema de construir casos de teste adequados, aos 
poucos, ou mesmo dividir essa tarefa entre vários testadores trabalhando independentemente.

O Proteum permite que os mutantes sejam gerados de acordo com os objetivos do teste, de forma seletiva e paulatina. $O$ usuário pode habilitar ou inibir a ação de qualquer operador de mutação do sistema, fazendo com que sejam gerados somente alguns mutantes de cada vez, ou seja, apenas aqueles mutantes produzidos pelos operadores habilitados.

Principalmente quando não se utilizam máquinas de alto desempenho, é importante que o sistema de mutação possua mecanismos para diminuir o tempo necessário para a aplicação do teste que, como já foi visto, pode ser grande devido ao número de mutantes gerados. Proteum faz isso através da seleção aleatória de uma porcentagem do total de mutantes, associando-se a cada operador de mutação uma determinada probabilidade de gerar ou não seus mutantes.

A execução e comparação dos resultados dos mutantes com os resultados do programa em teste é feita de maneira automática, sem intervenção do testador, através da função Executar Mutantes. Um ponto importante a ser destacado é que o resultado da execução dos mutantes sempre reflete a qualidade do conjunto de casos de teste no instante da execução. Isso permite que casos de teste sejam incluídos, excluidos, desabilitados e habilitados $e$, ainda assim, mantenha-se a coerência entre $o$ conjunto de casos de teste e 0 estado dos mutantes. Por exemplo, suponha-se que um mutante $\mathbf{X}$ foi morto pelo caso de teste $\mathbf{N}$ que, em seguida, é desabilitado. Ao efetuar-se novamente a operação de execução dos mutantes, este mutante deve ser "fessuscitado" pois o caso de teste que o matou não pertence mais ao conjunto de casos de teste, pelo menos logicamente.

Tradicionalmente, ao executar-se um mutante com um caso de teste que o mata, este mutante é descartado, sem que seja necessária sua execução com os demais casos de teste. No Proteum, o usuário pode preferir um outro comportamento: aplicar sobre cada mutante todos os casos de teste disponiveis, permitindo assim observar-se quais casos de teste são eficientes para matar cada mutante. Com este procedimento cada caso de teste pode ser avaliado individualmente, permitindo que se obtenha um conjunto mínimo de casos de teste que elimine todos os mutantes. Além disto, esse comportamento facilita a análise de quais são os mutantes que morrem com maior facilidade, ou seja, com maior número de casos de teste, podendo-se avaliar a eficiência ou a utilidade de cada operador de mutação.

Julgar a equivalência entre programas é, em geral, um problema indecidível. Algumas heurísticas podem ser aplicadas para identificar a equivalência entre alguns tipos de mutantes e o programa original. No Proteum, a tarefa de decidir se um mutante é equivalente fica por conta do testador. Através da função Marcar Mutante Equivalente o usuário compara o programa fonte original com o mutante-fonte e decide descartar o mutante ou não. 
A seguir são citadas algumas outras características relevantes do Proteum.

\section{Interface.}

Como já foi dito, a atividade de teste, além de suscetivel à imprecisão, é uma das que mais consomem tempo e recursos no processo de desenvolvimento de software. Por isso, é fundamental que uma ferramenta de teste, tentando facilitar a tarefa do testador, possua uma inteface amigável.

$\Gamma_{A}$ interface do Proteum com o usuário foi construida utilizando-se o XView (XWindow-system-based Visual/Integrated Environment for Workstations) [HEL91], uma biblioteca para construção de interfaces gráficas interativas que rodam sob o sistema Openwindow em uma estação Sun. $O$ resultado é uma interface gráfica onde o usuário pode manipular janelas, ícones, e um "mouse" para selecionar as operaçð̃es que deseja realizar. Como exemplo, a Figura 4.2. apresenta uma das janelas do ambiente, junto com outros aplicativos no ambiente Openwindows. $\mathbf{O}$ Apêndice $\mathbf{A}$ mostra, através de um exemplo completo, mais alguns aspectos da interface do Proteum.

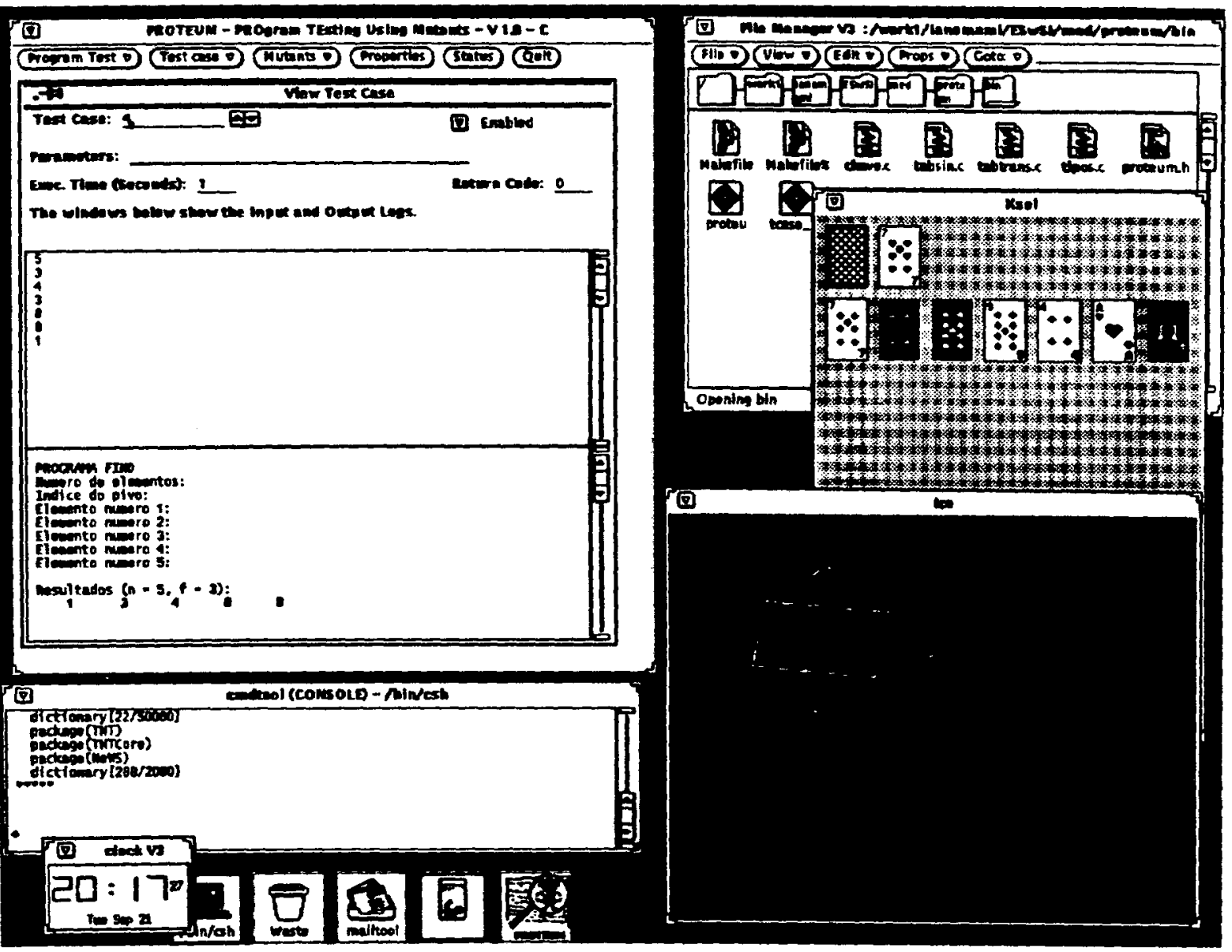

Figura 4.2. - Exemplo da Interface do Proteum 
Um dos problemas ao utilizar-se um "toolkit" para implementação de interfaces é que, em geral, os códigos da aplicaçăo e da interface são altamente conectados [OL192] Um dos requisitos básicos impostos pelas boas práticas da Engenharia de Software é que o projeto e implementação do sistema sejam feitos independentes da interface utilizada. $\mathrm{Na}$ implementação do Proteum, como será visto adiante, procurou-se tomar os devidos cuidados para que esse requisito fosse, quando possivel, satisfeito.

\section{Multilinguagem.}

Outra caracteristica importante para uma ferramenta de teste é não ser dependente de uma linguagem particular. Para ser uma ferramenta multilinguagem, o Proteum tem algumas partes do seu código construídas de maneira genérica, de forma que não fiquem amarradas a qualquer linguagem. Assim, a exemplo do que acontece em outros softwares [CHA91], Proteum pode ser configurado para diferentes linguagens utilizando-se para isso técnicas já conhecidas, empregadas na construção de compiladores [SET81].

\section{Teste de subprogramas.}

A utilização da Análise de Mutantes é mais indicada para o teste de unidade, onde cada unidade é composta por várias funções agrupadas em um único arquivo fonte.

Porém, muitas vezes deseja-se testar apenas uma ou algumas funções que compõem uma unidade. Por isso, o Proteum permite que o usuário selecione apenas uma parte do programa para ser testada. Isto é feito fornecendo-se o nome das funções que se deseja testar ao iniciar-se o teste.

\section{Ambiente compilado.}

O Proteum é um ambiente compilado, ou seja, a execução do programa original e de seus mutantes é feita através de código executável, gerado por um compilador, e não através de interpretação.

Num sistema interpretado obtém-se uma flexibilidade maior, podendo-se, por exemplo, executar uma única subrotina do programa, desde que sejam fornecidos os valores de seus parâmetros e das variáveis globais que ela utiliza, permitindo assim que apenas parte do programa seja testado. Além disto, a utilização da compilação exige que cada mutante, antes de executado, seja compilado, aumentando o tempo de aplicação do teste [KRA91b].

Por outro lado, a abordagem de compilar os mutantes, ao invés de interpretá-los, apresenta algumas vantagens que justificam sua escolha. Em geral, apesar do tempo gasto 
para compilar-se cada mutante, o tempo de execução de um mutante compilado é bastante inferior à execução do mesmo mutante de forma interpretada; assim, em termos de eficiência, em geral, deve-se optar pela execução compilada. Além disto, não existe a interferência de um interpretador nas execuções dos programas; algumas vezes o interpretador pode falhar em reproduzir o comportamento do ambiente onde o programa deve ser executado, fazendo com que seu comportamento, no instante do teste, seja diferente do esperado. Tal problema não ocorre com a compilação pois os programas executam em seus ambientes originais. Finalmente, deve-se levar em conta que as tendências das pesquisas, como integração aos compiladores de facilidades de suporte ao teste, conduzem a um sistema de mutação com execução de programas compilados.

Como não existe, no ambiente compilado, controle total da ferramenta sobre a execução dos mutantes, é necessário um meio para identificar os mutantes que têm terminação anormal ou que nunca terminam por estarem num laço infinito. Os primeiros são identificados através do código de retorno, que indica o que causou o fim da execução. Já os programas com laço infinito, procura-se reconhecê-los através de 'timeout", ou seja: se o tempo de execução do mutante alcança $\mathrm{N}$ vezes o tempo de execução do programa original, pode-se supor um comportamento anormal do mutante $e$ então abortar sua execução e considerá-lo morto.

Na Seção 4.1 a seguir, são discutidos os principais pontos pertinentes à implementação do Proteum.

\section{1. - Aspectos Relevantes da Implementação do Proteum}

Pode-se identificar três grandes grupos de módulos dentro da arquitetura do Proteum (Figura 4.3.). O primeiro grupo é dos módulos que compõem a interface. 0 segundo é dos módulos não dependentes da linguagem alvo da ferramenta e o último é dos módulos dependentes da linguagem, ou seja, aqueles módulos que devem ser alterados para configurar-se o Proteum para uma determinada linguagem.

A implementação do Proteum iniciou-se em janeiro de 1993. A atual fase de desenvolvimento foi concluída em jullho de 1993. Todo o projeto foi implementado utilizando-se a linguagem C, totalizando aproximadamente 27000 linhas de código, incluindo comentários, divididas em 71 unidades. 0 módulo LI é extraido da implementação da POKE-TOOL [CHA91] e adaptado para algumas particularidades do Proteum. A Tabela 4.2. mostra os três grupos de módulos implementados e seus tamanhos em LOC's.

As seções seguintes apresentam as principais caracteristicas de cada um dos três grupos. 


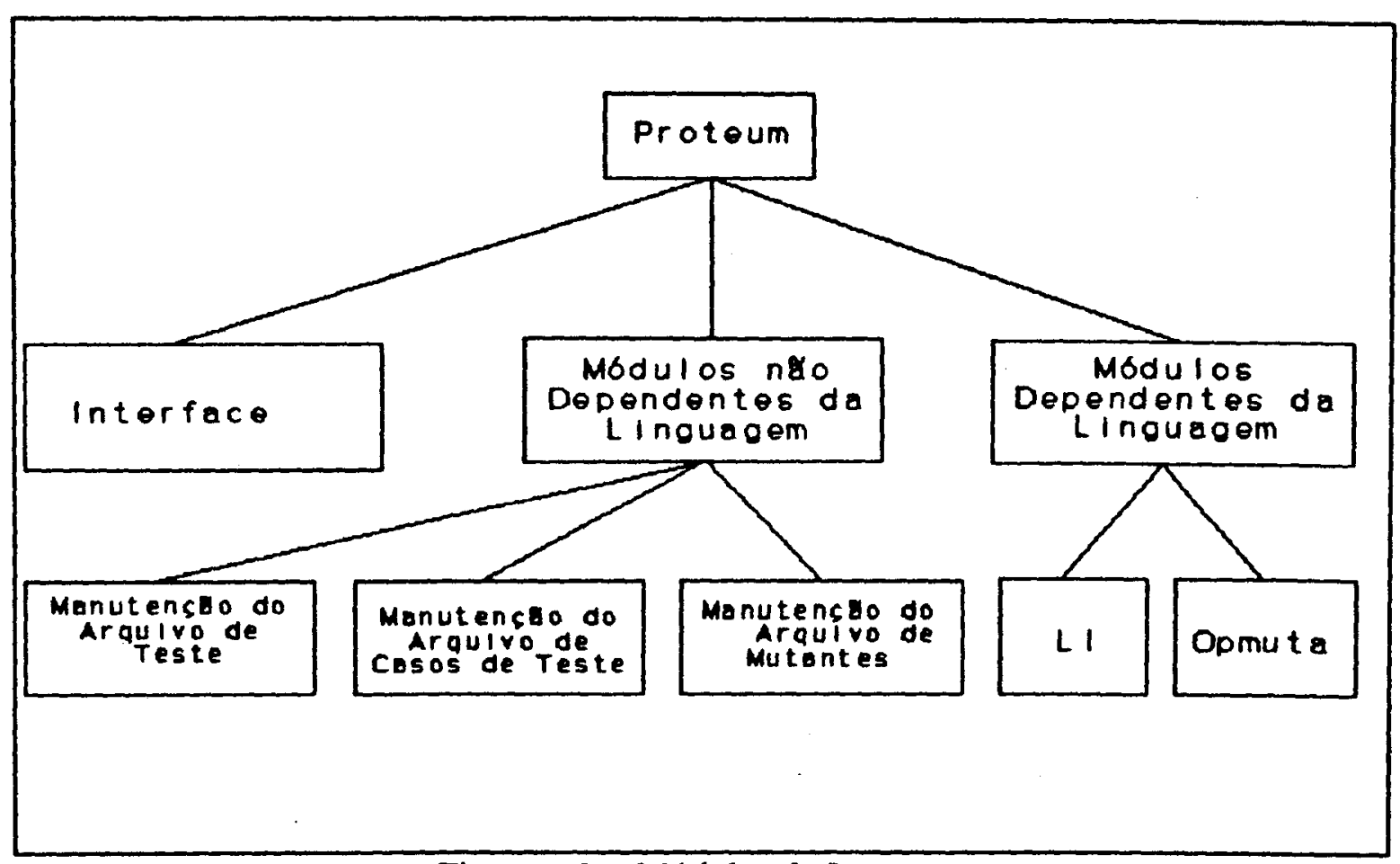

Figura 4.3. - Módulos do Proteum

Tabela 4.2. - Módulos Implementados

\begin{tabular}{|lcc|}
\hline Módulo & Unidades & LOC's \\
\hline Interface & 8 & 3706 \\
\hline Pteste & 1 & 478 \\
Tcase & 4 & 1444 \\
Mutants & 3 & 1328 \\
Tcase_ex & 1 & 308 \\
Globais & 5 & 934 \\
Gerais & 2 & 821 \\
\hline LI & 13 & 3351 \\
Opmuta & 34 & 14746 \\
\hline
\end{tabular}

\subsection{1. - Interface}

Como já foi citado, o Proteum conta com uma interface com o usuário baseada em janelas e desenvolvida utilizando-se o XView. Isto faz com que os módulos que implementam a interface sejam extremamente dependentes do ambiente e não sejam portáveis. Por isso procurou-se manter esses módulos isolados dos demais módulos da ferramenta. 
Para isso, as funções de interface são tratadas pelos outros módulos do Proteum como caixas pretas e trocam informaçð̃es com estes através de "buffers", assim, nenhum outro módulo necessita consultar estruturas ou variáveis especificas e dependentes da interface. Por exemplo, a função ftcase delete mostrada na Figura 4.4., é acionada quando o usuário escolhe eliminar alguns casos de teste. Esta chama uma função da interface (le_menu_tcase_delete) para ler um painel com dados sobre quais casos de teste o usuário deseja eliminar, passando como parâmetros: a variável buf_icase, onde são armazenados os dados fornecidos pelo usuário, e o endereço de duas funçð̃es que a rotina da interface se encarrega de acionar: uma quando o usuário confirma a operação de exclusão e a outra quando o usuário desiste da operação. Estas duas funções tiram as informações necessárias, fornecidas pelo usuário, do buffer buf_tcase.

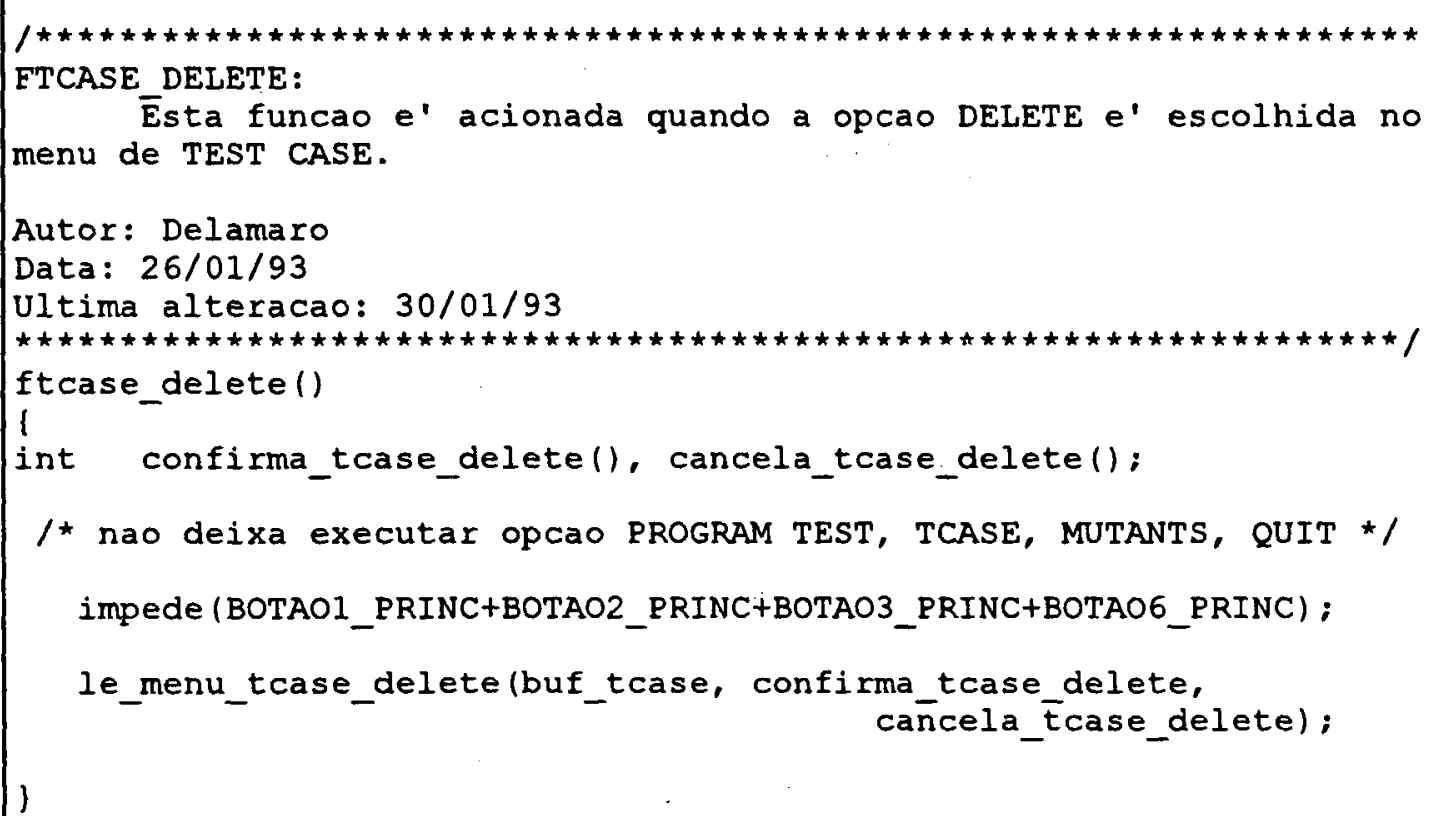

Figura 4.4. - Isolamento da Interface

Além disso, tomou-se o cuidado para que funções de interface possam consultar variáveis globais mas nunca alterá-las diretamente sendo, portanto, simples 'disparadores de funções". Com esses cuidados simples acredita-se que se conseguiu que os módulos "centrais" do Proteum sejam bastante independentes da interface.

\subsection{2. - Módulos Não Dependentes da Linguagem}

Algumas operações que o Proteum realiza independem da linguagem alvo, ou seja, da linguagem em que o programa sendo testado está escrito, enquanto outras operações são 
dependentes da linguagem. Exemplos de operações que não dependem da linguagem são: criação de um novo teste, edição dos casos de teste e execução dos mutantes.

Os módulos não dependentes da linguagem, basicamente, são aqueles que manipulam a base de dados de casos de teste e de mutantes. Esta base de dados é composta de cinco arquivos:

- Arquivo de Teste:

contém informação sobre as características globais do teste.

- Arquivo de Casos de Teste e Arquivo de Entrada/Saida:

armazenam o conjunto de casos de teste utilizados no teste.

- Arquivo de Índices e Arquivo de Descritores de Mutantes:

armazenam as descrições de como criar os mutantes.

Esses arquivos são descritos nas seções seguintes.

\subsubsection{1. - Arquivo de Teste}

Ao criar um teste de programa, o usuário fornece alguns dados e determina algumas características globais do teste, que são armazenadas neste arquivo, em formato ASCII. Este arquivo recebe o mesmo nome dado ao teste, com um sufixo '.PTM'. Por exemplo, se o usuário, ao testar o programa myprog.c, batiza o teste com o nome de teste-myprog, então cria-se um arquivo teste-myprog.PTM que será usado para identificar este teste de programa.

As informações contidas neste arquivo são:

- Arquivo fonte:

Nome do arquivo com o código fonte do programa a ser testado.

- Arquivo executável:

Nome do arquivo executável do programa a ser testado. 
- Comando de compilação:

Comando que deve ser utilizado para gerar-se 0 arquivo executável a partir do arquivo fonte.

- Tipo do teste:

Indica se trata-se de um teste convencional (tipo Test) ou um teste tipo pesquisa (Research), onde cada mutante é executado com todos os casos de teste, independentemente de já estar morto ou não.

- Anomalias de fluxo de dados

Indica quais tipos de anomalias devem ser utilizadas para descartar mutantes, quando utiliza-se a estratégia de SDAWM [MAR90] de minimização de mutantes. Embora esta estratégia não esteja implementada na atual versão do Proteum, a estrutura necessária para sua implementação já encontra-se no ambiente.

- Funçōes a serem testadas:

Lista com os nomes das funções que se encontram no arquivo fonte, que devem ser testadas.

Um exemplo de um Arquivo de Teste é mostrado na Figura 4.5. Note-se que este arquivo, assim como os demais arquivos de trabalho do Proteum, contém um campo com 64 caracteres de tamanho que identifica o tipo do arquivo, a versão do programa que o criou e a data da criação.

\begin{tabular}{|r|l|}
\hline & PROTEUM - PROGRAM TESTE FILE \\
Identificação & V $1.00-\mathrm{C}$ \\
& $24-08-93$ \\
& \\
Fonte & myprog.c \\
Executável & myprog \\
Tipo & Test myprog.c -o myprog -g -w \\
Comando de Compilação & UR DD \\
Anomalias & Funções \\
& <A L L F U N C T I O N S > \\
\end{tabular}

Figura 4.5. - Arquivo de Teste 


\subsubsection{2. - Arquivo de Casos de Teste e Arquivo de Entradas/Saídas}

Os casos de teste a serem utilizados na execução do programa em teste e dos mutantes são armazenados nestes dois arquivos. $\mathbf{O}$ Arquivo de Casos de Teste contém informação de tamanho fixo sobre os casos de teste, ou seja: parâmetros iniciais, tempo de execução do programa em teste com o caso de teste e código de retorno da execução. Os dados de tempo de execução e as saídas produzidas pelo programa são armazenados no Arquivo de Entradas/Saidas. O Arquivo de Casos de Teste é criado com extensão ".TCS" e o Arquivo de Entradas/Saídas é criado com extensão ".10".

As operações relacionadas com a manipulação de casos de teste são quatro: incluir, excluir, consultar (ler) e habilitar/desabilitar um caso de teste. A estrutura do Arquivo de Casos de Teste, para implementarem-se estas operações, é mostrada na Figura 4.6.

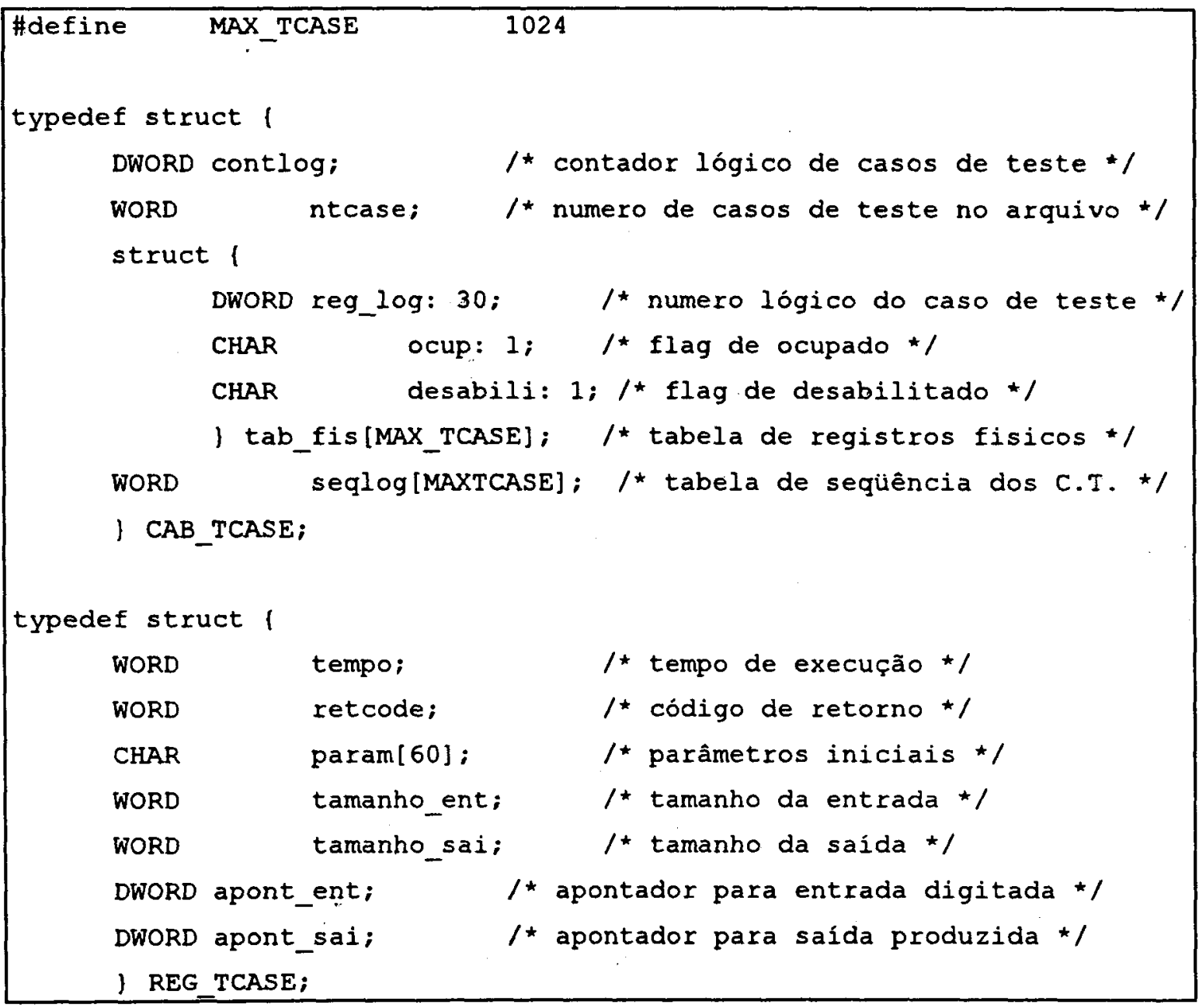

Figura 4.6. - Estrutura do Arquivo de Casos de Teste 
O Arquivo de Casos de Teste possui, logo após a identificação, um cabeçalho que controla a "ocupação" do arquivo seguido de vários registros, que contêm os casos de teste. A política para incluir e excluir caso de teste é a seguinte:

- ao ser incluído, o caso de teste é colocado num espaço vazio no meio do arquivo, fruto da exclusão de algum caso de teste; caso não exista tal espaço, o caso de teste é colocado no final do arquivo.

- ao se excluir um caso de teste, não existe uma retirada física do registro; apenas marca-se no cabeçalho que existe um espaço vago e que será utilizado numa futura inclusão.

- o número máximo de casos de teste é 1024. (constante MAX_TCASE da Figura 4.6.).

O cabeçalho do Arquivo de Casos de Teste é descrito na Figura 4.6. pela estrutura CAB_TCASE. A variável contlog é iniciada com o valor 1, quando o arquivo é criado, e é incrementada cada vez que um caso de teste é incluído no arquivo; sua função será vista adiante.

A variável ntcase do cabeçalho representa o número de casos de teste presentes no arquivo em qualquer instante. Ela é iniciada em 0 , é incrementada a cada inclusão e decrementada a cada exclusão.

No cabeçalho existe um vetor, chamado de tab_fis, com 1024 posições e que indica como está cada registro do arquivo: se está ocupado ou não e, caso esteja ocupado, por quem está ocupado, e se o caso de teste está habilitado ou não. Dentro deste vetor, o campo ocup indica se o registro correspondente está ocupado ou não; desabili indica se o caso de teste que ocupa aquele registro está ou não habilitado; o campo reg $\log$ recebe um número de seqüência do caso de teste, ou seja, ao incluir o caso de teste este campo recebe o valor da variável contlog. Isso permite que possam ser diferenciados casos de teste que ocupam, em tempos diferentes, o mesmo registro do arquivo, pois embora tenham o mesmo número "fisico" (de 0 a 1023), possuem numeros lógicos diferentes.

O vetor seqlog serve para guardar a ordem cronológica de inclusão dos casos de teste, ou seja, a ordem em que o usuário identifica os casos de teste. Na Figura 4.7. mostram-se os algoritmos das operações de inclusão e exclusão de casos de teste utilizando-se esta estrutura.

Como pode-se notar, o vetor seqlog é na verdade a porta de acesso do usuário ao Arquivo de Casos de Teste; o usuário só associa a um caso de teste um número de 1 a 1024 e que não corresponde ao número do registro que ele ocupa no arquivo. A variável seqlog serve para fazer-se esta tradução. Por isso, ao excluir-se um caso de teste, todos os que estão "acima dele" em seqlog são deslocados "para baixo", como acontece sob o ponto de vista do usuário. 


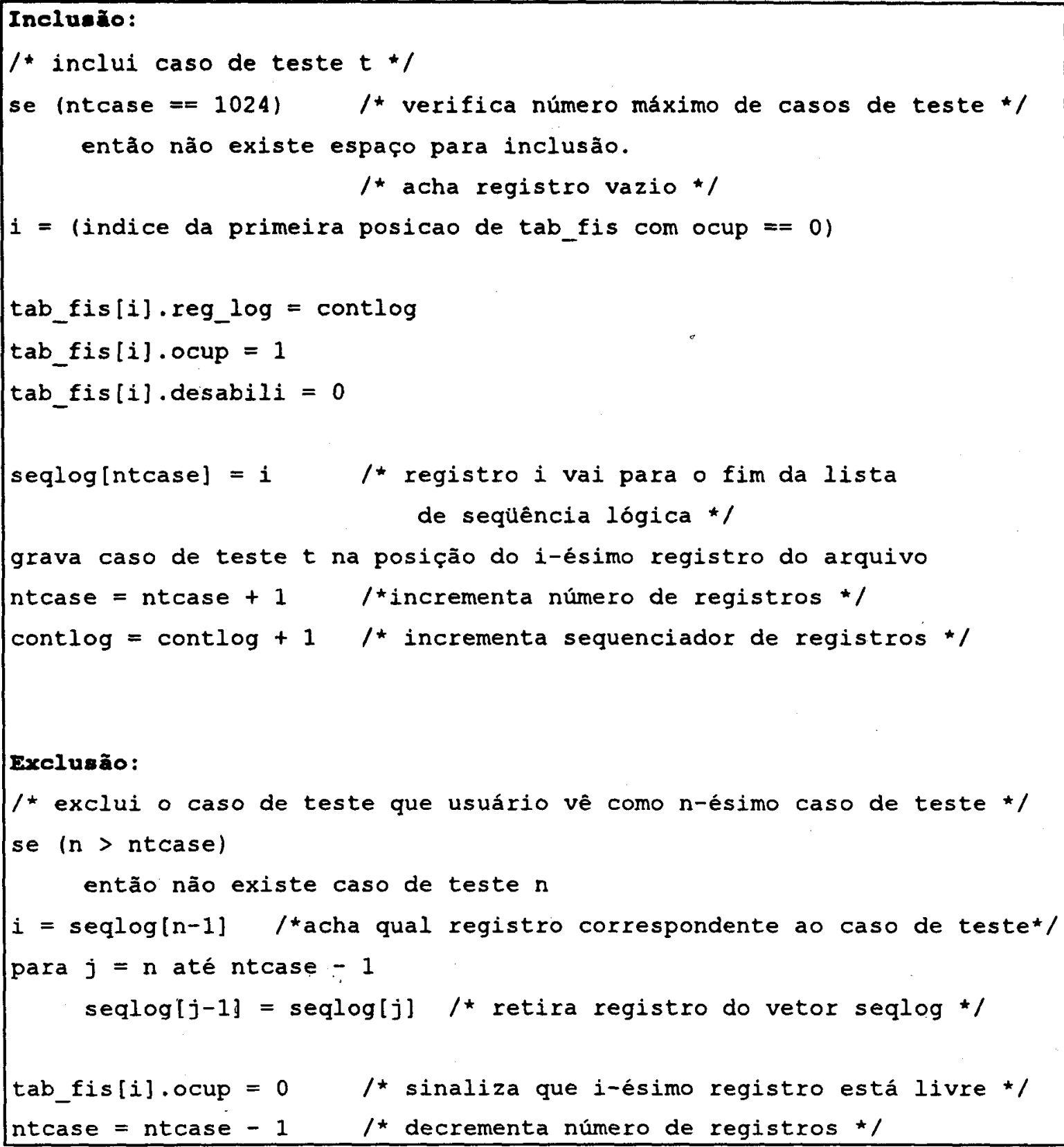

Figura 4.7. - Inclusão e Exclusão de Casos de Teste

Para desabilitar ou habilitar um caso de teste basta, respectivamente, ligar ou desligar o campo desabili do vetor tab_fis.

Seguindo o cabeçalho, vêm os registros que descrevem os casos de teste. 0 formato de cada registro é mostrado na Figura 4.6., representado pela estrutura REG_TCASE. O campo tempo indica o tempo de execução, em segundos, do programa em teste com o caso de teste; se o tempo de execução for menor que 1 segundo, assumese o valor 1 para este campo. $O$ campo retcode guarda o código de retorno produzido pela execução do programa; o código de retorno é um valor numérico que indica qual o 
resultado final da execução do programa ou qual a causa de sua terminação, em caso de erro. $O$ vetor param representa os parâmetros de entrada que caracterizam o caso de teste.

Os campos tamanho_ent e tamanho_sai indicam respectivamente, o tamanho das entradas fornecidas em tempo de execução e das saidas produzidas pela execução do caso de teste. Esses dados de entrada e resultados obtidos constituem-se, a princípio apenas de sequências de caracteres ASCII - outros tipos de dados como movimentação e "clicks" de mouse não são tratados - mas têm tamanho livre, ou seja, é dificil determinarse a priori um tamanho máximo para essas seqüências de caracteres. Por isso optou-se por mantê-las em um arquivo separado. Os campos apont_ent e apont_sai nos registros do Arquivo de Casos de Teste são apontadores que indicam quais registros do Arquivo de Entradas/Saidas correspondem, respectivamente, aos dados de entrada e às saidas do caso de teste.

O formato do Arquivo de Entradas/Saídas, que segue a identificação do arquivo, é mostrado na Figura 4.8. Cada registro (estrutura REG_IO) deste arquivo é um nó de uma lista ligada, que contém uma parte de texto e um apontador. $O$ campo texto contém a seqüência de caracteres da entrada ou saida do caso de teste; caso a seqüência não possa ser armazenada em um único registro, ela é quebrada em vários registros que são encadeados através do campo prox. Este campo contém o deslocamento, em relação ao inicio do arquivo, do próximo registro da lista, ou seja, do registro onde a cadeia de carecteres continua; o último registro da lista aponta para o primeiro, formando uma lista circular. Note-se que no cabeçalho do Arquivo de Entradas/Saídas existe uma única variável chamada livre. A princípio o valor desta variável, utilizada como um apontador para registros disponíveis do arquivo, é 0 (NULL). Quando um caso de teste é excluído, deve-se excluir os registros correspondentes do Arquivo de Entradas/Saídas; para isto, não é feita uma retirada fisica dos registros, apenas incluem-se as listas correspondentes ao caso de teste na lista de disponíveis, apontada pela variável livre.

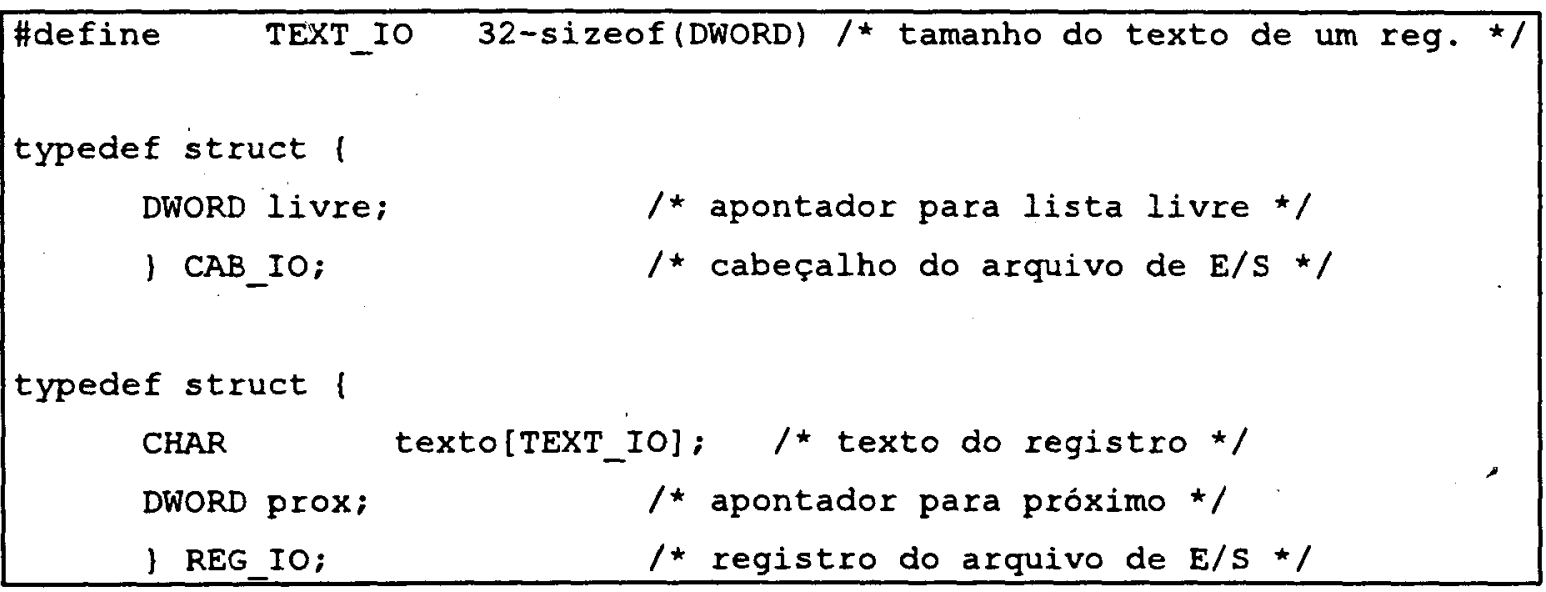

Figura 4.8. - Estrutura do Arquivo de Entradas/Saídas

O algoritmo para inclusão de um texto e exclusão de uma lista é mostrado na Figura 4.9.. Note-se que para utilizar estes algoritmos, os registros no Arquivo de Casos 
de Teste devem armazenar nos campos apont_ent e apont_sai o deslocamento do último registro da lista no Arquivo de Entradas/Saidas.

Vale lembrar que na inclusão (exclusão) de casos de teste, deve-se portanto incluir (excluir) registros tanto no Arquivo de Casos de Teste quanto no Arquivo de Entradas/Saidas.

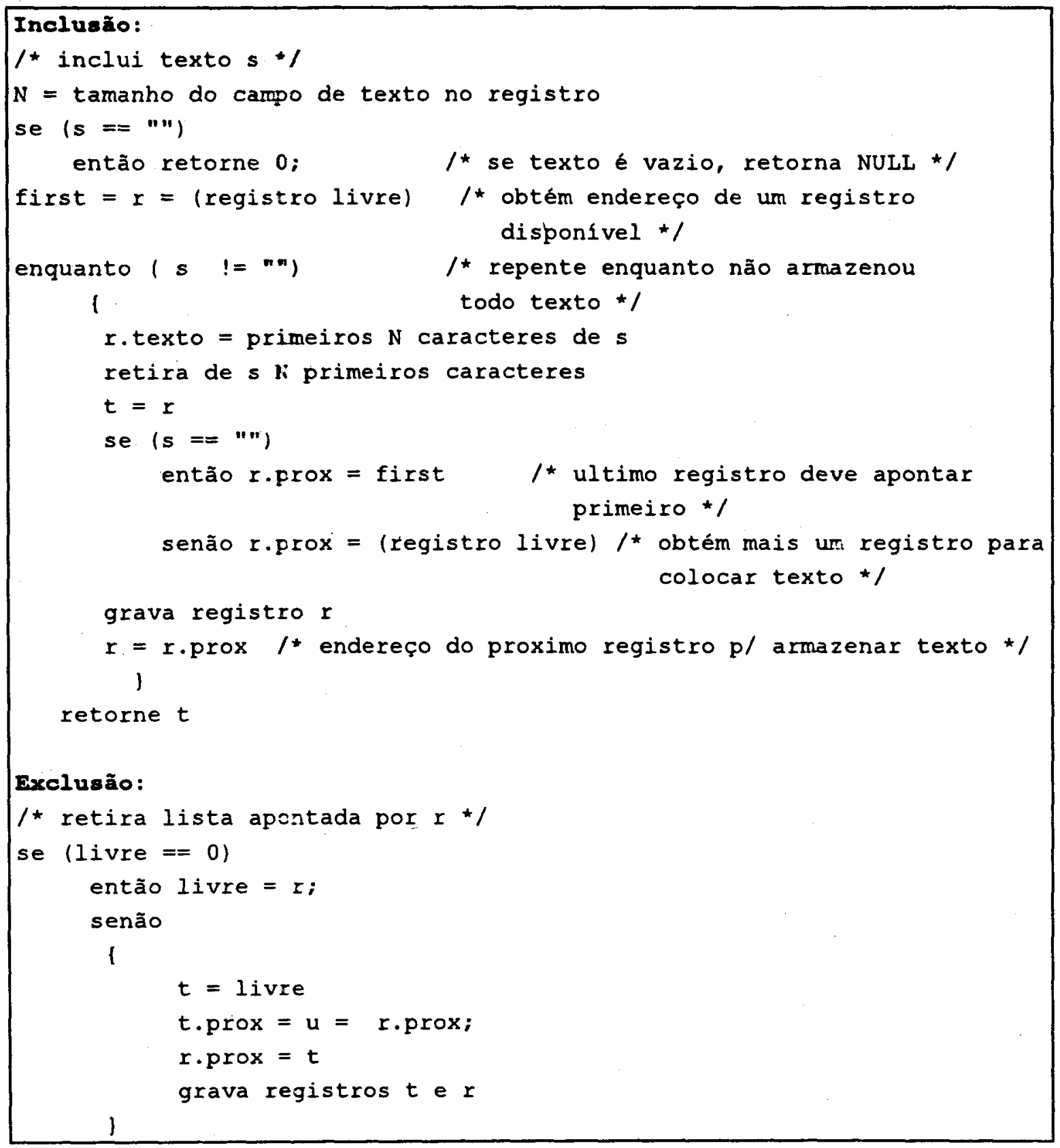

Figura 4.9. - Inclusão e Exclusão no Arquivo de E/S 


\subsubsection{3. - Arquivo de Índices e Arquivo de Descritores de Mutantes}

Ao gerar-se os mutantes de um programa, torna-se impraticável armazenar-se um arquivo fonte ou um arquivo executável para cada mutante, pois isso ocuparia um espaço muito grande em disco ou em outro meio de armazenamento secundário. Por isso, cria-se, para cada mutante, uma descrição de como construí-lo a partir do programa original; quando for preciso, aplicam-se as transformações sobre o fonte original para obter-se o fonte do mutante que após ser utilizado pode ser eliminado.

Uma maneira de se descrever um mutante é considerar o programa fonte como uma grande seqüência de caracteres sobre a qual deve-se aplicar uma ou várias vezes operações de retirada de uma subseqüência de caracteres e/ou inclusão de outras seqüências. Por exemplo, se um programa $P$ contém o comando if $(a<b)$ que deve ser transformado em if $(a>b)$, pode-se descrever este mutante indicando que deve-se retirar a seqüência "<" e incluir-se no seu lugar a seqüência ">".

Pode-se considerar a execução dos mutantes como um "gargalo" na aplicação do critério. No processo de execução, a criação do código executável do mutante pode ser um ponto crítico, em termos de tempo. Por isso, optou-se por esse tipo de descrição dos mutantes que agiliza a etapa de criação do arquivo fonte do mutante, o qual é compilado e executado.

Internamente, o Proteum tem acesso a "pedaços" do programa fonte - expressões, comandos e declarações - através da Linguagem Intermediária (LI) [CAR91], que será vista na próxima seção, permitindo que os mutantes sejam descritos da maneira mencionada acima. A Figura 4.10. mostra dois exemplos de como descrever mutantes. $O$ primeiro deles, já foi mostrado acima. Note-se porém que a transformação a ser realizada é retirar toda a expressão " $a<b^{n}$ e incluir no seu lugar a expressão " $a>b$ ", pois é mais fácil identificar, no programa fonte, toda a expressão que apenas o operador. $O$ segundo é um caso mais complicado onde um comando do-while é transformado num while. Neste caso, são necessárias duas operaçōes de retirada/inclusão.

Para gerenciar os mutantes, o Proteum mantém dois arquivos: o Arquivo de Descritores, que contém os descritores dos mutantes e o Arquivo de Índices, que contém informação auxiliar para facilitar o acesso aos decritores. Estes arquivos recebem o mesmo nome dado ao teste do programa, na sua criação, com os sufixos ".MUT" e ".IND", respectivamente.

O Arquivo de descritores é composto, além da identificação no início do arquivo, de vários registros, cada um com a descrição de um mutante e com informação sobre seu estado. A Figura 4.11. mostra como são esses registros. 


\begin{tabular}{|c|c|}
\hline $\max (a, b)$ & $\max (a, b)$ \\
\hline int $\quad a, b$; & int $\quad a, b$; \\
\hline 1 & 1 \\
\hline if $(a<b)$ & if $(a>b)$ \\
\hline printf("A menor que B"); & printf ("A menor que B"); \\
\hline else & else \\
\hline ) printf("B menor ou igual a $A ")$; & printf("B menor ou igual a A"); \\
\hline $\begin{array}{l}\text { Retirar: " } a<b \text { " } \\
\text { Incluir: " } a>b \text { " }\end{array}$ & \\
\hline tabascii() & tabascii() \\
\hline 1 & 1 \\
\hline int $\quad i$; & int $\quad i$ \\
\hline $\begin{array}{l}i=0 \\
\text { do }\end{array}$ & $i=0$ \\
\hline $\begin{array}{l}\text { printf }(" 8 c ", i) \text {; } \\
\text {, while }(i<256) \text {; }\end{array}$ & $\int_{1}^{\operatorname{printf}(" 8 \mathrm{c} ", i)}$ \\
\hline$\}$ & 1 \\
\hline $\begin{array}{l}\text { Retirar: "do" } \\
\text { Incluir: "while }(\mathrm{i}<256) \text { " } \\
\text { Retirar: "while }(\mathrm{i}<256) \text {;" } \\
\text { Incluir: " " }\end{array}$ & \\
\hline
\end{tabular}

Figura 4.10. - Exemplo de Descrição de Mutantes

Cada registro do Arquivo de Descritores tem duas partes, uma de tamanho fixo e outra de tamanho variável. A primeira, representada pela estrutura REG_MUTANTE, contém informação sobre o estado do mutante. $O$ campo tamanho indica qual o tamanho do descritor do mutante, ou seja, da parte variável do registro. Os campos status1 e status2 não estão sendo utilizados na atual versão do Proteum e estão reservados para incluir-se futuramente informações como: "causa-mortis" de um mutante ou motivo pelo qual um mutante é considerado equivalente. $O$ campo operador indica o número do operador de mutação que criou o mutante. 


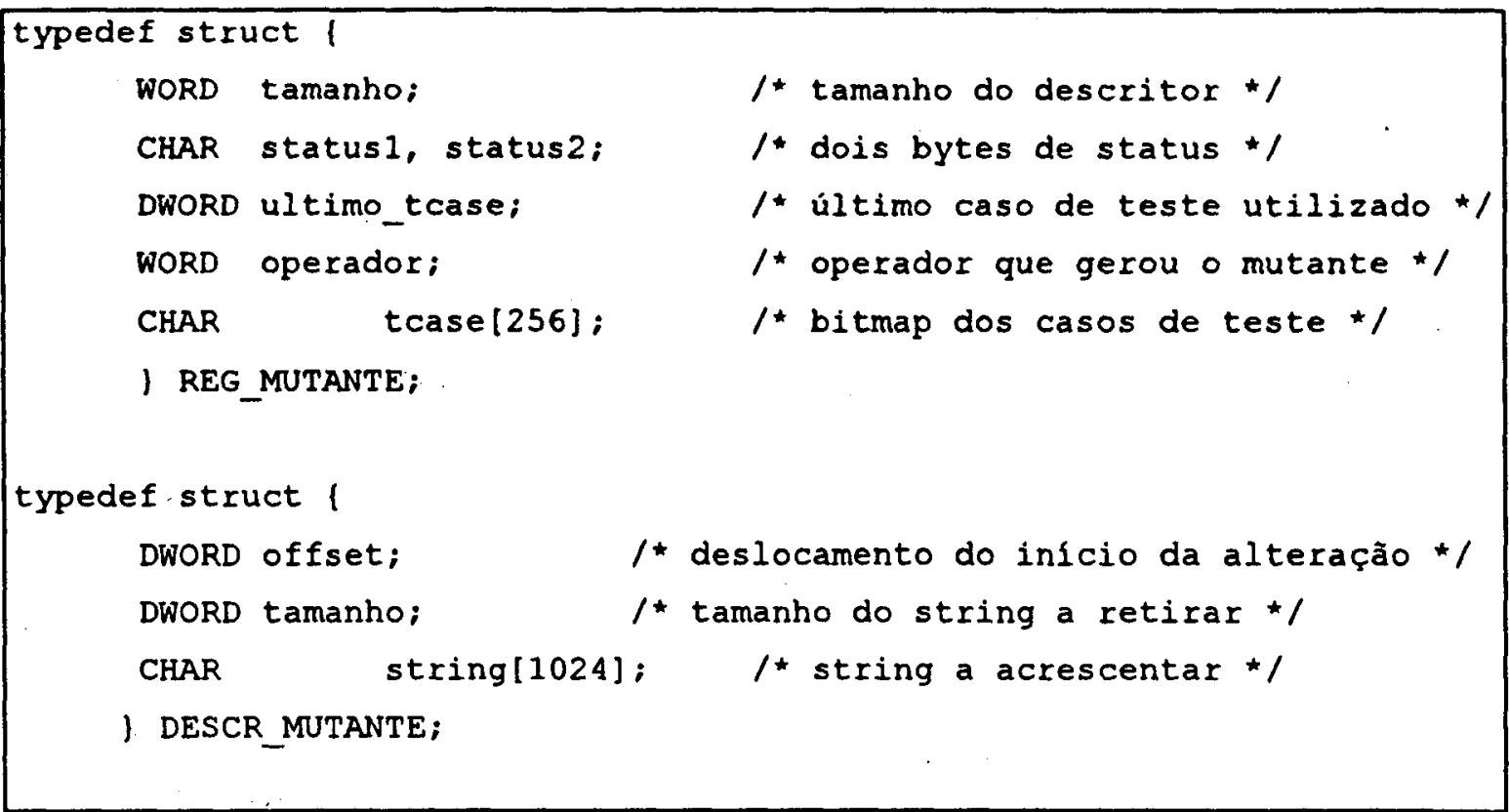

Figura 4.11. - Estruturas do Arquivo de Descritores

O campo ultimo_tcase indica qual o número de seqüência do último caso de teste com que o mutante já foi executado. Pode-se executar várias vezes a operação de execução dos mutantes. Por isso, é preciso reconhecer quando um mutante já foi executado com um caso de teste para não repetir-se esta execução. Quando um mutante é executado, o campo ultimo_tcase recebe o valor do número de seqüência do próximo caso de teste a ser incluído, dado pela variável contlog do arquivo de casos de teste. Assim, é possível saber-se, numa próxima execução, se determinado caso de teste é novo, ou seja, foi incluído depois da última execução do mutante (neste caso o número de seqüência do caso de teste é maior ou igual a ultimo_tcase) ou se é um caso de teste que já foi utilizado.

Além disso, pode ser que um mutante não seja executado com um caso de teste por este estar desabilitado. Porém, se este caso de teste for habilitado, deve-se utilizá-lo na próxima operação de execução dos mutantes. Por isso existe um controle individual para cada caso de teste através do campo tcase. Este vetor tem dois bits para cada um dos possíveis 1024 casos de teste com os possíveis valores:

0 - mutante não foi executado com o caso de teste;

1- mutante foi executado com o caso de teste e morreu com essa execução;

2- mutante foi executado com o caso de teste e não morreu com essa execução.

A Figura 4.12. mostra o algorítmo para decidir-se se um mutante deve ou não ser executado com determinado caso de teste. 


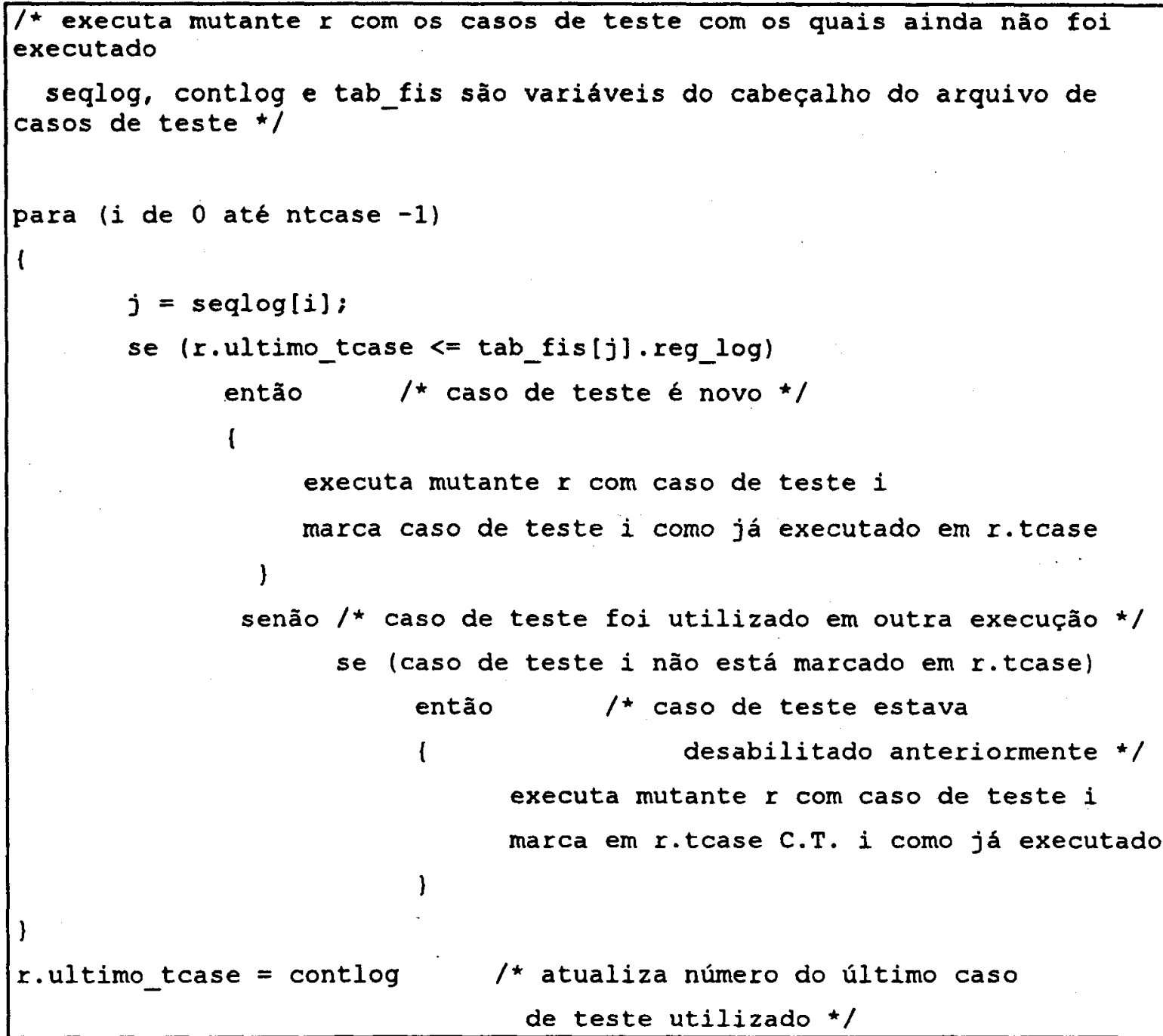

Figura 4.12. - Algoritmo de Execução de um Mutante

A parte variável é a que descreve as alterações que devem ser feitas no programa fonte para criar o fonte do mutante. Ela é composta de uma ou mais operações do tipo retirar/incluir, no formato da estrutura DESCR_MUTANTE. O campo offset indica qual o deslocamento, em relação ao início do programa fonte, da seqüência de caracteres que deve ser retirada. $O$ campo tamanho determina o tamanho da seqüência a ser retirada $e$ string contém a seqüência, com tamanho máximo de 1024 caracteres, que deve ser colocada no lugar daquela retirada.

O Arquivo de Índices facilita o acesso aos descritores de mutantes indicando, entre outras coisas, como localizar cada registro do arquivo de mutantes, visto que têm tamanho variável. O Arquivo de Índices possui um cabeçalho seguido por registros de índices, um para cada registro do Arquivo de Descritores. A Figura 4.13. mostra a estrutura deste arquivo. 


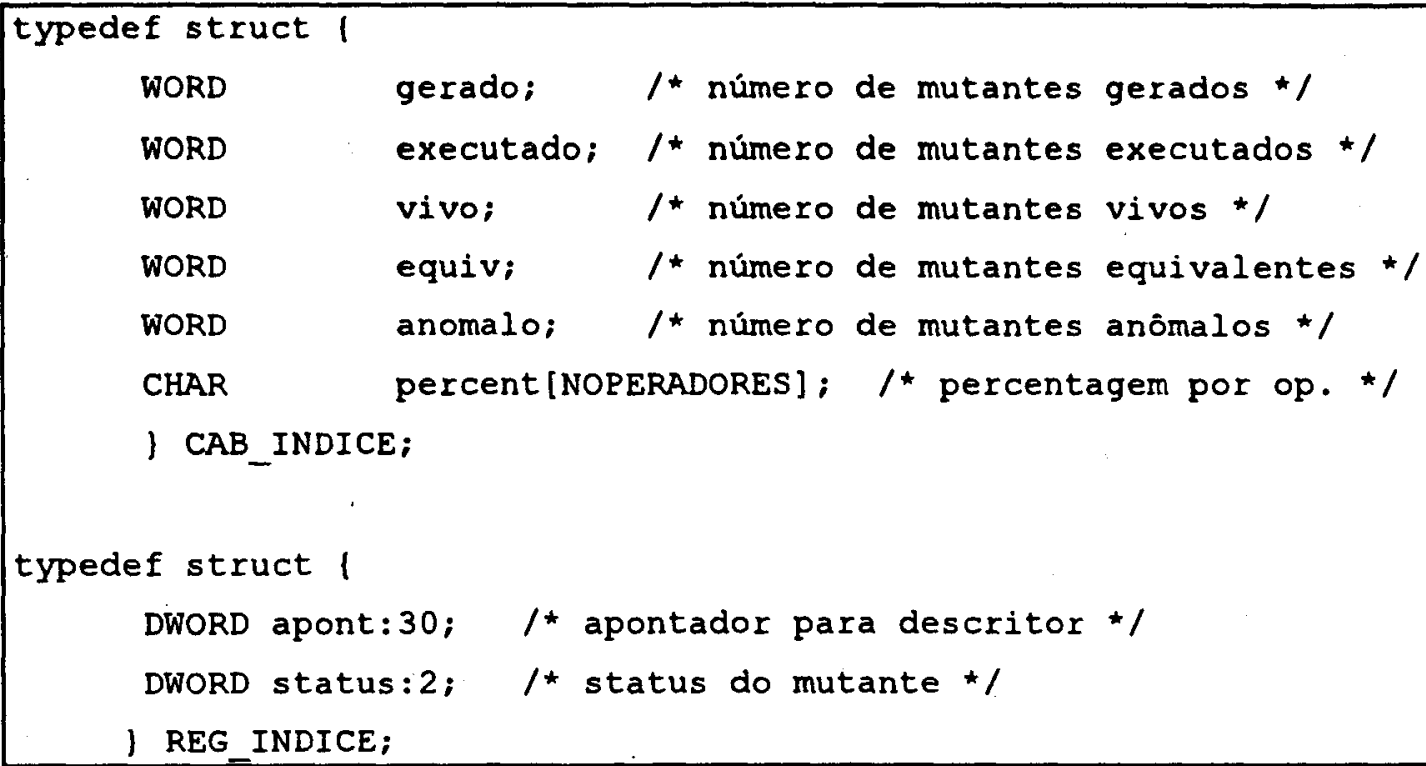

Figura 4.13. - Estrutura do Arquivo de Índices

A variável gerado mostra o número total de mutantes gerados. A variável executado indica quantos mutantes foram tratados na última operação de execução dos mutantes; como esta operação é, em geral, demorada, o usuário tem a opção de interrompê-la. Assim, com esta variável tem-se o controle de quais mutantes foram executados. As variáveis vivo, equiv e anomalo indicam quantos, entre os mutantes executados, estão vivos ou são equivalentes ou anômalos. Os mutantes anômalos são aqueles que não deveriam ter sido gerados. É o caso por exemplo de utilizar análise estática para identificar mutantes com anomalias de fluxo de dados e descartá-los, ou seja, considerá-los anômalos. É o caso também de mutantes que não se consegue executar; podem existir incompatibilidades entre a linguagem que o Proteum reconhece e a linguagem que o compilador do usuário reconhece. Por isso podem ser criados mutantes que, ao serem compilados pelo compilador do usuário, apresentem erros sintáticos ou semânticos, impossibilitando suas execuções. Esses mutantes também são considerados anômalos.

Os registros de índices têm dois campos: apont que contém o deslocamento do registro correspondente dentro do Arquivo de Descritores; e status que indica se o mutante está vivo, morto ou se é anômalo ou equivalente. Existem operações em que o usuário pode restringir seu escopo a apenas uma ou algumas dessas classes de mutantes. $\dot{E}$ o caso da visualização dos mutantes em que o usuário pode escolher consultar apenas os mutantes vivos, por exemplo. Para agilizar este tipo de operação, mantém-se a informação do estado do mutante no Arquivo de Índices, o que dispensa a consulta ao Arquivo de Descritores para localizar-se os registros da(s) categoria(s) que interessa(m). 


\subsection{3. - Módulos Dependentes da Linguagem}

Esta seção trata dos módulos que são dependentes da linguagem, ou seja que devem ser alterados ou configurados para apoiarem o teste de programas em uma determinada linguagem. $\mathbf{O}$ objetivo principal desses módulos é a criação dos mutantes, através da aplicação de operadores de mutação.

Inicialmente, o programa fonte é analisado e transformado para uma representação intermediária chamada de Linguagem Intermediária (LI), introduzida por Carnassale [CAR91], e que identifica as principais construções do programa fonte como comandos, expressões e declarações. Em seguida, são aplicados os operadores de mutação analisando-se o programa LI e trechos específicos do programa fonte, criando-se assim os descritores de mutação. Os módulos que realizam estas tarefas são chamados de Módulo LI e Módulo Opmuta e serão detalhados nas seções seguintes.

A Figura 4.14. mostra o esquema de criação dos mutantes. Os processos destacados na figura - "Traduzir para Linguagem Intermediária" e "Aplicar Operadores de Mutação" - representam os módulos dependentes da linguagem.

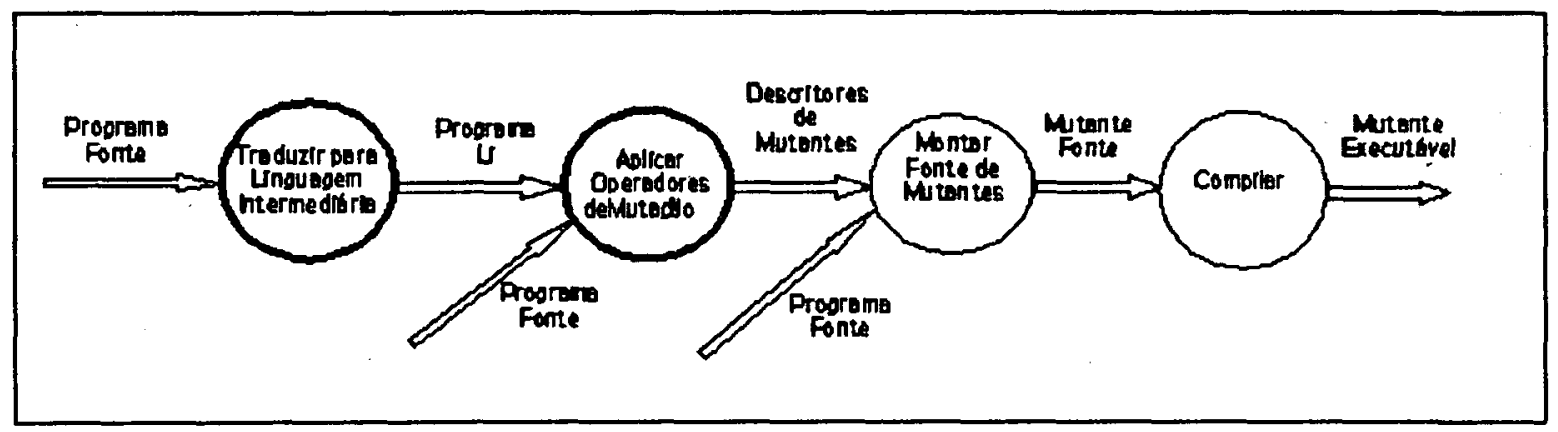

Figura 4.14. - Geração de Mutantes

\subsubsection{1. - Módulo LI}

O módulo LI utilizado no Proteum é basicamente o mesmo utilizado na POKE-TOOL [CHA91], com algumas pequenas alterações. Ele consiste, basicamente, de um analisador sintático que tem como entrada um programa fonte na linguagem alvo e produz um programa na Linguagem Intermediária.

O analisador sintático do módulo LI é genérico e deve ser instanciado para uso com uma dada linguagem. Para instanciá-lo é necessário elaborar tabelas e rotinas específicas para controlar as análises léxica e sintática. Detalhes de configuração do módulo LI são fornecidos por Leitão [LEI91]. 
A Linguagem Intermediária visa identificar ofluxo de execução em um programa. Basicamente a LI tem dois tipos de comandos: comandos sequienciais e comandos de controle de fluxo. Os comandos seqüenciais da $\mathrm{LI}$ indicam os comandos das linguagens procedurais que representam uma declaração de variável ou uma computação (comandos de atribuição ou chamadas de procedimentos) e que, portanto, não alteram o fluxo de execução. Os comandos de controle de fluxo são equivalentes aos comandos das linguagens procedurais que causam seleção, seleção múltipla, iteração e transferência.

Uma característica da LI é que todos os seus átomos são seguidos por números que identificam sua localização no programa fonte. Estes números (apontadores) são: início do átomo no programa fonte (a quantos caracteres do começo do arquivo se inicia o átomo); o comprimento do átomo (quantos caracteres tem o átomo); e a linha onde está o átomo. Utilizando a notação de Backus-Naur (terminais estão grafados em itálico, não terminais entre " $\ll$ " $e$ " $"$ " metasímbolos em negrito) pode-se descrever um programa LI da seguinte maneira:

$<$ program $>::=\{(<\mathrm{dcl}>\mid<\mathrm{s}>)\}\{<$ statement $>\} .4^{4}$

Ou seja, uma seqüência de átomos de declaração ou comandos seqüenciais seguidos por uma função que inicia por um "प", termina com um " "?"e contém uma lista de atomos de comandos. Um átomo de declaração <dcl $>$ é definido como:

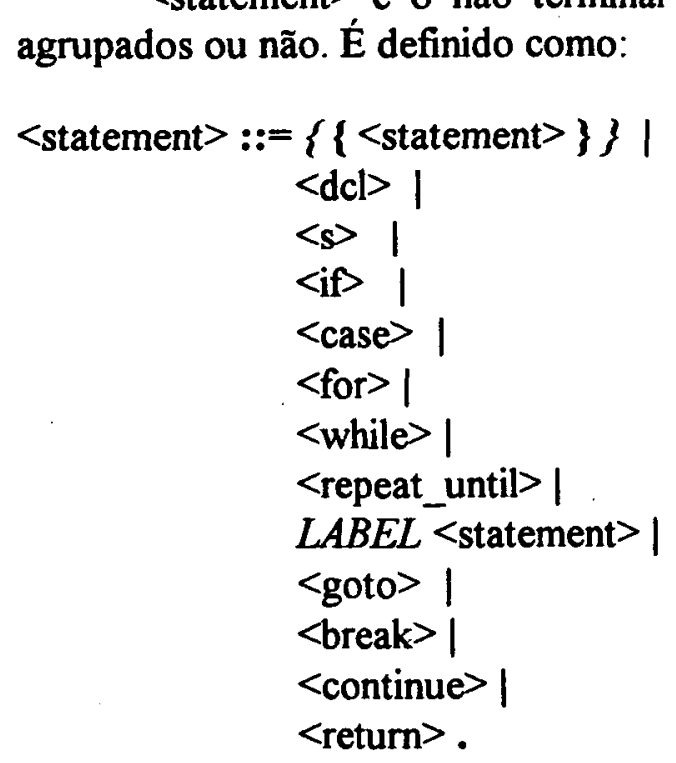
agrupados ou não. É definido como:

${ }^{4} \mathrm{Na}$ verdade, as versões mais atuais da $\mathrm{LI}$ estão ligeiramente modificadas, permitido a representação de vários subprogramas dentro de um único programa. 
Por exemplo, o comando <while> é definido como segue:

$<$ while $>::=<$ while_atm $><$ cond_while_atm $><$ statement $>$.

$<$ while_atm $>::=\$$ WHILE $<$ inicio $><$ comprimento $><$ linha $>$.

$<$ cond_while_atm $>::=\$ C<$ início $><$ comprimento $><$ inha $>$.

A Figura 4.15. mostra um exemplo de tradução de um programa em C para a LI.

\begin{tabular}{|c|c|c|c|c|}
\hline 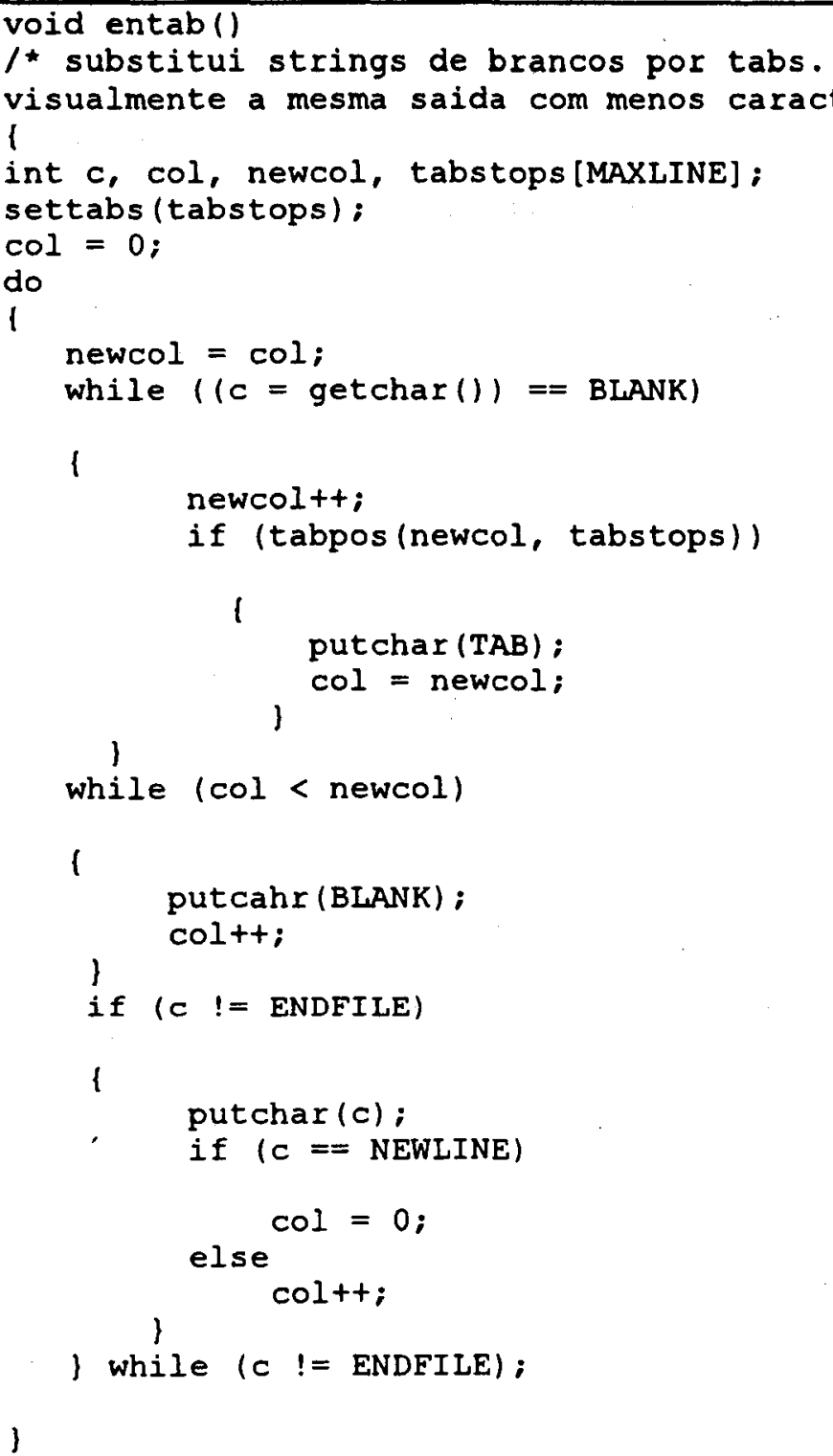 & 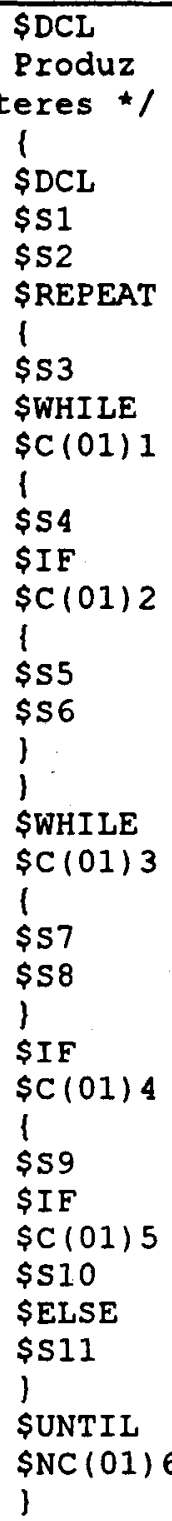 & $\begin{array}{l}182 \\
189 \\
234 \\
255 \\
268 \\
273 \\
279 \\
297 \\
303 \\
334 \\
342 \\
358 \\
361 \\
395 \\
407 \\
431 \\
453 \\
459 \\
465 \\
471 \\
488 \\
495 \\
516 \\
527 \\
533 \\
536 \\
553 \\
561 \\
579 \\
582 \\
603 \\
618 \\
631 \\
642 \\
647 \\
653 \\
668\end{array}$ & $\begin{array}{r}1 \\
36 \\
18 \\
8 \\
2 \\
1 \\
13 \\
5 \\
26 \\
1 \\
9 \\
2 \\
25 \\
1 \\
13 \\
13 \\
1 \\
1 \\
5 \\
12 \\
1 \\
15 \\
6 \\
1 \\
2 \\
12 \\
1 \\
11 \\
2 \\
12 \\
8 \\
4 \\
6 \\
1 \\
12 \\
1\end{array}$ & $\begin{array}{l}15 \\
16 \\
17 \\
18 \\
19 \\
20 \\
21 \\
22 \\
22 \\
23 \\
24 \\
25 \\
25 \\
26 \\
27 \\
28 \\
29 \\
30 \\
31 \\
31 \\
32 \\
33 \\
34 \\
35 \\
36 \\
36 \\
37 \\
38 \\
39 \\
39 \\
40 \\
41 \\
42 \\
43 \\
44 \\
44 \\
45\end{array}$ \\
\hline
\end{tabular}

Figura 4.15. - Exemplo de Tradução de Programa C para LI 


\subsubsection{2. - Módulo Opmuta}

O módulo Opmuta utiliza como ponto de partida o programa traduzido para a Linguagem Intermediária para criar os descritores de mutação. Cada operador de mutação é implementado através de um analisador sintático recursivo descendente para a LI, segundo a gramática mostrada acima.

Para simplificar, considere-se o exemplo do operador de mutação "troca de operador relacional". A função que implementa este operador deve percorrer o programa LI e, onde ocorrer algum operador relacional; substitui-lo pelos outros operadores. As figuras 4.16. e 4.17. mostram como seria a implementação se a LI possuísse apenas comandos seqüenciais (tipo \$S) ou comandos \$WHILE, iniciados por "y" e terminados por "\}".

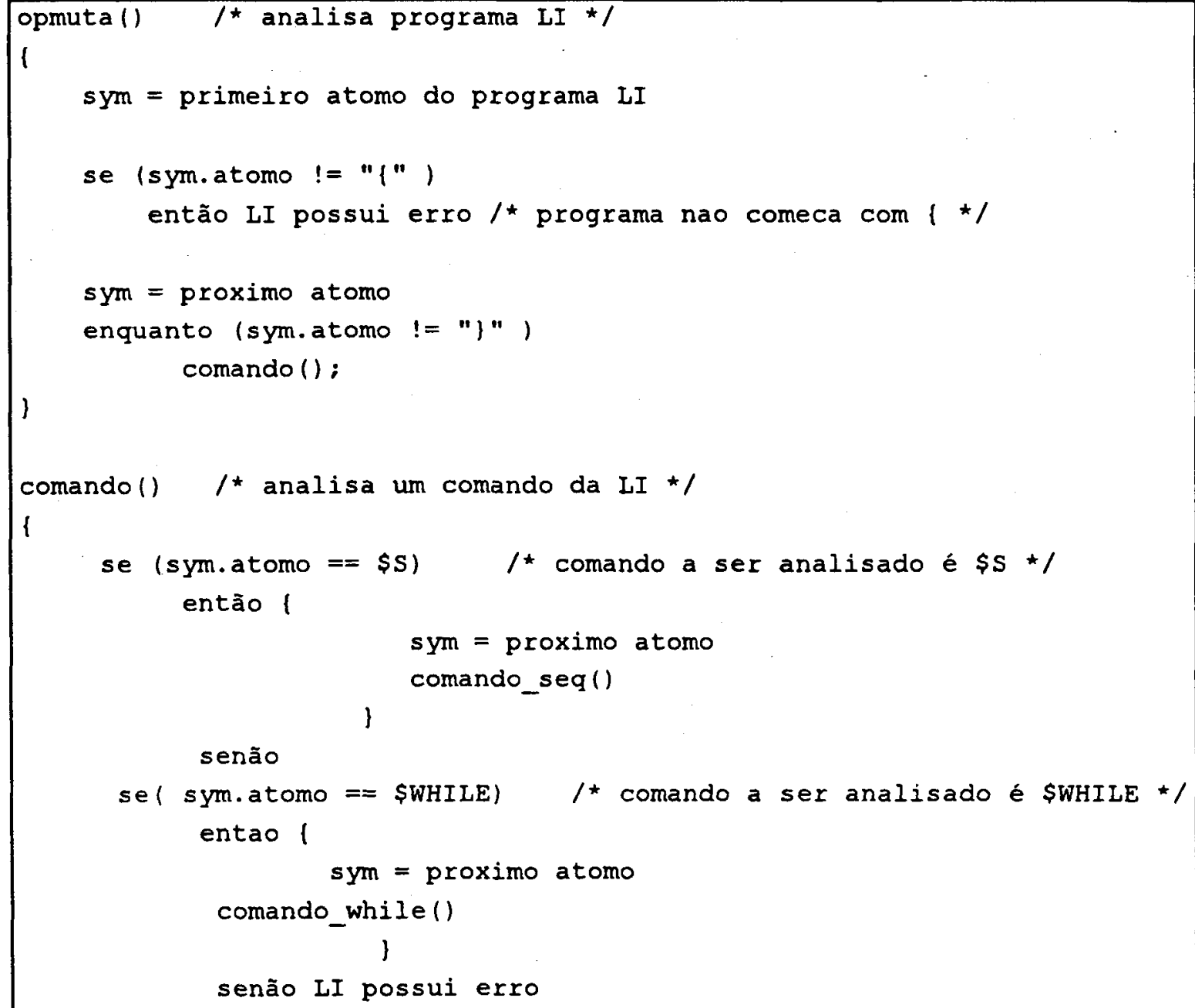

Figura 4.16. - Possivel Implementação de um Operador de Mutação (1) 


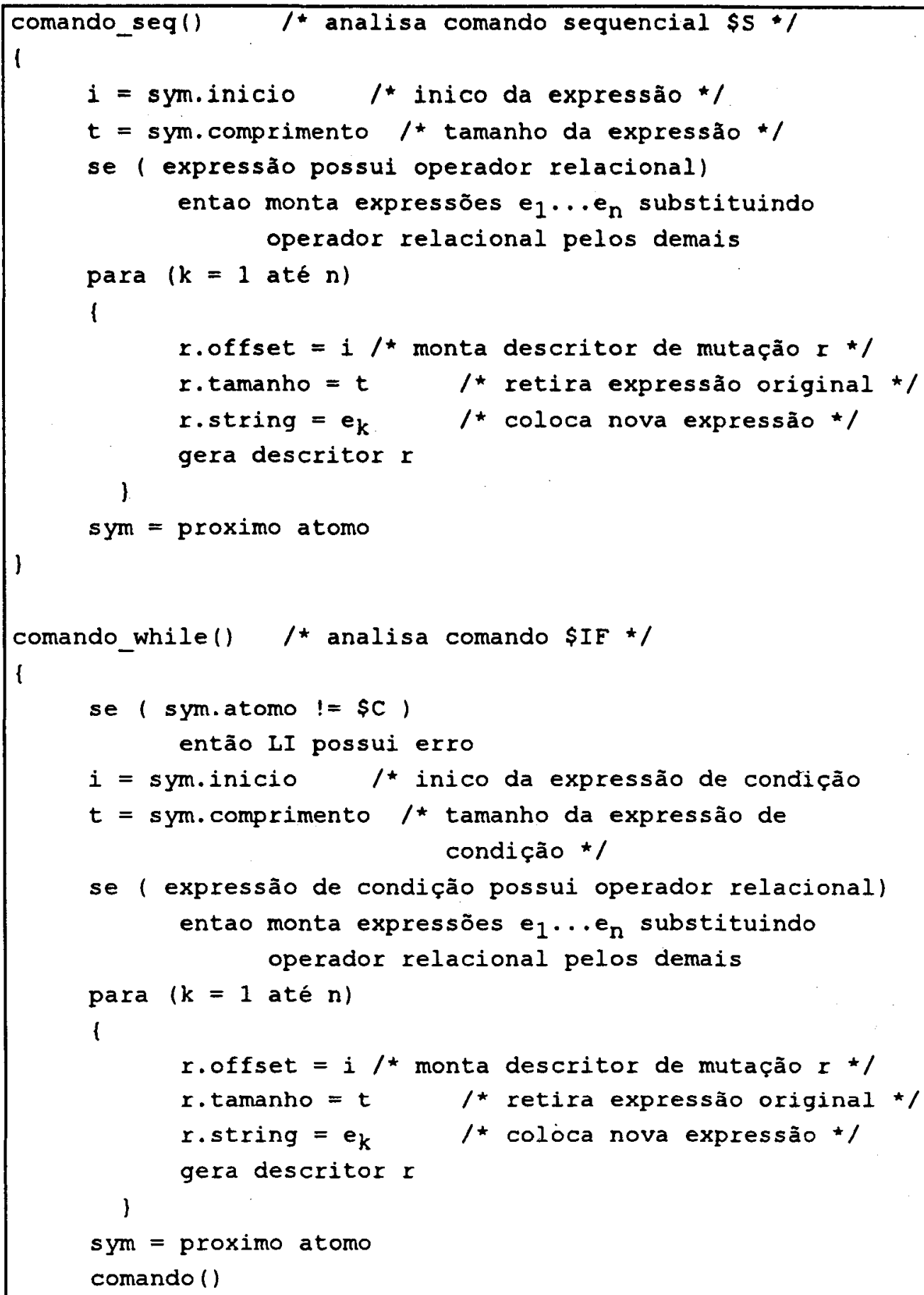

Figura 4.17. - Possível Implementação de um Operador de Mutação (2)

A única parte obscura do programa é o comando "se (expressão possui operador...". Para analisar a expressão, o módulo Opmuta necessita fazer a análise do programa fonte e verificar se há a ocorrência de algum operador relacional. Isto é feito recorrendo-se ao analisador sintático utilizado no módulo LI. Este analisador tem a 
capacidade de analisar trechos de programa separadamente, como expressões e declarações.

Assim, pode-se invocar o módulo LI para analisar apenas a expressão que interessa; como resultado obtém-se do analisador sintático a expressão em notação pósfixa. Isso permite que a expressão possa, com mais facilidade, ser analisada, modificada (por exemplo, trocando-se um operador relacional por outro), refeita na forma infixa e utilizada para substituir a expressão original num descritor de mutação.

Todos os operadores de mutação utilizam este mesmo esquema de análise e geração: análise recursiva do programa LI; e quando necessária, análise de declarações e de expressões. Estas últimas são montadas em notação pós-fixa para facilitar sua manipulação. O Proteum tem um conjunto de 71 operadores de mutação. A relação dos operadores implementados no Proteum e uma descrição do que eles fazem está no Apêndice A.

\section{2. - Aspectos de Configuração do Proteum}

Existe hoje uma gama muito grande de linguagens sendo utilizadas na implementação dos mais diversos sistemas de software. Essas linguagens variam tanto na área de aplicação nas quais são utilizadas como em aspectos estruturais. Tal situação aponta para uma característica necessária nas ferramentas de apoio à atividade de teste: prover facilidades para o suporte de diversas linguagens de programação.

Como já foi citado, a arquitetura do Proteum estabeleceu uma distinção entre as tarefas dependentes da linguagem alvo e daquelas outras que não dependem da linguagem alvo. Isto permite que os módulos responsáveis por essas últimas possam ser reutilizados nas configurações da ferramenta para diferentes linguagens.

Basicamente, dois módulos são dependentes da linguagem: o módulo LI e o módulo Opmuta. No módulo LI, para obter as informações dependentes da linguagem é necessário que a ferramenta possua um programa semelhante a um "front end" de um compilador, responsável por efetuar a análise léxica e sintática dos programas a serem testados. O módulo Opmuta precisa analisar os comandos do programa traduzido em Linguagem Intermediária e criar descritores que indiquem as alterações a serem efetuadas no programa fonte, necessitando portanto considerar aspectos particulares da linguagem alvo.

Como já foi descrito acima, o módulo Opmuta foi implementado de maneira que a cada operador de mutação é associado um programa responsável pela geração dos descritores de mutação. Isso significa que para configurar o Proteum ou incluir novos operadores de mutação é necessário um esforço de programação, devendo ser incluido um novo trecho de programa para tratar do novo operador. Se por um lado isso pode ser 
trabalhoso, essa abordagem apresenta também algumas vantagens; tal independência permite que cada operador seja tratado de modo atômico, facilitando, quando necessária, a alteração da sua semântica e até a inclusão de novos operadores, uma vez que para isso não é preciso alterar-se a parte do programa que implementa os outros operadores. Além disso, ao configurar-se o Proteum para uma nova linguagem, espera-se que a maior parte do módulo possa ser reaproveitada pois, em geral, os operadores de mutação para linguagens diferentes são parecidos, variando apenas pequenos aspectos sintáticos.

O módulo LI que o Proteum utiliza foi extraído da implementação da POKETOOL [CHA91] no qual foram feitas algumas pequenas alteraçōes, principalmente no grafo sintático utilizado para a linguagem $\mathrm{C}$ e nas rotinas semânticas do analisador sintático. Este módulo utiliza um enfoque genérico na implementação dos analisadores léxicos e sintáticos. Para instanciar estes analisadores é necessário prover tabelas e rotinas especificas que devem ser ligadas aos demais módulos do Proteum.

As tarefas abaixo estão descritas com detalhe no Manual de Configuração da POKE-TOOL [LEI91] e dão uma idéia das atividades a serem desenvolvidas na configuração do módulo LI para uma nova linguagem.

- Configurar o analisador léxico. Essa tarefa demanda que o configurador conheça bem os aspectos léxicos da linguagem alvo e está dividida em algumas sub-tarefas.

- Desenvolver um autômato finito que realize a análise léxica da linguagem;

- identificar as ações semânticas associadas às transições do autômato finito;

- transcrever este autômato para a notação aceita pelo analisador léxico genérico;

- completar o analisador léxico através de rotinas ('ações semânticas') que realizem a separação dos átomos da linguagem fonte, colocando-os nas estruturas de dados que o módulo LI utiliza para armazená-las; e

- depurar o analisador léxico conjuntamente com as ações semânticas.

- Configurar o analisador sintático. Essa tarefa demanda que o usuário conheça bem a sintaxe e a semântica da linguagem alvo e está dividida em algumas sub-tarefas.

- Descrever a gramática da linguagem alvo na forma de grafos sintáticos;

- identificar pontos onde devem ser ativadas as rotinas semânticas nos grafos sintáticos;

- transcrever os grafos sintáticos para a notação aceita pelo analisador sintático genérico; 
- complementar o analisador sintático com as rotinas semânticas que realizam a tradução do programa para a Linguagem Intermediária; e

- depurar o analisador sintático conjuntamente com as rotinas semânticas desenvolvidas.

- Compilar e ligar os arquivos que constituem os analisadores léxico e sintático genéricos, as ações e rotinas semânticas com os demais módulos.

\section{3. - Considerações Finais}

Foram apresentadas as principais características da ferramenta Proteum como interface, apoio a experimentos de pesquisa, suporte a multilinguagem, operação orientada a sessões de trabalho, e outras, procurando mostrar a importância de cada uma delas e indicar as linhas guias que nortearam a sua implementação. Algumas dessas características são comuns a outras ferramentas e algumas são próprias do Proteum como o suporte a experimentos de pesquisa e capacidade de importação de casos de teste.

Os aspectos funcionais foram detalhados apresentando-se as principais operações que podem ser executadas na ferramenta, caracterizando-se cada uma delas no contexto da aplicação do critério Análise de Mutantes.

Em seguida apresentaram-se os principais módulos do Proteum, divididos em três grupos: Interface, Módulos não Dependentes da Linguagem e Módulos Dependentes da Linguagem. Foram mostradas as estratégias utilizadas para manter-se uma independência entre a interface, construída através de um toolkit" gráfico, e os demais módulos da ferramenta. Foram mostrados também os formatos dos arquivos de dados que o Proteum manipula bem como os principais algoritmos utilizados.

Finalmente, foram abordados aspectos da instanciação da ferramenta para diferentes linguagens, indicando as etapas a serem seguidas para sua configuração. 


\section{Capítulo 5.}

\section{Avaliação do Proteum}

A disponibilidade do Proteum deve permitir que estudos empíricos sejam conduzidos buscando caracterizar mais precisamente a Análise de Mutantes e compará-la com outros critérios de teste. Este capítulo mostra o exemplo de alguns programas que foram submetidos à Análise de Mutantes, através do Proteum, e procura fornecer subsídios para mostrar a factibilidade de utilização da Análise de Mutantes para o teste de programas.

Além disso, a utlização do Proteum sobre um conjunto de programas "reais" é importante para o aspecto de validação da ferramenta. Mesmo após realizar testes dirigidos para validar separadamente os diversos módulos implementados, a utilização da ferramenta para o teste dos programas descritos a seguir mostrou-se de fundamental importância, tendo contribuído para aprimorar a implementação e apontando aperfeiçoamentos a serem realizados no Proteum.

Nesta avaliação foram utilizados quatro grupos de programas, em geral, casos conhecidos da literatura [MAT93b, KER81, BRI93, PRE88]. Sobre esses programas foi aplicada a Análise de Mutantes, com a geração de $100 \%$ dos mutantes. Em seguida, foram utilizados conjuntos de casos de teste gerados a partir de critérios de teste funcional e os resultados avaliados.

O intuito é analisar parâmetros estáticos relativos a esses programas, como o número de mutantes gerados. Não pretendeu-se avaliar a qualidade dos casos de teste empregados, o que caracterizaria uma comparação entre o critério Análise de Mutantes e o critério funcional utilizado na criação dos casos de teste. Deve-se notar que os Escores de Mutação obtidos não levam em conta o número de mutantes equivalentes, ou seja, os mutantes não foram analisados para verificar-se quais são equivalentes. Assim, os escores de mutação reais devem ser ligeiramente superiores aos encontrados. Portanto tais escores não servem como parâmetro para uma avaliação confiável dos conjuntos de casos de teste e nem tampouco para comparação entre os critérios; tal trabalho está fora do escopo desta dissertação. Uma avaliação de performance também foi conduzida, procurando medir o tempo de geração e o tempo de execução dos mutantes.

As seções seguintes apresentam um sumário das avaliações realizadas, destacandose alguns pontos considerados importantes. Para cada um dos programas foram 
levantados, entre outros, dados sobre: linhas de código do programa fonte, número de mutantes gerados, tempo de geração dos mutantes, tempo de execução dos mutantes, número de casos de teste utilizados na avaliação e escore de mutação obtido. Essas informações estão na Tabela 5.1. Na Tabela 5.2., os mutantes gerados estão divididos entre as quatro classes de operadores de mutação.

\section{1. - Programas Grupo I}

O primeiro grupo de programas analisados foi extraido do artigo de Mathur [MAT93b] que utilizou-os para conduzir uma comparação entre a Análise de Mutantes e o critério todos-usos [RAP85]. Os programas são brevemente descritos abaixo:

FIND: Este programa recebe como argumentos um vetor $a$ e um indice $f$, permutando os elementos de $a$ de modo que os elementos à direita da posição $f$ sejam maiores que ou iguais a $a[f]$ e os elementos à esquerda da posição $f$ sejam menores que ou iguais a $a[f]$.

STRMAT1: Recebe como entrada um texto e um padrão de zero ou mais caracteres. Se o padrão aparece no texto, então a posição da primeira ocorrência do padrão no texto é retornada; caso contrário o valır 0 é retornado.

STRMAT2: Idem ao STRMAT1 com algumas diferenças na estrutura do programa.

TEXTFMT: Recebe um texto como entrada e produz o mesmo texto formatado como saida. $O$ texto pode ser visto como uma sequência de palavras separadas por espaços, caracteres de tabulação e finalizadores de linha.

Cada um desses programas possui no arquivo fonte uma funçāo 'driver", chamada main; além da função que se objetiva aplicar o teste. $O$ programa TEXTFMT possui ainda mais três funções auxiliares: inchar, outchar e myeoln. $\mathrm{Na}$ avaliação apresentada nas Tabelas 5.1. e 5.2., os "drivers" e as funções auxiliares não foram testados, ou seja, somente foram gerados mutantes para as funções de interesse e não para os "drivers"s.

Os casos de teste utilizados foram criados com base no critério Particionamento em Classes de Equivalência. Os resultados obtidos podem ser vistos na Tabela 5.1. e na Tabela 5.2. Pode-se notar que, embora sejam programas pequenos, o número de mutantes gerados é razoavelmente grande. Apesar disto, percebe-se que com os recursos computacionais disponíveis - no caso uma estação Sun SPARCstation 2 - o tempo para geração e execução dos mutantes não é proibitivo para a realização dos testes.

5Para todos os programas desta avaliação, menos para o programa solar, foi utilizada esta abordagem. 
Tabela 5.1. - Dados da Avaliação do Proteum

\begin{tabular}{|c|c|c|c|c|c|c|c|}
\hline & Programa & LOC's & $\begin{array}{l}\text { \# Casos } \\
\text { De Teste }\end{array}$ & $\begin{array}{l}\text { Mutantes } \\
\text { Gerados }\end{array}$ & $\begin{array}{c}\text { Tempo de } \\
\text { Geração }\end{array}$ & $\begin{array}{l}\text { Tempo de } \\
\text { Execurato }\end{array}$ & $\begin{array}{l}\text { Escore de } \\
\text { Mutação }\end{array}$ \\
\hline \multirow[t]{4}{*}{ Grupo I } & FIND & 25 & 6 & 1125 & $22 \mathrm{~s}$ & $66 \mathrm{~min}$ & 0,81 \\
\hline & STRMAT1 & 21 & 6 & 788 & $16 \mathrm{~s}$ & $31 \mathrm{~min}$ & 0,79 \\
\hline & STRMAT2 & 16 & 6 & 586 & $15 \mathrm{~s}$ & $26 \mathrm{~min}$ & 0,77 \\
\hline & TEXTFMT & 25 & 6 & 959 & $25 \mathrm{~s}$ & $35 \mathrm{~min}$ & 0,88 \\
\hline \multirow[t]{7}{*}{ Grupo II } & CMP & 12 & 5 & 448 & $12 \mathrm{~s}$ & $16 \mathrm{~min}$ & 0,58 \\
\hline & COMPARE & 17 & 4 & 511 & $21 \mathrm{~s}$ & $23 \mathrm{~min}$ & 0,78 \\
\hline & COMPRESS & 14 & 3 & 493 & $13 \mathrm{~s}$ & $23 \mathrm{~min}$ & 0,73 \\
\hline & DODASH & 15 & 5 & 1271 & $32 \mathrm{~s}$ & $49 \mathrm{~min}$ & 0,63 \\
\hline & ENTAB & 18 & 4 & 413 & $13 \mathrm{~s}$ & $17 \mathrm{~min}$ & 0,84 \\
\hline & EXPAND & 15 & 6 & 432 & $13 \mathrm{~s}$ & $18 \mathrm{~min}$ & 0,69 \\
\hline & TRANSLIT & 29 & 8 & 1282 & $36 s$ & $74 \mathrm{~min}$ & 0,77 \\
\hline \multirow[t]{2}{*}{ Grupo III } & SOLAR-I & 212 & 1 & 24590 & $7 \mathrm{~min} 38 \mathrm{~s}$ & $15 \mathrm{~h}$ & 0,72 \\
\hline & SOLAR-II & 212 & 1 & 2410 & $7 \mathrm{~min}$ & $1 \mathrm{~h} 41 \mathrm{~min}$ & 0,72 \\
\hline \multirow[t]{6}{*}{ Grupo IV } & GAUSJ & 75 & 7 & 4070 & $85 \mathrm{~s}$ & $2 \mathrm{~h} 50 \mathrm{~min}$ & 0,67 \\
\hline & LUDCMP & 59 & 7 & 2922 & $64 \mathrm{~s}$ & 1h $37 \mathrm{~min}$ & 0,86 \\
\hline & LUBKSB & 23 & 8 & 936 & $23 \mathrm{~s}$ & $31 \mathrm{~min}$ & 0,88 \\
\hline & TRIDAG & 17 & 9 & 873 & $28 \mathrm{~s}$ & $23 \mathrm{~min}$ & 0,85 \\
\hline & MPROVE & 16 & 8 & 451 & $15 \mathrm{~s}$ & $13 \mathrm{~min}$ & 0,85 \\
\hline & VANDER & 34 & 8 & 1714 & $40 \mathrm{~s}$ & $58 \mathrm{~min}$ & 0.85 \\
\hline
\end{tabular}

Tabela 5.2. - Mutantes por Classes

\begin{tabular}{|l|l|c|c|c|c|c|}
\cline { 2 - 7 } \multicolumn{1}{c|}{} & Programa & Comandos & Operadores & Variáveis & Constantes & Total \\
\hline Grupo I & FIND & $120(11 \%)$ & $277(25 \%)$ & $523(46 \%)$ & $205(18 \%)$ & 1125 \\
\hline \multirow{5}{*}{ Grupo II } & STRMAT1 & $177(22 \%)$ & $254(32 \%)$ & $166(21 \%)$ & $191(24 \%)$ & 788 \\
\cline { 2 - 7 } & STRMAT2 & $107(18 \%)$ & $218(37 \%)$ & $150(26 \%)$ & $111(19 \%)$ & 586 \\
\cline { 2 - 7 } & TEXTFMT & $101(10 \%)$ & $346(36 \%)$ & $207(22 \%)$ & $305(32 \%)$ & 959 \\
\hline \multirow{5}{*}{ Grupo III } & $79(18 \%)$ & $127(28 \%)$ & $119(27 \%)$ & $123(27 \%)$ & 448 \\
\cline { 2 - 7 } & COMPARE & $70(14 \%)$ & $156(30 \%)$ & $170(33 \%)$ & $115(23 \%)$ & 511 \\
\cline { 2 - 7 } & COMPRESS & $70(14 \%)$ & $214(43 \%)$ & $110(22 \%)$ & $99(20 \%)$ & 493 \\
\cline { 2 - 7 } & DODASH & $63(5 \%)$ & $422(33 \%)$ & $427(34 \%)$ & $359(28 \%)$ & 1271 \\
\cline { 2 - 7 } & ENTAB & $90(22 \%)$ & $141(34 \%)$ & $79(19 \%)$ & $103(25 \%)$ & 413 \\
\cline { 2 - 7 } & EXPAND & $68(15 \%)$ & $209(48 \%)$ & $60(14 \%)$ & $95(15 \%)$ & 432 \\
\cline { 2 - 7 } & TRANSLIT & $124(10 \%)$ & $447(35 \%)$ & $336(26 \%)$ & $375(29 \%)$ & 1282 \\
\hline & SOLAR I & $1190(5 \%)$ & $3071(12 \%)$ & $12865(52 \%)$ & $7464(30 \%)$ & 24590 \\
\hline \multirow{5yyyyyy}{*}{ GOLAR II } & $136(6 \%)$ & $292(12 \%)$ & $1257(52 \%)$ & $725(30 \%)$ & 2410 \\
\hline & GAUSJ & $223(5 \%)$ & $629(15 \%)$ & $2372(58 \%)$ & $846(20 \%)$ & 4070 \\
\hline & LUDCMP & $194(7 \%)$ & $538(18 \%)$ & $1595(55 \%)$ & $595(20 \%)$ & 2922 \\
\cline { 2 - 7 } & LUBKSB & $70(7 \%)$ & $236(25 \%)$ & $475(50 \%)$ & $155(17 \%)$ & 936 \\
\cline { 2 - 7 } & TRIDAG & $56(6 \%)$ & $283(32 \%)$ & $307(35 \%)$ & $227(26 \%)$ & 873 \\
\cline { 2 - 7 } & MPROVE & $45(10 \%)$ & $115(25 \%)$ & $208(46 \%)$ & $83(18 \%)$ & 451 \\
\cline { 2 - 7 } & VANDER & $105(6 \%)$ & $420(25 \%)$ & $813(47 \%)$ & $376(22 \%)$ & 1714 \\
\hline
\end{tabular}


Para cada um desses programas foram também gerados os mutantes para as demais funções, ou seja, para os "drivers" e funçð̃es auxiliares. Na Tabela 5.3. estão apresentados os números obtidos, comparados com os números relatados no experimento de Mathur [MAT93b]. É importante notar que os números reportados por Mathur referem-se às versões dos programas em FORTRAN, testados através da ferramenta Mothra e utilizando, portanto, outro conjunto de operadores de mutação.

Tabela 5.3. - Comparação C x FORTRAN

\begin{tabular}{|l|c|c|}
\hline Programa & $\begin{array}{c}\text { \# de Mutantes - C } \\
\text { (Proteum) }\end{array}$ & $\begin{array}{c}\text { \# de Mutantes - FORTRAN } \\
\text { (Mothra) }\end{array}$ \\
\hline FIND & 1507 & 1060 \\
\hline STRMAT1 & 1268 & 1121 \\
\hline STRMAT2 & 1416 & 1082 \\
\hline TEXTFMT & 1508 & 1888 \\
\hline
\end{tabular}

\section{2. - Programas Grupo II}

Este grupo é composto por um subconjunto de programas, extraídos do livro de Kernighan [KER81], utilizados por Maldonado [MAL91] na caracterização de um benchmark para avaliação da Familia de Critérios Potenciais Usos, e inicialmente propostos e utilizados por Weyuker [WEY90].

$\mathrm{Na}$ avaliação do Proteum com esses programas foram utilizados casos de teste criados por Rossi [ROS93], baseando-se no critério funcional de Particionamento em Classes de Equivalência. Esses casos de teste foram utilizados na comparação empírica entre os critérios Potenciais Usos e critérios funcionais.

Os estudos comparativos realizados com a POKE-TOOL mostraram para esses programas os resultados da Tabela 5.4. Os valores representam, para os critérios potenciais usos, os percentuais das associações requeridas que foram satisfeitas pelos casos de teste e para a Análise de Mutantes, o percentual de mutantes mortos: Estes estudos mostram a natureza complementar dos critérios funcionais e estruturais. Com o Proteum pode-se agora estender esses estudos comparando-se a Análise de Mutantes não só com critérios funcionais mas também com critérios estruturais como os Critérios Potenciais Usos. 
Tabela 5.4. - Síntese Comparativa entre Critérios Potenciais Usos e Análise de Mutantes

\begin{tabular}{|l|c|c|c|c|c|}
\hline Programa & $\begin{array}{c}\text { \# Casos } \\
\text { de Teste }\end{array}$ & $\begin{array}{c}\text { Todos- } \\
\text { potenciais- } \\
\text { usos }\end{array}$ & $\begin{array}{c}\text { Todos- } \\
\text { potenciais- } \\
\text { usos/DU }\end{array}$ & $\begin{array}{c}\text { Todos- } \\
\text { potenciais- } \\
\text { du-caminhos }\end{array}$ & $\begin{array}{c}\text { Análise de } \\
\text { Mutantes }\end{array}$ \\
\hline CMP & 5 & 46,15 & 46,15 & 41,67 & 58 \\
\hline COMPARE & 4 & 78,94 & 65,79 & 25,00 & 78 \\
\hline COMPRESS & 3 & 66,67 & 64,10 & 50,00 & 73 \\
\hline DODASH & 5 & 33,33 & 18,19 & 19,04 & 63 \\
\hline ENTAB & 4 & 63,75 & 55,00 & 38,57 & 84 \\
\hline EXPAND & 6 & 47,37 & 39,47 & 40,00 & 69 \\
\hline TRANSLIT & 8 & 76,81 & 59,42 & 11,71 & 77 \\
\hline
\end{tabular}

\section{3. - Programas Grupo III}

Este grupo é, na verdade, composto de um único programa sobre o qual aplicaram-se dois tipos de teste distintos. $\mathrm{O}$ programa solar é um exemplo interessante pois além de ser maior que os demais programas utilizados, apresenta características de programação bastante peculiares.

Este programa foi produzido como parte de um experimento que apresentou uma abordagem para a utilização de métodos de avaliação da cobertura de casos de teste para software na avaliação de casos de teste em simulação de hardware [BRI93]. Basicamente, utilizou-se uma descrição, na forma de uma Máquina de Estado Finito, do hardware de um arbitrador de barramento e transformou-se esta descrição num programa correspondente em C. Os dados utilizados na simulação do hardware foram então avaliados no teste do programa em $\mathrm{C}$, utilizando-se critérios estruturais através da POKE-TOOL.

Esses casos de teste, construídos considerando-se apenas aspectos funcionais do hardware, mostraram-se pobres frente aos critérios estruturais baseados em fluxo de dados. $\mathbf{O}$ mesmo fato pode-se constatar aplicando-se a eles a Análise de Mutantes. Além do baixo escore de mutação, outros pontos interessantes puderam ser notados; por exemplo, nem todos os mutantes gerados pelo operador STRP (Apêndice B) foram mortos, indicando que nem todos os comandos do programa foram executados.

O programa é composto por duas funções: main e clock. No início da função main são inicializadas algumas variáveis globais. Os mutantes gerados pelo operador de mutação que retira comandos do programa (operador SSDL) aplicado nestes comandos de inicialização também não foram mortos pelo conjunto de casos de teste. Neste caso, isto ocorre pois estes mutantes são equivalentes. $O$ que ocorre é que após o trecho de inicializações, é chamada a funcão clock com parâmetro 0 ; tal chamada repete as inicializações. Isto mostra que alguns operadores de mutação, além de modelarem erros 
típicos, são úteis também para a localização de outros problemas, como por exemplo código supérfluo.

Alguns experimentos têm mostrado que a seleção aleatória é uma boa opção para a diminuição do número de mutantes [MAT93c]. O programa solar é um bom exemplo de quando utilizar tal estratégia. O teste chamado de SOLAR-I foi executado com $100 \%$ dos mutantes gerados e o SOLAR-II com 10\% dos mutantes; este último apresenta-se como uma alternativa caso não se deseje ou não se possa executar um teste que demore 15 horas.

Outra avaliação feita com o programa solar é em relação ao tamanho dos arquivos criados. À medida que cresce o número de mutantes, pode-se imaginar que o Arquivo de Descritores e o Arquivo de Índices de mutantes cresçam muito, tornando o teste proibitivo. A Tabela 5.5. mostra o tamanho dos arquivos para os testes SOLAR-I e SOLAR-II. Note-se que com os recursos disponiveis estes valores são perfeitamente aceitáveis, não constituindo problema para o teste de programas "grandes".

Tabela 5.5. - Tamanho dos Arquivos de Mutantes

\begin{tabular}{|l|c|c|c|c|}
\hline Programa & $\begin{array}{c}\text { Mutantes } \\
\text { Gerados }\end{array}$ & $\begin{array}{c}\text { Arquivo de } \\
\text { Descritores }\end{array}$ & $\begin{array}{c}\text { Tamanho } \\
\text { Médio de } \\
\text { Descritores }\end{array}$ & $\begin{array}{c}\text { Arquivo de } \\
\text { Indices }\end{array}$ \\
\hline SOLAR-I & 24590 & 8479036 & 77 & 98514 \\
\hline SOLAR-II & 2410 & 836952 & 79 & 9786 \\
\hline
\end{tabular}

\section{4. - Programas Grupo IV}

O último grupo de abrange outra classe de programas. São programas para aplicações científicas, compostos principalmente por operações numéricas e com matrizes. Os programas selecionados do livro "Numerical Recipes in C" [PRE88] são os seguintes:

GAUSJ: Solução de uma equação linear pelo método de eliminação de Gauss-Jordan.

LUDCMP: Dada uma matriz $n \times n$, esta função calcula sua decomposição LU.

LUBKSB: Resolve o conjunto de $n$ equações lineares do tipo $A . X=B$.

TRIDAG: Resolve um sistema de equações lineares tridiagonal.

MPROVE: Aperfeiçoamento da resolução de equaçōes lineares do tipo $A . X=B$.

VANDER: Resolve um sistema linear de Vandermond. 
Os resultados, mostrados nas Tabelas 5.1. e 5.2., foram obtidos na avaliação de um conjunto de casos de teste construído utilizando-se o critério de Particionamento em Classes de Equivalência [KUB93].

Classes especificas de programas, como os programas deste grupo, devem possuir também classes específicas de erros comuns. Com o auxilio do Proteum é possivel, após categorizarem-se estes erros, avaliarem-se os operadores de mutação mais eficientes para revelá-los ou mesmo definirem-se novos operadores de mutação que privilegiem esses tipos de erros.

\section{5. - Considerações Finais}

A avaliação do Proteum, feita a partir de 19 programas - quase todos casos clássicos da literatura - com características distintas, revelou-se importante no processo de validação da ferramenta, mostrando a utilidade de seu uso para casos "reais".

Além disso, permitiu que se tivesse um 'feeling", do ponto de vista de usuário, do ambiente de teste. Isto permitiu que fossem determinadas novas caracteristicas que devem ser adicionadas para uma evolução da ferramenta. Entre outras podemos citar:

- Pequenas alterações de interface; por exemplo, aumentar a janela de visualização de mutantes.

- 'Pretty print" para exibição de mutantes. Muitas vezes, ao serem criados, os mutantes fazem com que a indentação apresentada pelo programa original seja perdida. Por isso, tais mutantes são apresentados de forma confusa tornando dificil seu entendimento.

- Permitir que um mutante seja executado interativamente pelo usuário. Com isso permite-se experimentar um caso de teste sem incluí-lo efetivamente no conjunto de casos de teste; caso ele seja capaz de matar o mutante, ai então incluí-lo.

- Permitir ao usuário que determine uma configuração padrão para seus testes; dentre os parâmetros que podem ser configurados estão: diretório corrente, percentagens para geração dos mutantes, anomalias de fluxo de dados a serem procuradas (quando for implementado), "timeout" para eliminação de mutantes, etc.

Uma das dificuldades sentidas durante esta avaliação foi quanto à determinação dos mutantes equivalentes. Em geral, o número de mutantes que restaram vivos, após serem executados com os casos de teste criados com critérios funcionais, foi grande. Assim torna-se dificil a localização dos mutantes equivalentes pois o número de mutantes a serem analisados é grande. Uma das soluções para esse problema é a implementação de heurísticas para determinação de alguns tipos de mutantes equivalentes. 
Por outro lado, a determinação de uma estratégia mais sistematizada para a aplicação do critério pode também ajudar. Uma das táticas a serem utilizadas, por exemplo, é deixar a determinação dos mutantes equivalentes para uma fase final do teste, ou seja quando já se dispõe de um conjunto com vários casos de teste e que deve ter qualidade pelo menos razoável; assim, os mutantes que continuam vivos têm uma chance maior de serem equivalentes. Deve-se determinar também uma ordem para geração dos mutantes, escolhendo-se primeiro aqueles para os quais são mais fáceis determinarem-se casos de teste efetivos. Por exemplo, aplicando-se primeiramente os operadores de mutação sobre comandos, consegue-se, com certa facilidade, determinar um conjunto de casos de teste que tem características mínimas, como a cobertura de pelo menos todos os comandos do programa. Tal conjunto de casos de teste deve ser eficaz para eliminar boa parte dos demais mutantes; pelo menos aqueles que são mais "Sensiveis", ou seja, que morrem com mais facilidade. Obviamente, a determinação de tais estratégias passa pela experimentação e experiência no uso do critério e da ferramenta.

Finalmente, deve-se chamar a atenção para as restrições apresentadas pela ferramenta. Algumas delas, como a impossibilidade de execução distribuida dos mutantes, estão além do escopo deste trabalho e devem ser vistas como uma continuação dele. Um ponto que chamou a atenção durante a avaliação foi quanto à linguagem aceita pela ferramenta. A decisão de utilizar-se o mesmo modelo de análise léxica e sintática utilizado na POKE-TOOL [CHA91] foi importante pois permitiu que se avançassem rapidamente alguns passos na implementação do Proteum. Por outro lado, algumas limitações - como a restrição ao uso de diretivas \#include, \#define, etc. - mostram-se bastante inconvenientes, obrigando o usuário a adequar seus programas à ferramenta; portanto, outro trabalho que deve ser realizado é a eliminação destas restrições de linguagem, garantindo ao usuário uma compatibilidade maior. 


\section{Capítulo 6.}

\section{Conclusões e Desdobramentos}

1

Esta dissertação apresentou, inserida no contexto de Engenharia de Software e, mais especificamente, como parte das atividades de teste de software, a Análise de Mutantes: um critério de adequação de casos de teste baseado em erros. Esse critério tem se mostrado bastante atrativo para o teste de unidade, fato demostrado pelo grande número de trabalhos que têm sido publicados, envolvendo direta ou indiretamente o critério [CHO93, DEM91, MAT93a, MAT93b, OFF93].

Durante este trabalho de mestrado desenvolveu-se o Proteum (Program Testing Using Mutants), uma ferramenta para apoiar a aplicação do critério Análise de Mutantes. O objetivo principal da implementação dessa ferramenta é que ela, além de possuir características comuns a outras ferramentas, possa incluir também características próprias, visando não só sua aplicação como ferramenta para desenvolvimento de software mas também como instrumento para novas pesquisas e para atividades de ensino. $O$ desenvolvimento do Proteum versão 1.0 - C, foi importante pois, apesar de suas limitações, representa o primeiro passo para alcançar-se tal objetivo.

O Proteum é uma ferramenta multilinguagem, e na sua versão atual apoia o teste de programas escritos em C; foi desenvolvido em estações de trabalho SUN, rodando sob ambiente Openwindows; sua implementação, feita em C, tem cerca de 27000 linhas de código, incluindo comentários. Deve-se notar que apesar de ter-se encontrado na literatura uma única referência a outra ferramenta que apóia a aplicação da Análise de Mutantes para programas $C$ [KRA91b], não se tem detalhes sobre ela nem conhecimento da sua utilização nos meios acadêmicos e tampouco comercialmente.

A especificação e o desenvolvimento do Proteum levaram em conta caracteristicas mínimas que devem estar presentes numa ferramenta de apoio à atividade de teste. Sua operação dirigida a sessões de trabalho, facilidades para definição e manipulação de casos de teste, interface gráfica baseada em janelas, são algumas dessas características.

Outro ponto que norteou sua implementação - e que deve continuar presente no seu desenvolvimento - foi $o$ de fornecer facilidades para a condução de experimentos empíricos, permitindo que pesquisas sejam desenvolvidas na avaliação e comparação de 
critérios de teste e de modo mais geral, na área de Validação, Verificação e Teste de Software.

Foram aplicados testes sobre um conjunto de programas, em geral casos conhecidos da literatura. Tal tarefa serviu como parte das atividades de validação e avaliação da ferramenta, permitindo que problemas na implementação fossem localizados e corrigidos e que fossem identificados possíveis melhoramentos, alguns já realizados. Com isto avalia-se que a versão atual do Proteum é um protótipo que encontra-se num estágio adiantado de desenvolvimento e que, com mais algum esforço de implementação, deve tornar-se um produto pronto para utilização nos meios acadêmicos e comerciais.

\section{1. - Desdobramentos}

Um das motivações para implementar-se o Proteum foi a possibilidade de desenvolver estudos empíricos envolvendo a Análise de Mutantes; portanto, sua aplicação mais imediata é na condução de tais experimentos. Esses experimentos têm como principais objetivos a avaliação do critério e comparação com outros critérios, em particular com critérios de teste estrutural baseados em fluxo de dados. Deve-se também procurar esclarecer pontos ainda obscuros sobre a aplicação do critério tais como: quais operadores de mutação são "mais importantes", ou seja quais contribuem mais para a criação de bons casos de teste?; quais as reais conseqüências em utilizar-se métodos de minimização de mutantes?; como utilizar-se, em conjunto, a Análise de Mutante e critérios estruturais?

Outra aplicação imediata que pode ser dada ao Proteum, e que não deve ser esquecida, é sua possivel utilização no ensino. Tal ferramenta pode ser utilizada, em cursos de graduação ou pós-graduação, como instrumento para demonstração na prática de conceitos ligados à atividade de desenvolvimento e teste de software.

Várias outras atividades podem ser realizadas, relacionadas com a ferramenta desenvolvida. Algumas delas, seguindo as tendências de trabalhos já propostos como: implementação de estratégias para minimização de mutantes; utilização de arquiteturas de alto desempenho para execução de mutantes; geração automática de casos de teste; implementação de heurísticas para determinação automática de mutantes equivalentes; geração de mutantes em nível de código executável; etc.

O Proteum propõe-se a ser uma ferramenta multilinguagem. Trabalhos deverão ser realizados configurando-o para diferentes linguagens, que apresentem características diversas. Por exemplo: linguagens para aplicações comerciais como Cobol ou Clipper; linguagens para aplicações científicas como FORTRAN; linguagens para aplicações paralelas/concorrentes como OCCAM; linguagens orientadas a objetos como $\mathrm{C}++$ ou Sather [OMO93]. É importante lembrar que cada um desses trabalhos envolve, além da configuração da ferramenta para as características sintáticas da linguagem alvo, a 
adaptação dos operadores de mutação já definidos e possivelmente a definição de novos operadores que se adaptem a características particulares dessas linguagens.

Usualmente caracterizam-se três fases (niveis) de teste: teste de unidade, teste de integração e teste de sistema. A aplicação da Análise de Mutantes concentra-se principalmente em nivel de unidade. $O$ autor desta dissertação, durante o programa de doutoramento no IFQSC-USP, procurará estender e explorar a aplicação dos conceitos aqui abordados para outros niveis de teste, em particular para o teste de integração. Além disso, o paradigma de desenvolvimento de software e linguagens de programação orientados a objetos têm sido reconhecidos como abordagens poderosas e práticas. Diversas metodologias e linguagens têm surgido seguindo esse paradigma. Por isso, 0 trabalho de doutoramento deverá ser conduzido procurando observar essa tendência, 0 que possivelmente implica a necessidade de rever e reformular alguns conceitos de teste a fim de acomodar as particularidades do paradigma. Tal trabalho envolverá também a especificação e implementação de ferramentas de teste para viabilizar a realização de estudos empíricos e a aplicação dos conceitos e critérios desenvolvidos ao longo do trabalho. 


\section{Bibliografia}

[ACR79] Acree, A., Budd, R., Demillo, R.A., Lipton, R., Sayward, F.G., 'Mutation Analysis", Technical Report GIT-ICS-79/08, Georgia Institute of Technology, Set 1979.

[ACR80] Acree, A., 'On Mutation”, Ph.D. thesis, School of Information and Computer Science, Georgia Institute of Technology, Ago 1980.

[ADR82] Adrion, W.R., Branstad, M.A., Cherniavski, J.C., "Validation, Verification, and Testing of Computer Software", Computing Surveys, vol 14, No. 2, Jun 1982.

[AGA79] Agarwal, V.K., Masson, G.M., 'Recursive Coverage Projection of Test Sets", IEEE Trans. on Computers, vol. c-28, No. 11, Nov 1979.

[AGR89] Agrawal, H., Demillo,R.A., Hathaway, B., Hsu, W., Hsu, Wy., Krauser, E.W., Martin, R.J., Mathur, A.P., Spafford, E., 'Design of Mutant Operators for the C programming Language", Technical Report SERC-TR-41-P, Software Eng. Research Center, Purdue University, Mar 1989.

[BEI90] Beizer, B., Software Testing Techniques, Segunda Edição, Van Nostrand Reinhold, New York, 1990.

[BRI93] Brites, C.F.V, Chaim, M.L., Costa, H.S.G., Jino, M., Kondo, R.S., Maldonado, J.C., "Software Test Evaluation Applied to Hardware Simulation", SBMICRO, 1993.

[BUD80] Budd, T.A., DeMillo, R.A., Lipton, R.J., Sayward, F.G., "Theoretical and Empirical Studies on Using Prog Mutation to Test the Functional Correctness of Prog.", 7th ACM Symposium on Principles of Programming Languages, Jan 1980.

[BUD81] Budd, T.A., 'Mutation Analysis: Ideas, examples, problems and prospects", Computer Program Testing, North-Holand Publishing Company, 1981.

[BUD82] Budd, T.A., Angluin, D., "Two Notions of Correctness and Their Relation to Testing", Acta Informatica 18, 1982.

[CAR91] Carnassale, M., GFC - Uma Ferramenta Multilinguagem para Geração de Grafo de Programa, Dissertação de Mestrado, DCA/FEE/UNICAMP, Fev 1991. 
[CHA91] Chaim, M.L., POKETOOL - Uma Ferramenta para Suporte ao Teste Estrutura] de Programas Baseado en Análise de Fluxo de Dados, Dissertação de Mestrado, DCA/FEE/UNICAMP, Abr 1991.

[CHO89a] Choi, B.J., Mathur, A.P., Pattison, B., "pMothra: Scheduling Mutants For Execution on a Hypercube", Third Symposium on Software Testing, Analysis and Verification, Key West, Dez 1989.

[CHO89b] Choi, B.J., DeMillo, R.A., Krawser, E.W., Martin, R.J., Mathur, A.P., Offut, A.J. Pan, H., Spafford, E.H., "The Mothra Tool Set", Proceedings of the 22nd Hawaii International Conference on Systems and Software, Kona, Hawaii, Jan 1989.

[CHO93] Choi, B., Mathur, A.P., 'High-Performance Mutation Testing", Journal of System and Software, No. 20, 1993.

[COW88] Coward, P.D., "A Review of Software Testing", Information and Software Technology, vol 30, No. 3, Abr 1988.

[DEM78] DeMillo, R.A., Lipton, R.J., Sayward, F.G., 'Hints on Test Data Selection: Help for the Practicing Programmer", Computer, vol. 11(4), Abr 1978.

[DEM80] DeMillo, R.A., 'Mutation Analysis as a Tool for Software Quality Assurance”, Proc. of COMPSAC 80, Chicago - IL, Out 1980.

[DEM81] DeMillo,R.A., Hocking, D.E., Merrit, M.J., "A Comparison of Some Reliable Test Data Generation Procedures", Technical Report GIT-ICS-81/08, Georgia Institute of Technology, Abr 1981.

[DEM88] DeMillo, R.A., Guindi, D.S., King, K.N., McKraken, W.N., Offutt, A.J., "An Extended Overview of the Mothra Testing Environment", Proc. of the Second Workshop on Software Testing, Verification and Analysis, Banff - Canada, 1988.

[DEM91] DeMillo, R.A., Offut, A.J., 'Constraint-Based Automatic Test Data Generation", IEEE Trans. on Software Eng., vol 17, No. 9, Set 1991.

[DEU82] Deutsch, M.S., Software Verification and Validation, Englewwod Cliffs, Prentice-Hall, 1982.

[FEL75] Feller, W., An Introduction to Probability and its Applications, Wiley, 1957.

[FRI75] Friedman, A.D., Logical Design of Digital Systems, Computer Science Press, 1975 .

[HEL91]_Heller, D., XView Programming Manual, O’Reilly \& Associates, Canadá, 1991. /

[HOR92] Horgan, J.R., Mathur, A.P., "Assessing Testing Tools in Research and Education", IEEE Software, vol 9, No. 3, Mai 1992. 
[HOW76] Howden, W.E., 'Reliability of Path Analysis Testing Strategy", IEEE Trans. on Software Eng., vol. SE-2, Set 76.

[HOW78] Howden, W.E., “Algebraic Program Testing”, Acta Informatica 18, 1978.

[HOW82] Howden, W.E., 'Weak Mutation Testing and Completeness of Test Sets", IEEE Trans. on Software Eng., vol. SE-8, No. 4, Jul 1982.

[KER81] Kernighan, B.W., Plauger, P.J., Software Tools in Pascal, Addison-Wesley Publishing Conpany, Reading, Massachusets, 1981

[KRA88] Krauser, E.W., Mathur, A.P., Rego, V., 'High Performance Testing on SIMD Machines", Proc. of the Second Workshop on Software Testing, Verification and Analysis, Banff - Canada, 1988.

[KRA91a] Krawser, E.W., Mathur, A.P., Rego, V., 'High Performance Software Testing on SIMD Machines", IEEE Trans. on Software Eng., vol 17, No. 15, Mai 1991.

[KRA9lb] Krauser, E.W., Compiler Integrated Testing, Ph.D. thesis, Purdue University, Dez 1991.

[KUB93] Kuboki, L.A., Relatório Técnico de Iniciação Científica, em preparação.

[LEI91] Leitão, P.S., Configuração do Módulo li da POKE-TOOL.para a Linguagem C, Relatório Técnico, FEE/UNICAMP, Campinas - S.P, 1991.

[LUT90] Lutz, M., “Testing Tools”, IEEE Software, vol 7, No. 3, Mai 1990.

[MAL89] Maldonado, J.C., Chaim. M.L., Jino, M., "Arquitetura de Uma Ferramenta de Teste de Software de Apoio ao Critério Potenciais Usos", Proc. XXII Congresso Nacional de Informática, São Paulo - SP, Set 1989.

[MAL91] Maldonado, J.C., Critérios Potenciais Usos: uma Contribuição ao Teste Estrutural de Software, Tese de Doutorado, FEE/UNICAMP, Campinas - S.P., 1991.

[MAR90] Marshall, A.C., Hedley, D., Riddell, I.J., Hennell, M.A., 'Static Dataflow-aided Weak Mutation Analysis (SDAWM)", Information and Software Technology, vol 32, No. 1, Jan/Fev 1990.

[MAT88] Mathur, A.P., Krauser, E.W., 'Modeling Mutation on Vector Processor', Proc. of the Second Workshop on Software Testing, Verification and Analysis, Banff - Canada, 1988.

[MAT93a] Mathur, A.P., Wong, W.E., "A Formal Evaluation of Mutation and Data Flow-based Test Adequacy Criteria", Tech Report SERC-TR-133-P, Software Engineering Research Center, Purdue University, Jan 1993. 
[MAT93b] Mathur, A.P., Wong, W.E., "An Empirical Comparison of Mutation and Data Flow-based Test Adequacy Criteria", Tech Report SERC-TR-135-P, Software Engineering Research Center, Purdue University, Fev 1993.

[MAT93c] Mathur, A.P., Wong, W.E., 'Reducing the Cost of Mutation Testing: A Case Study", Tech Report SERC-TR-138-P, Software Engineering Research Center, Purdue University, Jun 1993.

[MYE79] Myers, G.J., The Art of Software Testing, Wiley, New York, 1979.

[OFF87] Offut, A.J., King, K.N., "A Fortran 77 Interpreter for Mutation Analysis", Proc. of the SIGPLAN 87 Symp. on Interpreters and Interpretive Techniques, St. Paul Minnesota, Jul 1987.

[OFF93] Offut, A,J., Rothermel, G., "An Experimental Evaluation of Selective Mutation", 15th International Conference on Software Engineering, Baltimore - Maryland, Mai 1993.

[OL192] Oliveira, M.C.F., Caldeira, S.M.A., Masiero, P.C., Olivera Jr, O.N., "A Discussion on Human-Computer Interfaces for Writing Support Tools", XII International Conference of the Chilean Computer Society, Santiago del Chile, Out 1992.

[OMO93] Omohundro, S.M., The Sather Language, International Computer Science Institute, Berkley - CA, Jun 1993.

[PRE88] Press, W.H., Brian, P.F., Teukolsky.S.A., Vetterling, W.T., Numerical Recipes in C - The Art of Scientific Computing, Cambridge University Press, Cambridge 1988.

[PRE92] Pressman, R.S., Software Engineering: A Practitioner's Approach, Terceira Edição, McGraw-Hill, 1992.

[PRI90] Price, A.M., Zorzo, A., "Visualizando o Fluxo de Controle de Programas", IV Simpósio Brasileiro de Eng. de Software, Águas de São Pedro - SP, Out 1990.

[RAP85] Rapps, S., Weyuker, E.J., 'Data Flow Analysis Techniques for Test Data Selection", IEEE Trans. on Software Eng., vol. SE-11, Abr 1985.

[ROS93] Rossi, A.C., Estudo Empírico Comparativo entre Teste Funcional - Critério Particionamento de Equivalência - e o Teste Estrutural Baseado na Análise de Fluxo de Dados - Critérios Potenciais Usos, Relatório Técnico, 1993.

[SET81] Setzer, V.W., Melo, I.S.H., A Construção de um Compilador, Editora Campus, Rio de Janeiro, Terceira Edição, 1981.

[SPA90] Spafford, E.H., "Extending Mutation Testing to Find Environmental Bugs", Technical Report SERC-TR-21-P, Software Eng. Research Center, Purdue University, 1990. 
[WEY90] Weyuker, E.J., "The Cost of Data Flow Testing: An Empirical Study", IEEE Trans. on Software Eng., vol SE-16, No. 2, Fev 1990.

[WHI80] White, L.J., Cohen, E.I., "A Domain Strategy for Computer Program Testing", IEEE Trans. on Software Eng., vol.SE-6, No. 3, Mai 1980.

[WHI81] White, L.J., 'Software Testing and Verification", in Computer Program Testing, North-Holland Publishing Company, 1981.

[WO088] Woodward, M.R., Halewood, K., 'From Weak to Strong, Dead or Alive? An Analysis of Some Mutation Testing Issues", Proc. of the Second Workshop on Software Testing, Verification and Analysis, Banff - Canada, Mai 1988.

[WU88] Wu, D., Hennel, M.A., Hedley, D., Riddell,I.J., "A Pratical Method for Software Quality Control Via Program Mutation", Proc. of the Second Workshop on Software Testing, Verification and Analysis, Banff - Canada, Mai 1988.

[ZHU93] Zhu, H., Hall, P.A.V., "Test Data Adequacy Measurement", Software Engineering Journal, Jan 1993. 


\section{Apêndice A.}

\section{Um Exemplo Completo}

Este apêndice mostra um exemplo completo de uma sessão de teste baseada na Análise de Mutantes utilizando-se a ferramenta de teste Proteum. $O$ programa a ser testado é uma versão corrigida do programa find, extraído do artigo de Mathur [MAT93b] ${ }^{6}$. Este programa recebe como parâmetros um vetor de inteiros $a[]$ e um índice $f$ e permuta os elementos de $a$ de maneira que, depois de permutados, os elementos à direita da posição $f$ são maiores que ou iguais a $a[f]$ e os elementos à esquerda da posição $f$ são menores que ou iguais a $a[f]$.

$\mathrm{O}$ arquivo find.c, mostrado na Figura A.1., que contém o programa fonte, possui além da função find, a função main que é apenas um "driver" que solicita ao usuário os dados de entrada: os elementos do vetor e o índice do elemento que será o pivô.

A função main não recebe nenhum parâmetro e a função find recebe como parâmetros dois inteiros, $n$ e $f$, que são, respectivamente, o número de elementos do vetor e o índice do pivô; o vetor $a$ é armazenado como uma variável global. $O$ programa executável está no arquivo findd (para diferenciar do programa find, um utilitário do Unix).

\section{A.1. - A Sessão de Teste}

O primeiro passo é invocar, de dentro do Openwindows, o Proteum, dando o comando Proteu. Com isso, aparece a primeira tela do Proteum, mostrada na Figura A.2. Nela podem ser identificadas cinco possiveis opções: Program Test, Test Case, Mutants, Properties e Quit.

O próximo passo é criar o teste do programa. Selecionando a opção Program Teste no menu principal temos o menu mostrado na Figura A.3., com três possíveis

\footnotetext{
${ }^{6}$ Neste artigo, o programa find, apesar de apresentado como correto, possui um erro que foi corrigido para inclusão nesta dissertação.
} 
opções: uma para carregar um teste que já existe (opção Load), a segunda para criar um novo teste (opção $\mathrm{New}$ ) e a última para salvar o estado corrente do teste sendo conduzido (Save). No caso, como trata-se da criação do teste para o programa find, deve-se selecionar a opção New.

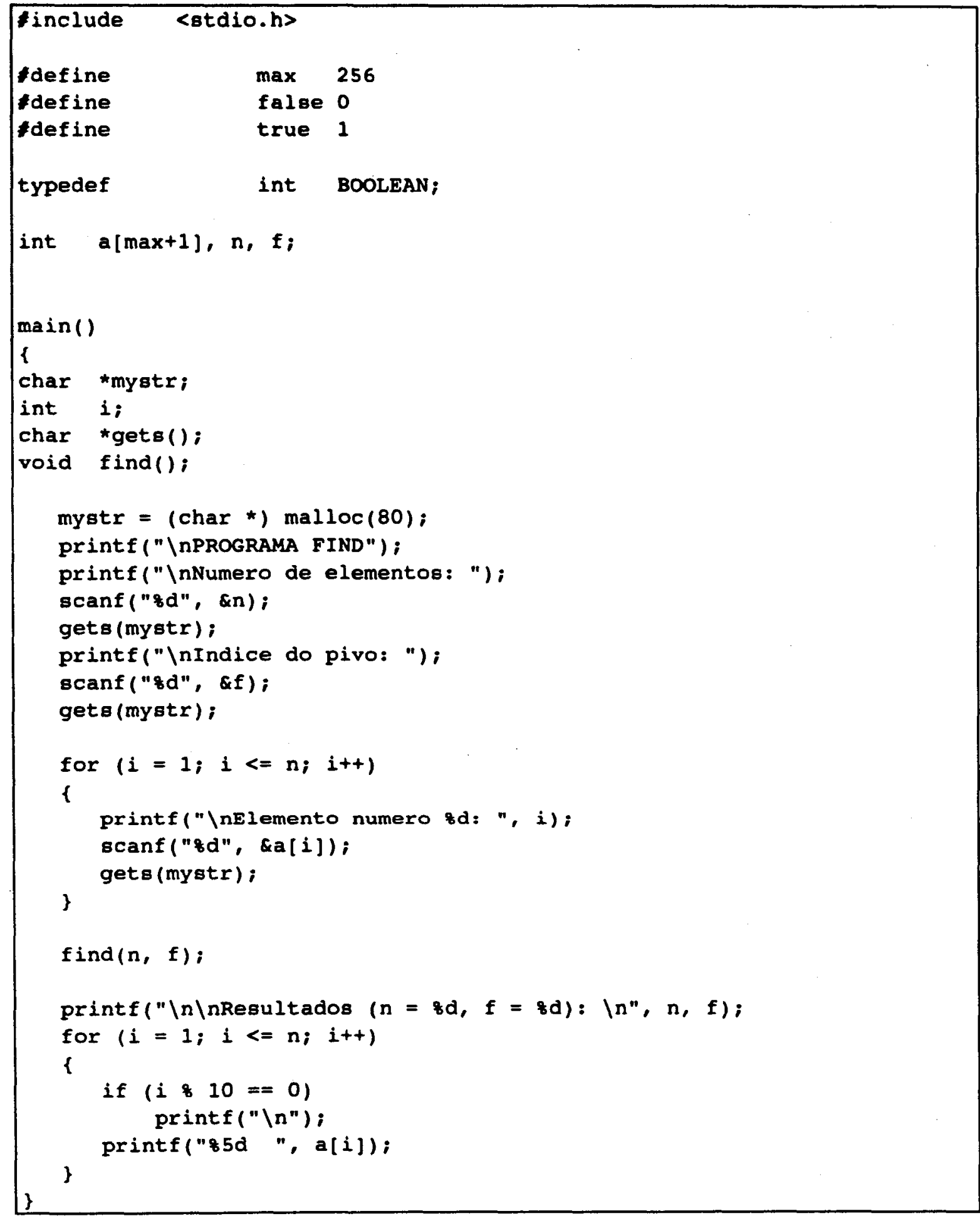




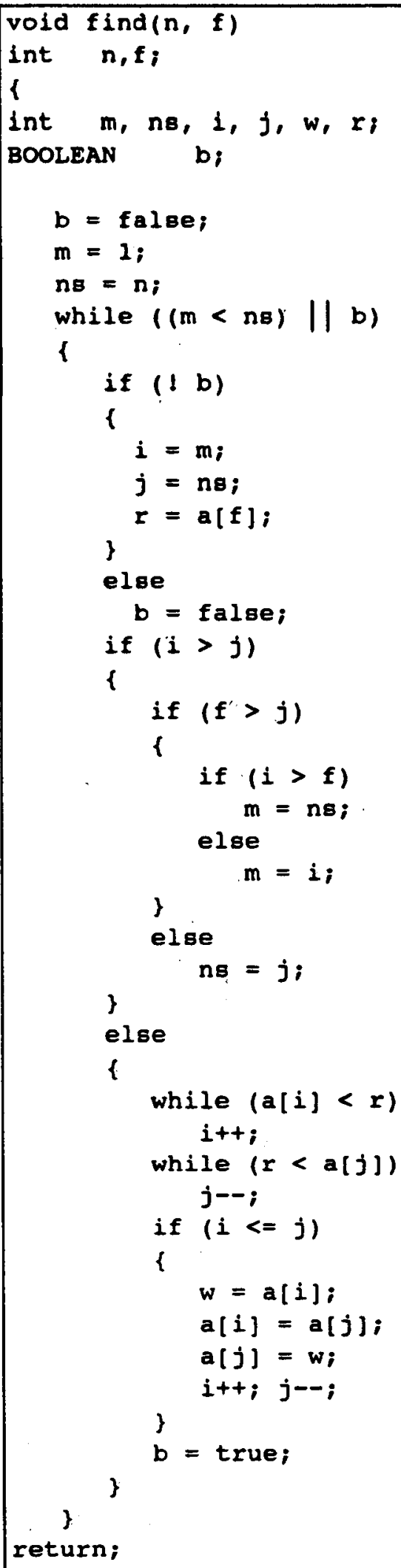

Figura A.1. - Programa find 
Figura A.2. - Menu Principal

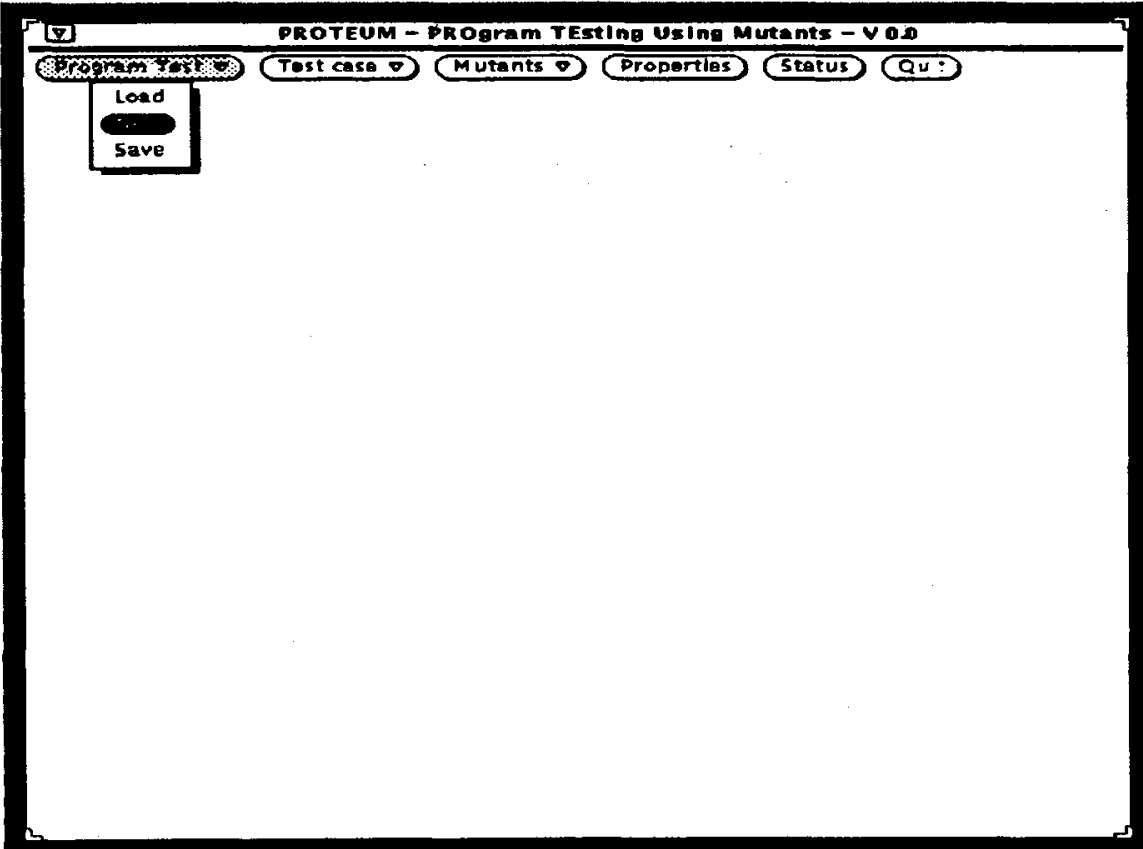

Figura A.3. - Opção para Criar Teste 
- $-0=0 \quad$ Croate Now Program Test

Directory: /work1/lenomaml/ESwSI/mod

proorem Text Name:

source mooram:

Enocutable Program:

Compllation comand:

Trpe: Tost Research Anomaly Trpes: $U A$ DU $D$

Functions: All Soloct

Confirm Cance1

Figura A.4. - Painel para Criação de Teste

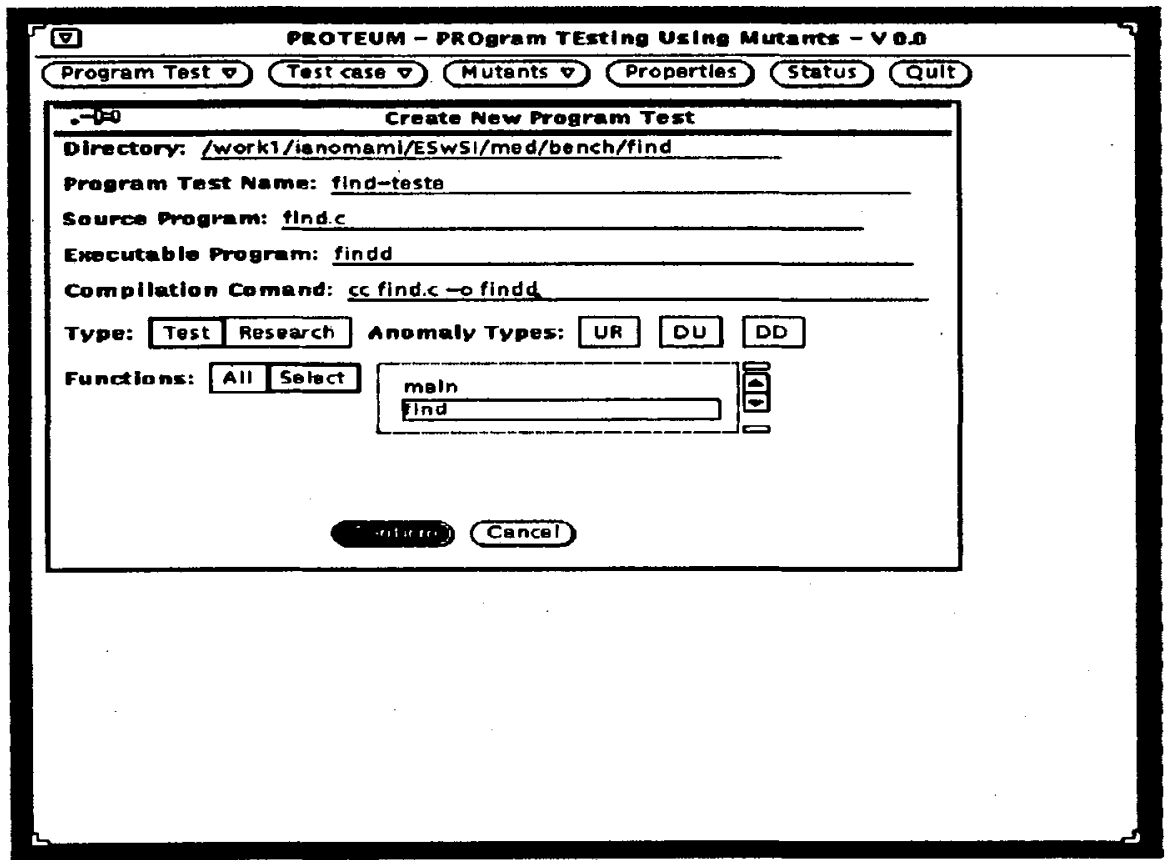

Figura A.5. - Confirmando a Criação de um Teste 
Selecionada esta opção o Proteum solicita alguns dados para a criação. Isto é feito através do painel da Figura A.4. O primeiro campo a ser preenchido neste painel é o diretório onde será conduzido o teste, ou seja, onde estão o programa fonte e o programa executável e onde serão criados os arquivos de trabalho do Proteum. 0 próximo passo é escolher um nome para identificar o teste, por exemplo, find-teste. Em seguida deve-se fornecer o nome do arquivo fonte (find.c), do executável (findd) e o comando que deve ser usado para criar o programa executável a partir do fonte. No presente caso, utiliza-se o compilador $\mathrm{C}$ do Unix com o comando $c c$ find.c -o findd -w. $\mathrm{O}$ tipo do teste escolhido é Test. Além disso, será testada apenas a função find, não interessando o teste da função main que é apenas um "driver", portanto escolhe-se a opção Select e dentro da lista de funções do programa, seleciona-se a função desejada.

Basta agora conferir as informações e confirmá-las através do botão Confirm (Figura A.5.). Está criado assim um teste para o programa find, identificado pelo nome find-teste. Para conferir, basta acionar o botão Status no menu principal e será exibido um sumário sobre o teste que está sendo conduzido. A Figura A.6. mostra a situação do teste find-teste.

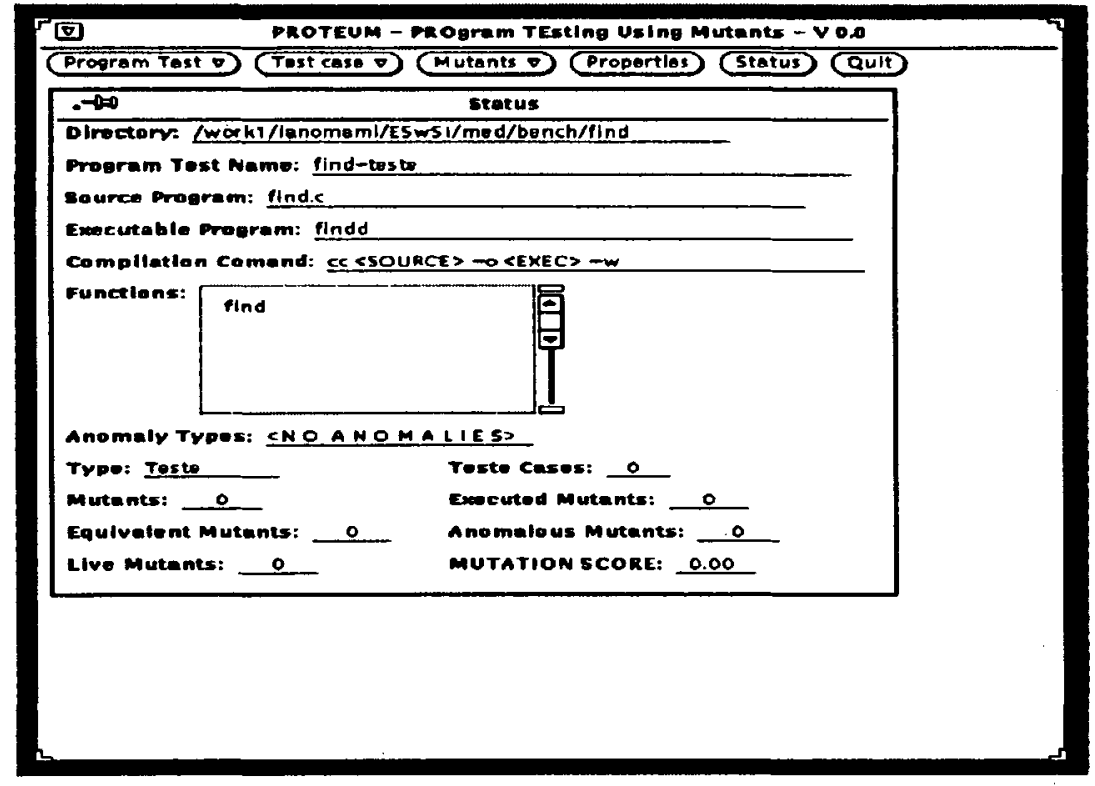

Figura A.6. - Status inicial

Pode-se então partir para o teste propriamente dito. Inicialmente pode-se criar os mutantes, escolhendo-se no menu de mutantes a opção Generate, ilustrada na Figura A.7. O Proteum então permite que se escolham porcentagens do número de mutantes a gerar. A Figura A.8. mostra que foram selecionados $100 \%$ dos mutantes para a classe de mutações de comandos e $0 \%$ para as outras três classes. Poder-se-ia escolher também porcentagens individuais para cada operador; selecionando um dos botões Statement Mutations, Operator Mutations, Variable Mutations e Constant Mutations é apresentada a lista de operadores da classe, onde pode-se alterar as porcentagens de geração. 


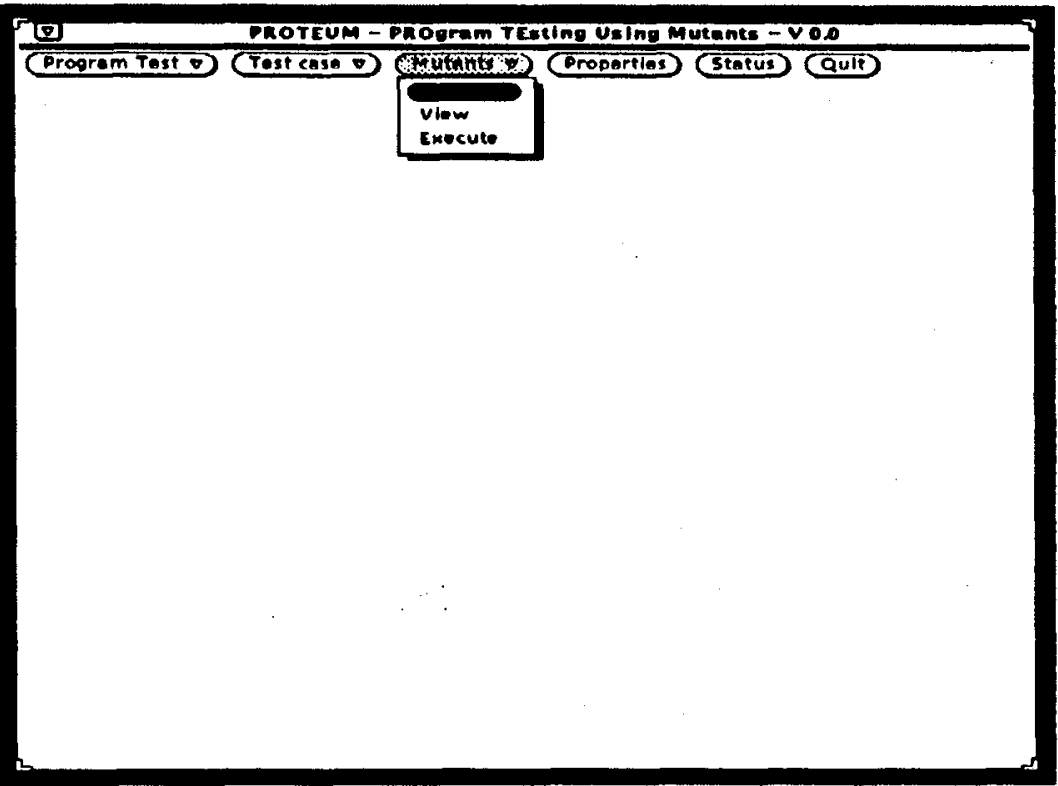

Figura A.7. - Menu de Mutantes

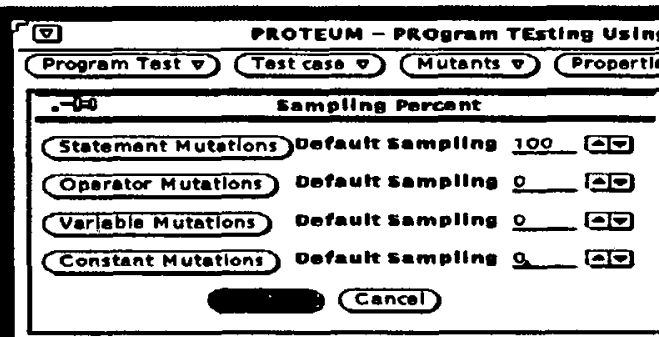

Figura A.8. - Menu para Geração de Mutantes 
O Proteum inicia a geração dos mutantes e vai exibindo o número do operador de mutação sendo aplicado. Terminada a geração, exibe também uma mensagem com o número de mutantes gerados. No caso do find-teste, são gerados 119 mutantes para a classe escolhida, como é mostrado na Figura A.9.

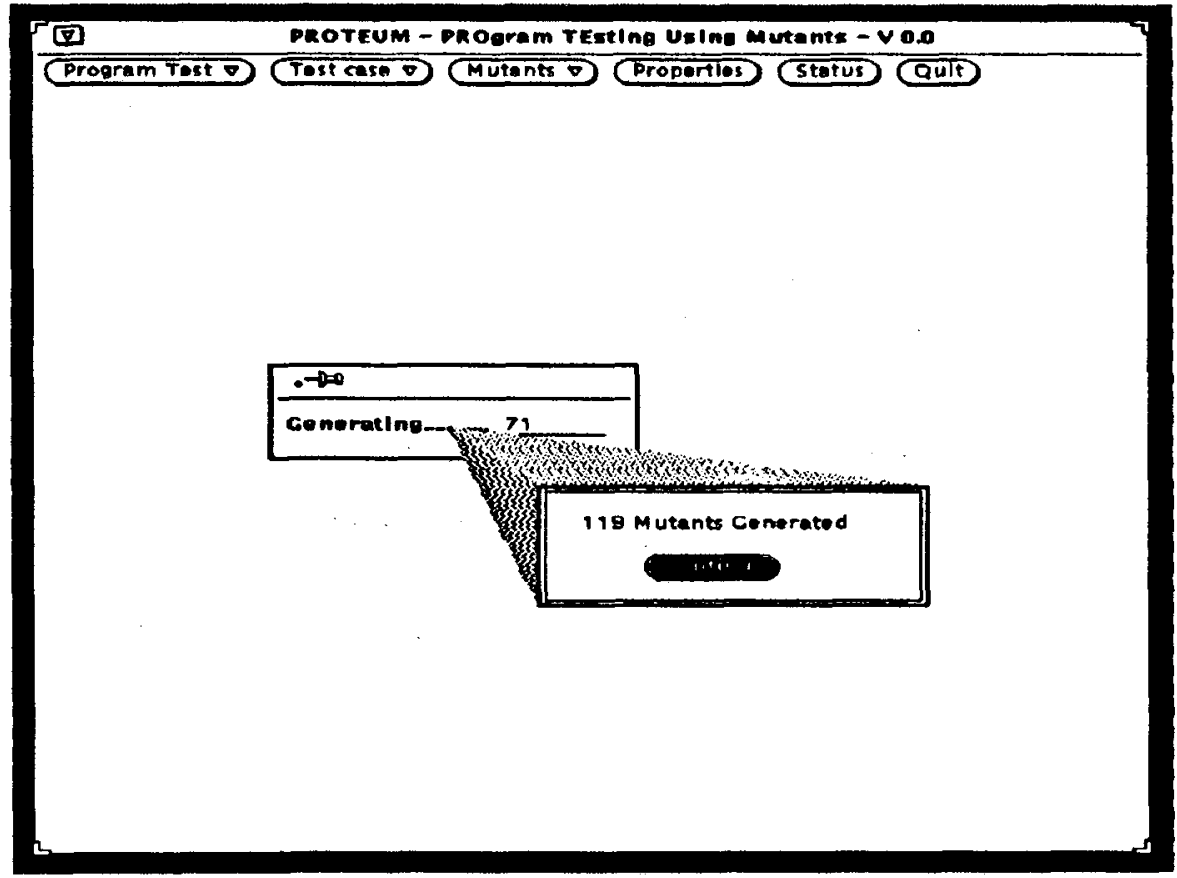

Figura A.9. - Final da Geração de Mutantes

Para poder executar os mutantes e avaliar o conjunto de casos de teste (afinal é este o objetivo do teste) faltam apenas os próprios casos de teste. A seguir serão introduzidos os casos de teste a serem avaliados. Para isso escolhe-se a opção Add do menu de casos de teste (Figura A.10.). Então o Proteum irá iniciar a execução do programa find, com o qual o testador deve interagir. Primeiro solicitam-se os parâmtros iniciais para execução do programa. Como o find não aceita parâmetros via linha de comando, deve-se deixar vazio o painel mostrado na Figura A.11. pressionando-se apenas a tecla "return".

O testador passa a interagir com o find através da tela da Figura A.12. que simula um terminal. Após fornecer os valores que o programa solicita (número de elementos, índice do pivô e elementos do vetor) e verificar o resultado produzido, o usuário pode confirmar, caso o comportamento do programa seja correto, ou cancelar a inclusão do caso de teste. $O$ Proteum pede essa confirmação ao usuário através da mensagem da Figura A.13. 


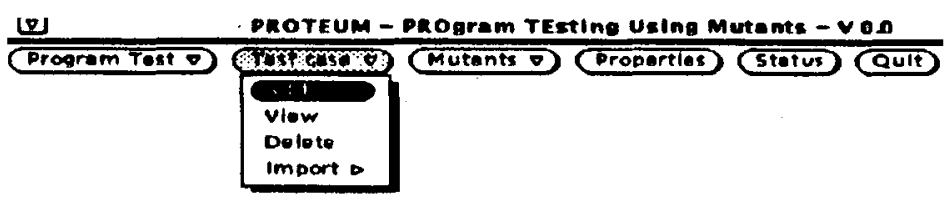

Figura A.10. - Menu de Casos de Teste

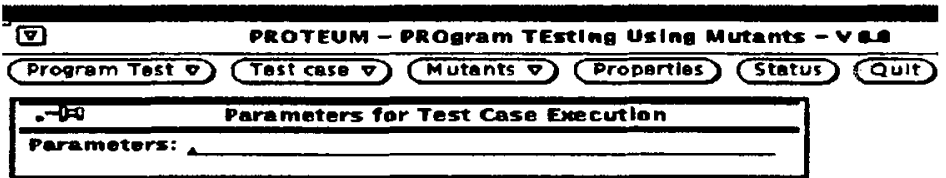

Figura A.11. - Painel para Parâmetros Iniciais 


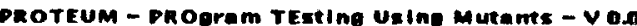

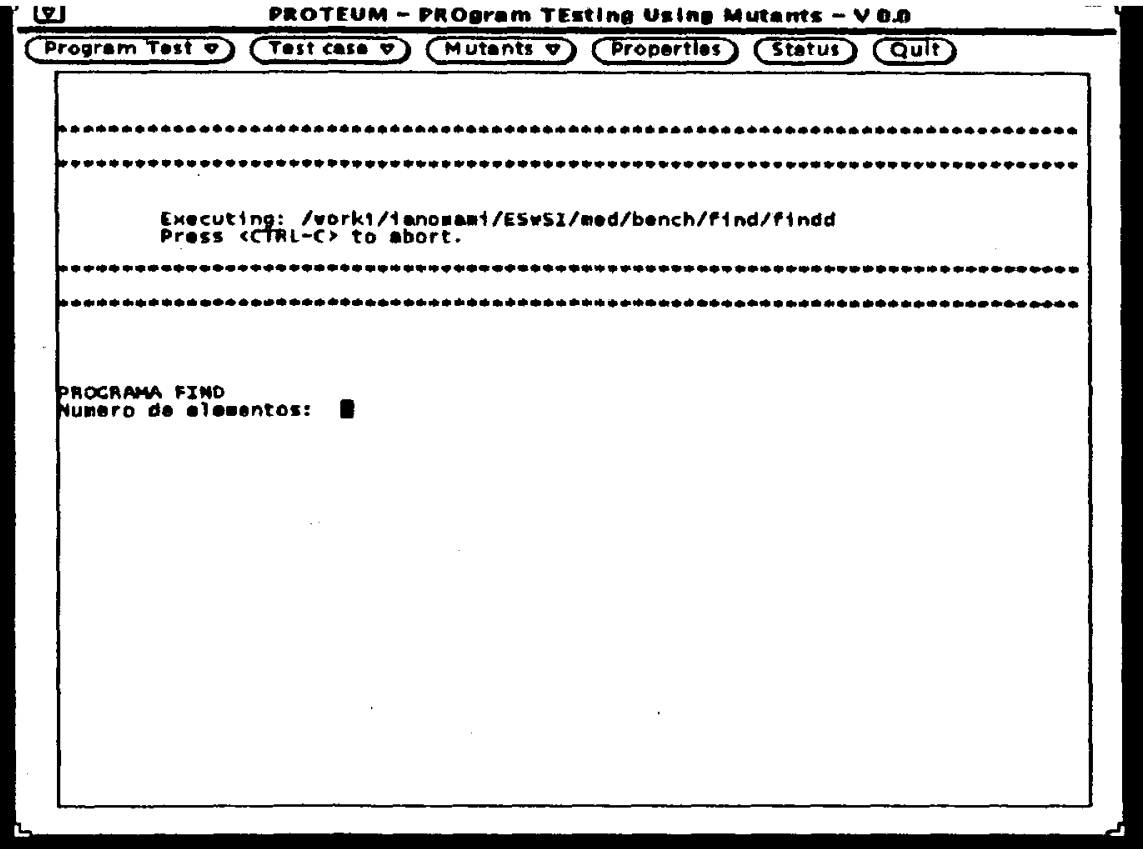

Figura A.12. - Tela de Inclusão de Caso de Teste

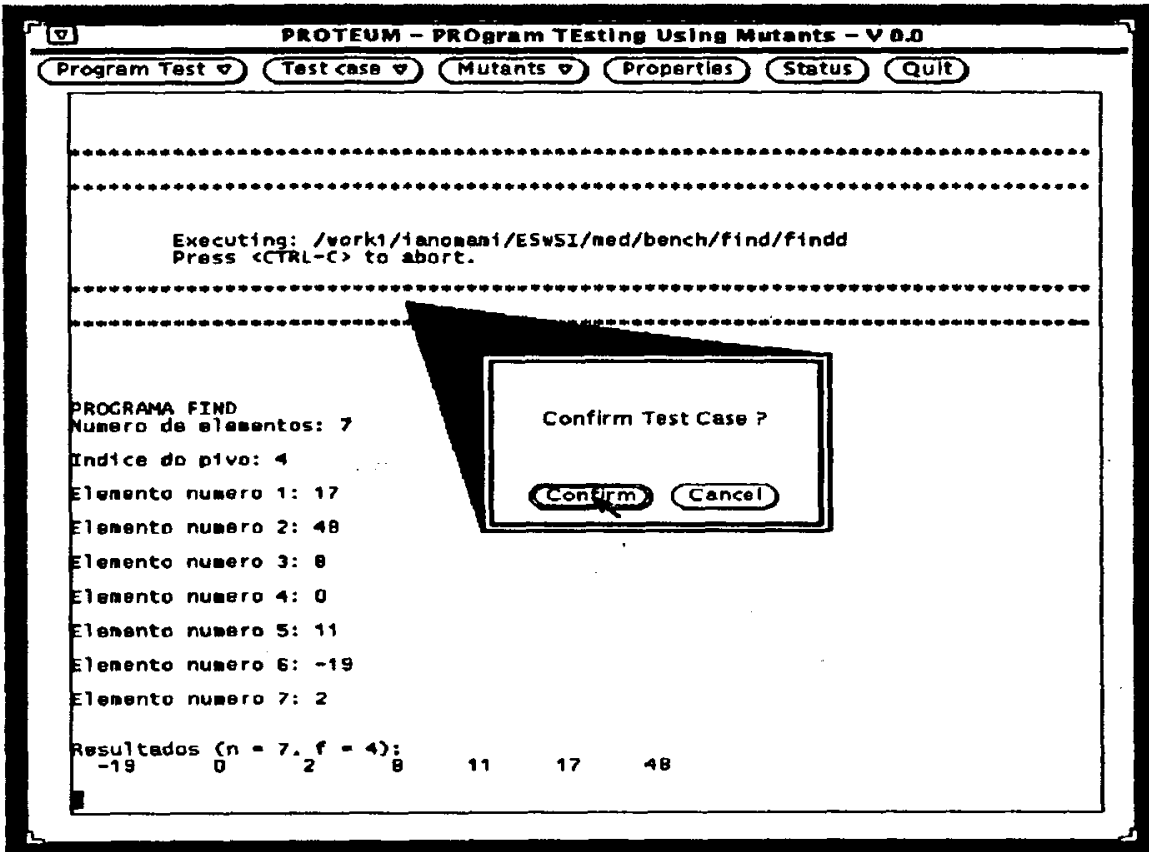

Figura A.13. - Confirmação de Caso de Teste 
Agora já existe (pelo menos) um caso de teste e pode-se executar os mutantes. Selecionando a opção Execute do menu de mutantes, o Proteum inicia a execuf̧ão utilizando os casos de teste habilitados. À medida em que vai executando, o Proteum exibe o número dos mutantes executados. Como esta pode ser uma operação demorada, existe a possibilidade de interrompê-la através do botão Cancel do painel mostrado na Figura A.14.. Interrompendo a execução, o usuário não perde o trabalho executado pois numa próxima execução os mutantes não serão executados com os mesmos casos de teste com os quais já foram executados.

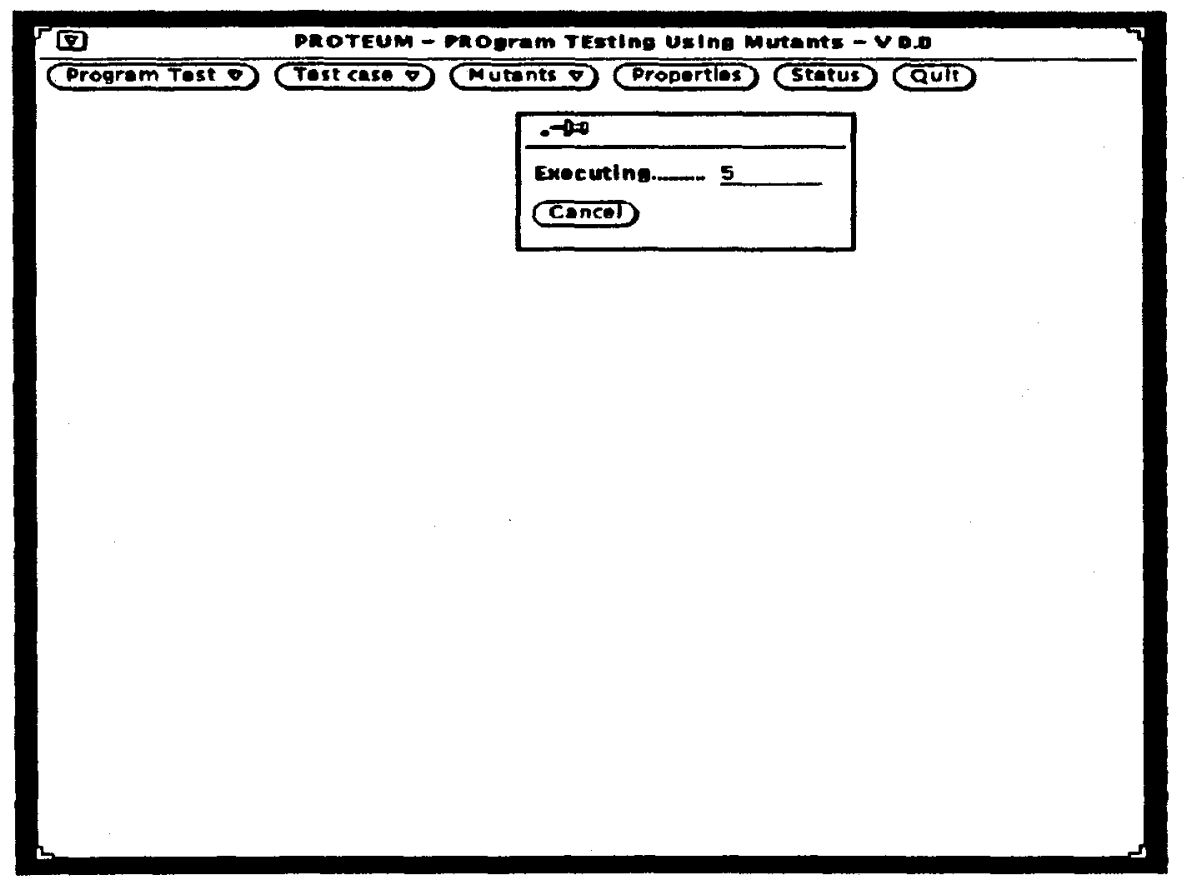

Figura A.14. - Execução dos Mutantes em Andamento

Terminada a execução pode-se verificar os resultados no painel de status (Figura A.15.). O conjunto de casos de teste não conseguiu matar 10 dos 119 mutantes, produzindo um escore de mutação de 0,91 . Resta analisar os mutantes vivos e descobrir porque. A opção View permite que isto seja feito. Deixando selecionada apenas a opção Live da lista no topo do painel, são exibidos só os mutantes que estão vivos. Assim podese decidir se os mutantes são ou não equivalentes. 0 mutante mostrado na Figura A.16. é um mutante equivalente (o return excluido do fim da função não faz diferença) e pode ser marcado como tal através do botão no alto do painel.

Por outro lado o mutante da Figura A.17. não é equivalente e deve-se tentar matálo através de novos casos de teste. Como já é sabido, este mutante só pode ser morto quando a condição passada como parâmetro para a função TRAP_ON_TRUEO for verdadeira, o que portanto não aconteceu quando utilizou-se o único caso de teste disponivel. Assim, tem-se uma indicação de como matar este mutante. 


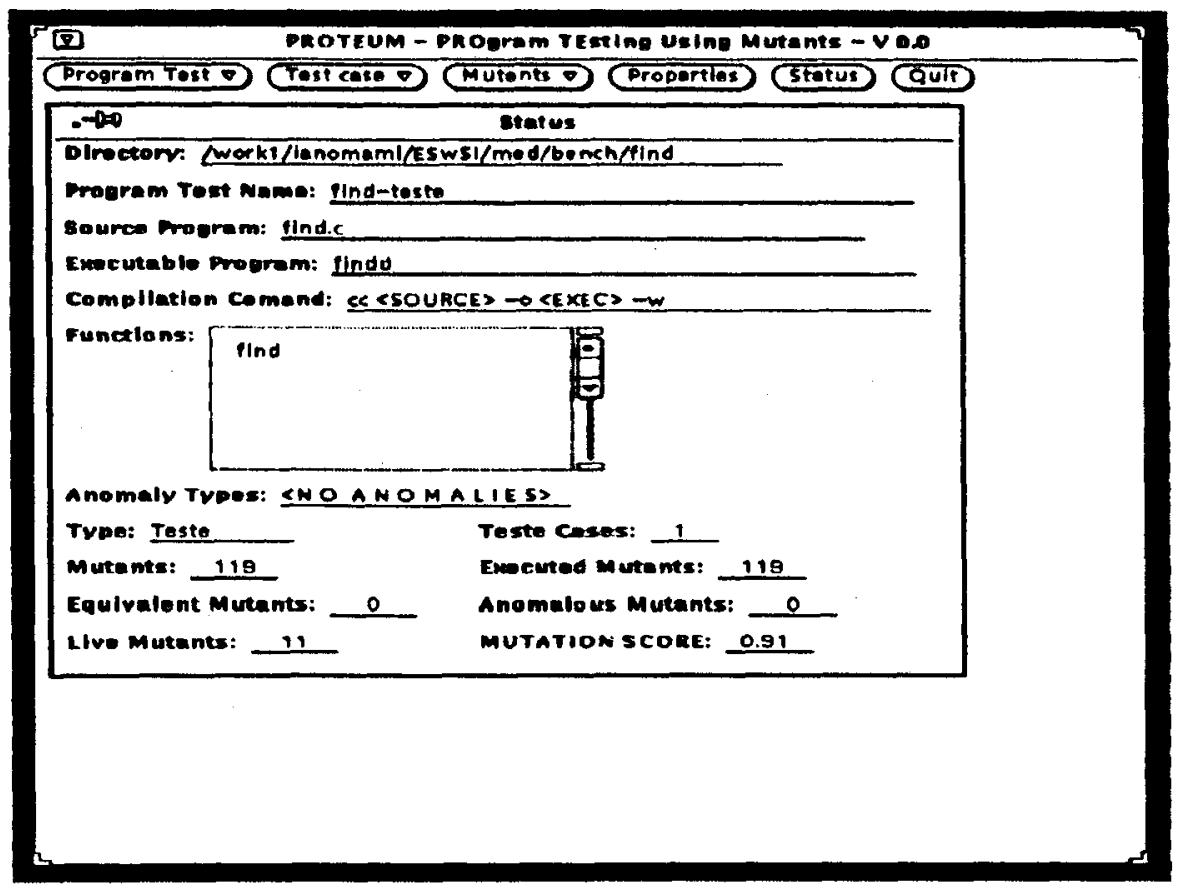

Figura A.15. - Status após Execução

Desta maneira, o teste pode continuar com a repetição desses passos: geração, execução, análise dos mutantes (possivelmente com a identificação de mutantes equivalentes) $e$ inclusão de novos casos de teste.

Alcançados os requisitos para o conjunto de casos de teste, ou mesmo antes, caso o usuário "canse" da sessão de teste, ele pode abandonâ-la; ou através do botão Quit do menu principal ou da opção Quit do quadro principal do Proteum, como mostra a Figura A.18. Em ambos os casos o usuário pode escolher entre salvar as operações executadas ou desfazer todas as operações feitas durante a sessão de teste ou ainda cancelar a saída do ambiente.

Pode-se posteriormente retornar ao teste do programa find, entrando no Proteum e selecionando-se a opção Load do menu Program Test. O nome do teste, find-teste, deve ser fornecido para que o teste seja carregado e possa continuar do ponto em que foi abandonado. 


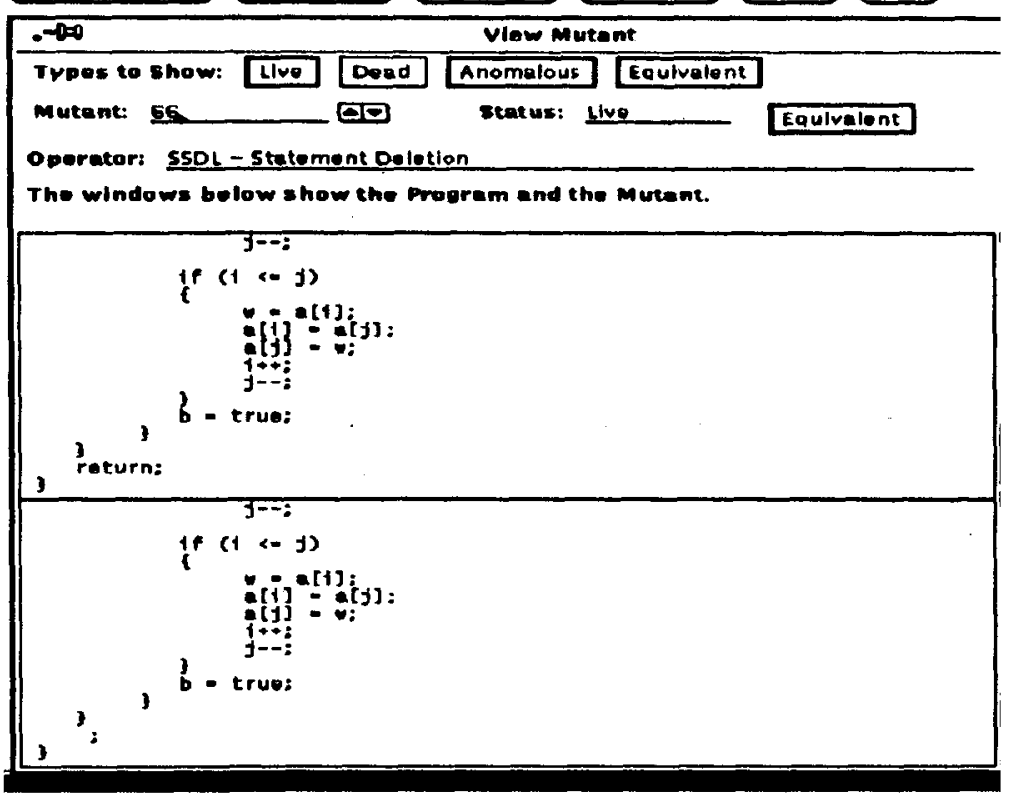

Figura A.16. - Mutante Equivalente

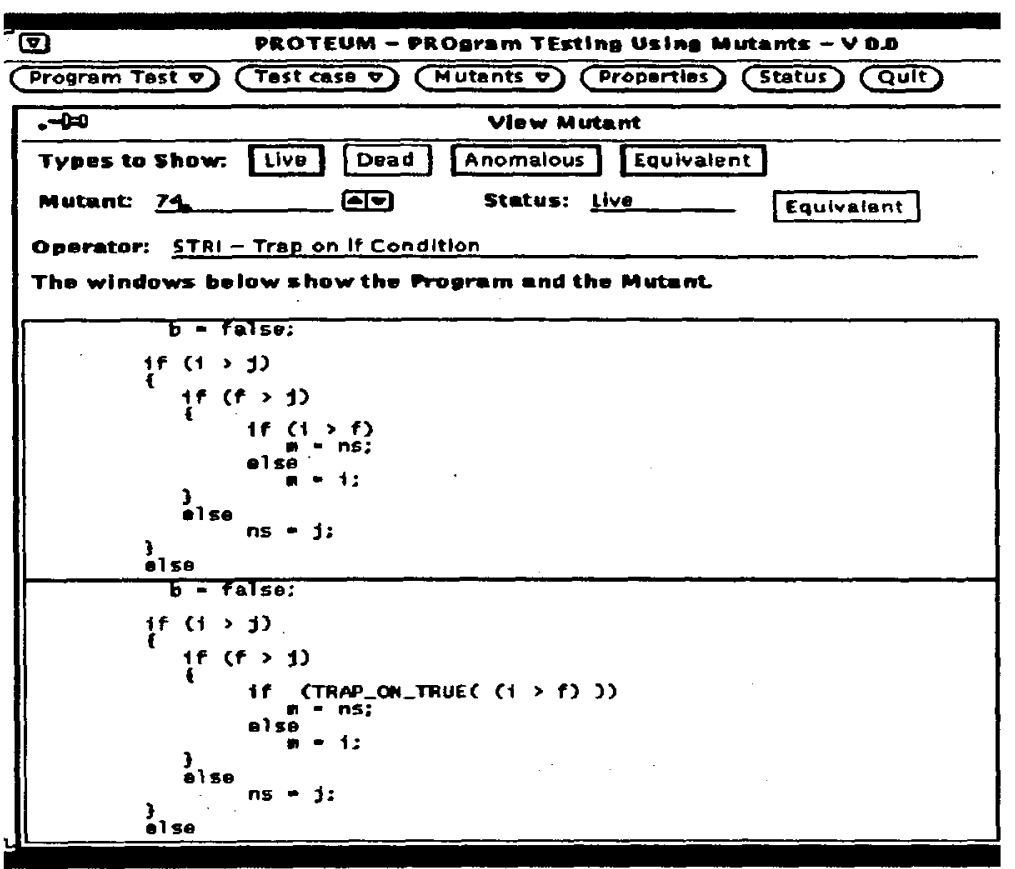

Figura A. 17. - Mutante Vivo 


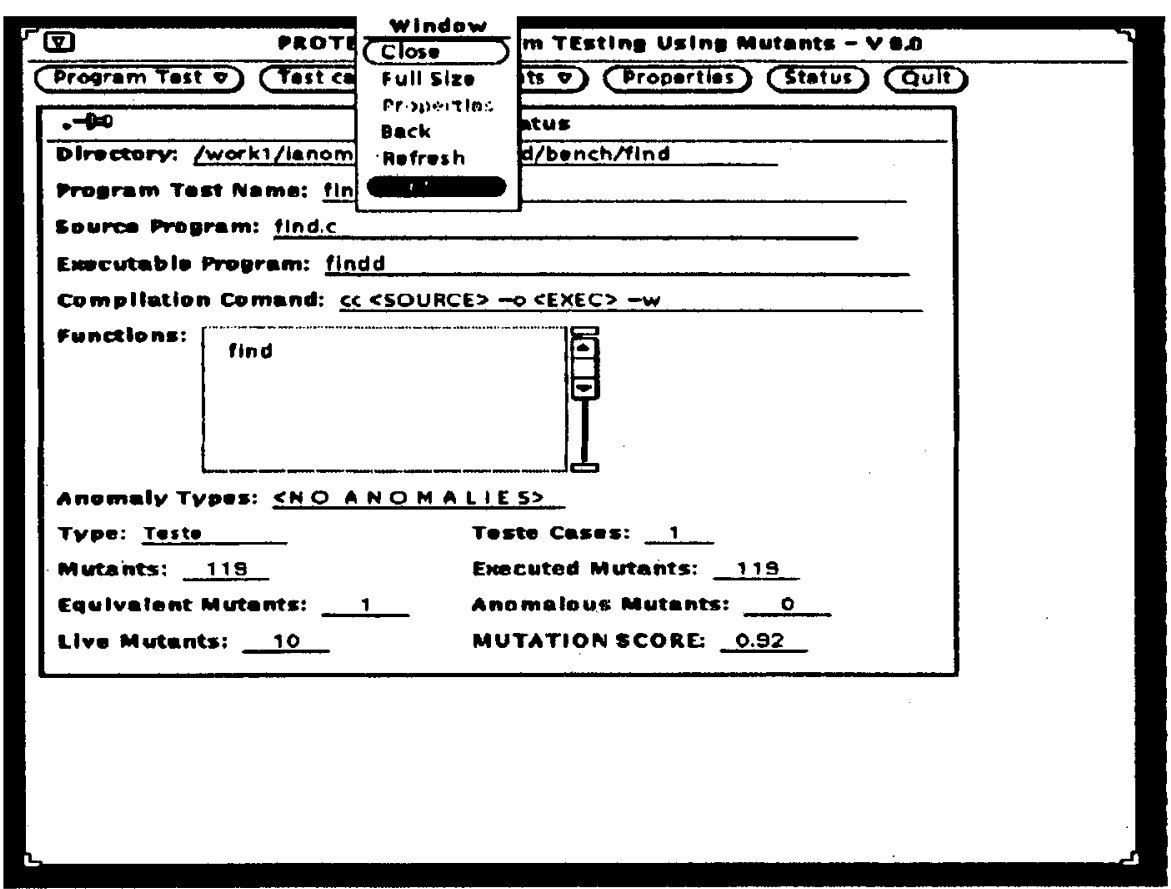

Figura A.18. - Menu do Quadro Principal

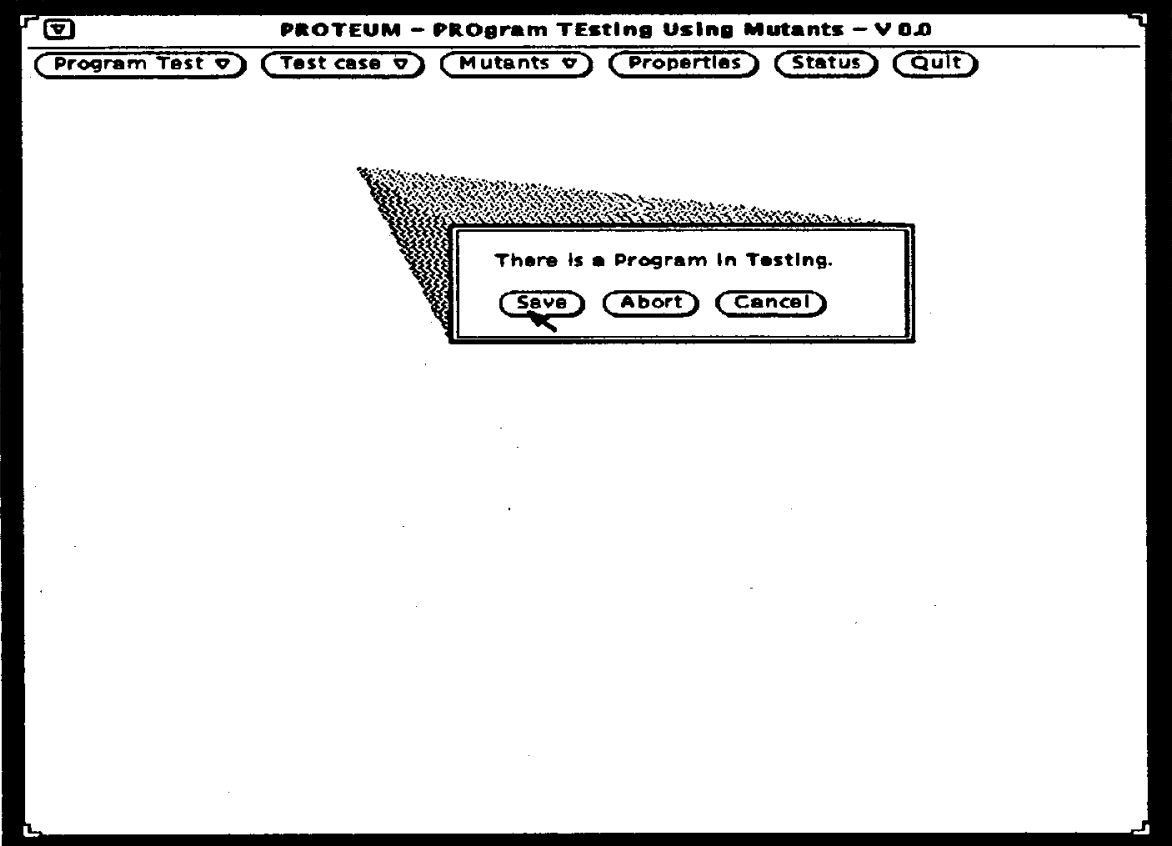

Figura A.19. - Confirmação para sair do Proteum 


\section{Apêndice B.}

\section{Operadores de Mutação}

Este apêndice apresenta os operadores de mutação que foram implementados na versão 1.00 - C do Proteum. Esses operadores baseiam-se nos propostos por Agrawal et al [AGR89]. Nesse documento, produzido no Software Engeeniring Research Center, Purdue University, os autores propõem 80 operadores para a linguagem ANSI C 7 .

Alguns dos operadores foram, para facilitar a implementação, reunidos e no Proteum estão implementados como um único operador. É o caso, por exemplo, dos operadores VGSR e VLSR que foram reunidos num único operador: Vsrr. $O$ operador VGSR (VLSR) troca cada referência escalar por todas as variáveis escalares globais (locais) do programa. $\mathbf{O}$ operador Vsrr troca cada referência escalar por todas as variáveis, locais ou globais, do programa. Com isso obteve-se um número menor de operadores de mutação sem perdas significativas, em relação ao conjunto original de operadores.

Dos operadores propostos no documento citado, somente dois não foram implementados no Proteum. A Tabela B.1. mostra a lista dos operadores implementados.

Tabela B.1. - Operadores Implementados

\begin{tabular}{|l|l|}
\hline Nome & \multicolumn{1}{|c|}{ Operação } \\
\hline STRP & Trap on Statement Execution \\
\hline STR & Trap on if Condition \\
\hline SSDL & Statement Deletion \\
\hline SRSR & return Statement Replacement \\
\hline SGLR & goto Label Replacement \\
\hline SCRB & continue Replacement by break \\
\hline SBRC & break Replacement by contimue \\
\hline SBRn & Break Out to Nth Enclosing Level \\
\hline SCRn & Continue Out to Nth Enclosing Level \\
\hline
\end{tabular}

${ }^{7} \mathrm{O}$ documento apresenta uma tabela-resumo com 77 operadores. Porém existem no texto outros operadores que não aparecem na tabela. 


\begin{tabular}{|l|l|}
\hline SWDD & while Replacement by do-while \\
\hline SDWD & do-while Replacement by while \\
\hline SMTT & Multiple Trip Trap \\
\hline SMTC & Multiple Trip Continue \\
\hline SMVB & Move Brace Up and Down \\
\hline SSWM & switch Statement Mutation \\
\hline OAAA & Aritmetic Assigment Replacement \\
\hline OAAN & Aritmetic Operator Replacement \\
\hline OABA & Aritmetic by Bitwise Assigment Replacement \\
\hline OABN & Aritmetic by Bitwise Operator Replacement \\
\hline OAEA & Aritmetic by Plain Assigment Operator \\
\hline OALN & Aritmetic by Logical Operator Replacement \\
\hline OARN & Aritmetic by Relational Operator Replacement \\
\hline OASA & Aritmetic by Shift Assigment Replacement \\
\hline OASN & Aritmetic by Shift Operator Replacement \\
\hline OBAA & Bitwise by Aritmetic Assigment Replacement \\
\hline OBAN & Bitwise by Aritmetic Operator Replacement \\
\hline OBBA & Bitwise Assigment Replacement \\
\hline OBBN & Bitwise Operator Replacement \\
\hline OBEA & Bitwise by Plain Assigment Replacement \\
\hline OBLN & Bitwise by Logical Operator Replacement \\
\hline OBRN & Bitwise by Relational Operator Replacement \\
\hline OBSA & Bitwise by Shift Assigment Replacement \\
\hline OBSN & Bitwise by Shift Operator Replacement \\
\hline OEAA & Plain by Aritmetic Assigment Replacement \\
\hline OEBA & Plain by Bitwise Assigment Replacement \\
\hline OESA & Plain by Shift Assigment Replacement \\
\hline OLAN & Logical by Aritmetic Operator Replacement \\
\hline OLBN & Logical by Bitwise Operator Replacement \\
\hline OLLN & Logical Operator Replacement \\
\hline OLRN & Logical by Relational Operator Replacement \\
\hline OLSN & Logical by Shift Operator Replacement \\
\hline ORAN & Relational by Aritmetic Operator Replacement \\
\hline ORBN & Relational by Bitwise Operator Replacement \\
\hline ORLN & Relational by Logical Bitwise Operator Replacement \\
\hline ORRN & Relational Operator Replacement \\
\hline ORSN & Relational by Shift Operator Replacement \\
\hline OSAA & Shift by Aritmetic Assigment Replacement \\
\hline OSAN & Shift by Aritmetic Operator Replacement \\
\hline OSBA & Shift by Bitwise Assigment Replacement \\
\hline OSBN & Shit by Bitwise Operator Replacement \\
\hline OSEA & Shift by Plain Assigment Replacement \\
\hline OSLN & Shift by Logical Operator Replacement \\
\hline
\end{tabular}




\begin{tabular}{|l|l|}
\hline OSRN & Shift by Relational Operator Replacement \\
\hline OSSA & Shift Assigment Replacement \\
\hline OSSN & Shift Operator Replacement \\
\hline Ouor & Unary Operator Mutations \\
\hline OLNG & Logical Negation \\
\hline OCNG & Logical Context Negation \\
\hline OBNG & Bitwise Negation \\
\hline OIPM & Indirection Operator Precedence \\
\hline OCOR & Cast Operator Replacement \\
\hline Vsrr & Scalar Variable Reference Replacement \\
\hline Varr & Array Reference Replacement \\
\hline Vtrr & Structure Reference Replacement \\
\hline Vprr & Pointer Reference Replacement \\
\hline VSCR & Structure Component Replacement \\
\hline VDTR & Domain Traps \\
\hline VTWD & Twidle Mutations \\
\hline CRCR & Required Constant Replacement \\
\hline Cccr & Constant for Constant Replacement \\
\hline Ccsr & Constant for Scalar Replacement \\
\hline
\end{tabular}

Os operadores dividem-se em quatro classe:
1. mutações de comandos;
2. mutaçōes de operadores;
3. mutações de variáveis e
4. mutaçōes de constantes.

Utilizou-se a mesma convenção de nomes proposta por Agrawal, já que todas as mensagens do Proteum são em inglês. $\mathbf{O}$ nome de um operador é composto por quatro letras; a primeira (sempre em letra maiúscula) indica qual a classe do operador: $\mathbf{S}$ (statement), $\mathbf{O}$ (operator), $\mathbf{V}$ (variable) ou $\mathbf{C}$ (constant). As outras três letras servem como um mnemônico para o operador.

A seguir são apresentados, com uma breve explicação, cada um dos mutantes implementados no Proteum. Note-se que a explicação de cada operador procura refletir o tipo de erro que esse operador procura revelar, não refletindo necessariamente a implementação do Proteum que pode diferir da implementação sugerida mas mantém as características do operador. 


\section{B.1. - Mutações de Comandos}

\section{Trap on Statement Execution: STRP}

Este operador visa revelar erros de código não alcançável. Cada comando é substituido por uma função trap_on_statement0 que quando executada termina a execução do mutante. Portanto, para matar tal mutante é necessário que a execução passe por esse comando, mostrando que ele é alcançável.

\section{Trap on if Condition: STRI}

Procura garantir que a condição de cada comando if seja avaliada, pelo menos uma vez pelo ramo verdadeiro e pelo ramo falso. Cada comando do tipo if (e) $S$ gera dois mutantes:

$$
\text { if (trap_on_true(e)) e if (trap_on_false(e)) }
$$

Quando trap_on_true (trap_on_false) é executada, o mutante é abortado se a expressão avaliada é verdadeira (falsa). Caso contrário, a função retorna o valor da expressão.

\section{Statement Deletion: SSDL}

Procura mostrar que cada comando tem influência sobre a saída do programa. SSDL sistematicamente elimina cada comando do programa.

\section{return Statement Replacement: SRSR}

Cada função em $\mathrm{C}$ possui pelo menos um comando return, mesmo que seja implicito, no final do corpo da função. Este operador troca cada um dos comandos de uma função por todos os comandos return que existem na mesma função.

\section{goto Label Replacement: SGLR}

Cada comando do tipo goto $l$ tem o seu rótulo substituído por todos os outros rótulos que aparecem na mesma função. 
continue Replacemente by break: SCRB

Cada comando continue é substituido por um comando break.

break Replacement by continue: SBRC

Cada comando break é substituido por um comando continue, quando possível (break de case, por exemplo, não pode ser substituído).

\section{Break Out to $\mathbf{N}^{\text {th }}$ Enclosing Level: SBRn}

Um comando break ou contimue pode ser usado dentro de diversos niveis de aninhamento. Por exemplo, quando usado dentro de um comando de laço, como o for, diz-se que seu nivel é 1; se esse comando for estiver aninhado dentro de outro laço, então o nivel do break (continue) é 2, e assim por diante. Em alguns casos, ao usar-se o break ou continue com nível de aninhamento maior que 1, pretende-se terminar não só o laço do qual ele faz parte, mas também laços de niveis mais externos.

Supondo um comando break (continue) aninhado no nivel $\mathrm{N}$, este operador de mutação sistematicamente troca este break (continue) pela função break_out to_level_n(J), para $2 \leq \mathrm{J} \leq \mathrm{N}$. Esta função, quando executada faz com que os $\mathrm{J}$ laços imediatamente externos sejam interrompidos.

\section{Continue Out to Nth Enclosing Level: SCRn}

É semelhante ao operador SBRn com a diferença que ao ser executada, a função continue_out_to_level_n(J) transfere a execução para o final do laço $\mathrm{J}$ níveis acima, como se fosse um continue de vários níveis.

while Replacement by do-while: SWDD

Cada comando while (e) $S$ é alterado para formar o comando do $S$ while (e).

do-while Replacement by while: SDWD

Cada comando do $S$ while (e) é alterado para formar o comando while (e) $S$. 
Este operador procura assegurar que cada laço é iterado mais que uma vez. Para isso é introduzida, no inicio de cada laço, uma chamada à função trap_after_n_loop_iteration( $N)$. Esta função, quando executada pela $\mathrm{N}$-ésima vez, interrompe a execução do programa. No Proteum foi implementado com $\mathrm{N}=2$.

\section{Multiple Trip Continue: SMTC}

Este operador introduz, no início de cada laço, uma chamada à função false_after_n_loop_iteration( $N$ ). Esta função, quando executada depois da $\mathrm{N}$-ésima vez, interrompe a execução do laço, como se fosse um comando contimue. No Proteum foi implementado com $\mathrm{N}=2$.

\section{Move Brace Up or Down: SMVB}

Move o "?" pertencente a um comando repetitivo (while, do-while e for) para cima e para baixo, quando possivel. Movendo para cima, exclui-se o último comando que estava dentro do comando composto. Para baixo, inclui-se no laço o próximo comando que não fazia parte dele.

\section{switch Statement Mutation: SSWM}

Substitui o comando swich (e) pelo comando switch (trap_on_case (e, a)). Esta função aborta a execução do mutante quando $a==e$, onde a é cada um dos rótulos utilizados nos case's do comando. Assim, para matar os mutantes desse operador é necessário que a expressão $e$ seja avaliada pelo menos uma vez para cada valor utilizado nos cases's.

\section{B.2. - Mutações de Operadores}

\section{Binary Operator Mutations: Obom}

Esta é uma subclasse que engloba vários operadores de mutação: todos aqueles que fazem a substituição de um operador binário por outro. Todos os operadores desta subclasse foram implementados separadamente. 
Os operadores que compõem esta subclasse são relacionados na Tabela B.1., iniciando com o operador OAAA até o operador OSSN. Seus nomes revelam o tipo de substituição que o operador realiza. A segunda letra indica o tipo de operador que deve ser retirado do programa para gerar o mutante. A terceira letra indica qual o tipo do operador que deve ser colocado no lugar. A última letra indica se os operadores são de atribuição ou não.

A Tabela B.2. mostra as possibilidades para os nomes de operadores:

Tabela B.2. - Nomes dos Operadores da Classe Obom

\begin{tabular}{|l|lll|}
\hline & Tipo do Operador & Operadores & Código \\
\hline Não Atribuição & Aritmético & $+-^{*} / \%$ & A \\
& Bitwise & $\mid \& \wedge$ & B \\
& Lógico & $\| \& \&$ & L \\
& Deslocamento & $><<$ & S \\
& Relacional & $<>=!=>=<=$ & R \\
\hline Atribuição & Aritmético & $+=-==/=\%=$ & A \\
& Bitwise & $\&=\wedge=\mid=$ & B \\
& Plano & $=$ & E \\
& Deslocamento & $<<=>>=$ & S \\
\hline
\end{tabular}

Por exemplo, o nome OAAN indica que cada operador aritmético (primeiro A) deve ser substituído pelos outros operadores aritméticos (segundo A). O nome OASA indica que operadores aritméticos de atribuição devem ser substituídos por operadores de deslocamento e atribuição.

\section{Unary Operator Mutations: Ouor}

Esta subcategoria engloba dois operadores: OPPO e OMMO. Estes dois operadores, no Proteum, foram reunidos num único operador com o nome da subclasse: Ouor. Ele troca expressões do tipo $x++$ por duas outras expressões: $x-$ e $++x$ e expressões do tipo $++x$ por $-x$ e $x++$. De forma análoga, atua sobre o operador de decremento (--). 


\section{Logical Negation: OING}

Dada a expressão $x$ op $y$, onde op é um dos operadores relacionais \&\& ou $\|$, este operador gera três mutantes com as seguintes expressões: $x$ op $! y, ! x$ op y e ! ( $x$ op $y)$.

\section{Logical Context Negation: OCNG}

Este operador reverte as condições do comandos if, while, do-while, for e expressão condicional “?”, incluindo uma negação lógica na expressão.

\section{Bitwise Negation: OING}

Dada a expressão $x$ op $y$, onde op é um dos operadores $\wedge, \&$ ou |, este operador gera três mutantes com as seguintes expressões: $x o p \sim y, \sim x$ op $y \mathrm{e} \sim(x$ op $y)$.

\section{Indirection Operator Precedence: OIPM}

Expressões que envolvam operador de incremento/decremento e operador de indireção podem, muitas vezes, conter erros de precedência. Por isso, expressões do tipo ${ }^{*} p++$ são transformadas em $\left({ }^{*} p\right)++$ por este operador de mutação.

\section{Cast Operator Replacement: OCOR}

Operadores de "cast" que envolvem apenas tipos primitivos da linguagem (int, char, long, float, etc) são substituídos por operadores de cast com todos os outros tipos primitivos da linguagem. Cast com ponteiros não são tratados.

\section{B.3. - Mutações de Variáveis}

\section{Scalar Variable Reference Replacement: Vsrr}

Este operador do Proteum é a união de dois operadores propostos por Agrawal: VGSR e VLSR. Este operador substitui cada referência escalar por todas as variáveis escalares, globais e locais, do programa. Note-se que uma referência escalar não diz respeito apenas a varáveis escalares. No exemplo abaixo, as expressões * $p$ e $v[0]$ também são referências escalares e por isso devem ser substituídas. 
int $v[10]$;

char *p;

$v[0]=256$;

${ }^{*} \mathrm{p}=$ In';

\section{Array Reference Replacement: Varr}

Idem para referências a vetores.

\section{Structure Reference Replacement: Vtrr}

Idem para referências a estruturas e uniões.

\section{Pointer Reference Replacement: Vprr \\ Idem para referências a apontadores.}

\section{Structure Component Replacement: VSCR}

Referências a componentes de uma estrutura são substituídas por referências aos demais componentes da mesma estrutura, respeitando-se os tipos dos componentes.

\section{Domain Traps: VDTR}

Cada referência escalar $e$ é substituida pelas chamadas às funções trap_on_zero(e), trap_on_positive(e) e trap_on_negative(e). Estas funções abortam a execução dos mutantes caso a expressão tenha valor zero, positivo ou negativo, respectivamente. Caso contrário, retornam o valor da expressão.

\section{Twiddle Mutations: VTWD}

Referências escalares $e$ são substituídas por $\operatorname{pred}(e)$ e succ(e), ou seja, os valores vizinhos, que no Proteum foram implementados como $e-1$ e $e+1$. 


\section{B.4. - Mutações de Constantes ${ }^{8}$}

\section{Required Constant Replacement: CRCR}

Este operador troca cada referência escalar por constantes requeridas, ou seja, pelas constantes 0,1 e -1 ou $0.0,1.0$ ou -1.0 , dependendo do tipo da referência.

\section{Constant for Constant replacement: Cccr}

Este operador também é a reunião de dois outros: CGCR e CLCR. Ele aplica-se a cada constante do programa, trocando-a por todas as outras constantes que aparecem na mesma função.

\section{Constant for Scalar Replacement: Ccsr}

Este operador também é a reunião de dois outros: CGSR e CLSR. Ele aplica-se a cada referência escalar do programa, trocando-a por todas as constantes que aparecem na mesma função.

${ }^{8}$ Os operadores CRCR e Ccsr na verdade aplicam-se a referências escalares. Apesar disso, manteve-se, na implementação, a definição original que define-os como mutação de constantes. 